\title{
Compendium of HFIR and REDC Infrasound and Low- Frequency Acoustic Emissions
}

Edna S. Cárdenas (INL) Scott M. Watson (INL) Thomas V. Holschuh (INL) James $\mathrm{T}$. Johnson (INL) Karina A. Asmar (UH) Monica Maceira (ORNL) Riley Hunley (ORNL) Richard Hale (ORNL) Milton A. Garcés (UH) David L. Chichester (INL)

September 2018

INL is a U.S. Department of Energy National Laboratory operated by Battelle Energy Alliance 


\section{DISCLAIMER}

This information was prepared as an account of work sponsored by an agency of the U.S. Government. Neither the U.S. Government nor any agency thereof, nor any of their employees, makes any warranty, expressed or implied, or assumes any legal liability or responsibility for the accuracy, completeness, or usefulness, of any information, apparatus, product, or process disclosed, or represents that its use would not infringe privately owned rights. References herein to any specific commercial product, process, or service by trade name, trade mark, manufacturer, or otherwise, does not necessarily constitute or imply its endorsement, recommendation, or favoring by the U.S. Government or any agency thereof. The views and opinions of authors expressed herein do not necessarily state or reflect those of the U.S. Government or any agency thereof. 


\title{
Compendium of HFIR and REDC Infrasound and Low-Frequency Acoustic Emissions
}

\author{
Edna S. Cárdenas (INL) \\ Scott M. Watson (INL) \\ Thomas V. Holschuh (INL) \\ James T. Johnson (INL) \\ Karina A. Asmar (University of Hawai'i, UH) \\ Monica Maceira (Oak Ridge National Laboratory, ORNL) \\ Riley Hunley (ORNL) \\ Richard Hale (ORNL) \\ Milton A. Garcés (UH) \\ David L. Chichester (INL)
}

September 2018

Idaho National Laboratory

Idaho Falls, Idaho 83415

Prepared for the

U.S. Department of Energy

National Nuclear Security Administration

Under DOE Idaho Operations Office

Contract DE-AC07-05ID14517 


\begin{abstract}
This document is a compilation of infrasound and low-frequency acoustic signatures that characterize select nuclear reactor operations and hot-cell operations observed at Oak Ridge National Laboratory (ORNL) in fiscal year 2018. Also included here are the results of digital signal analyses describing these signatures. This effort provides insight about the feasibility of using acoustic signatures for local and remote-sensing and identification of nuclear fuel-cycle operations. The signatures included here, in this first year of on-site observations at ORNL, will become part of the broader basis set of signatures collected by researchers involved in the Multi-Informatics for Nuclear Operations Scenarios (MINOS) venture. The effort by MINOS researchers is to gain a deeper knowledge base of nuclear facility operations which may be used to improve nuclear facility monitoring capabilities. This compendium comprises signatures developed from sound signals that were measured at ORNL's High Flux Isotope Reactor and the Radiochemical Engineering Development Center during the week of June 18, 2018. Most facility operations were performed specifically for this campaign, although some measurements were obtained in the course of normal operations. The knowledge gained from developing the signatures included herein will provide a better understanding that will be useful for upcoming measurement campaigns; as additional data becomes available it will be included in newer versions of this compendium.
\end{abstract}




\section{CONTENTS}

ABSTRACT.

ACRONYMS

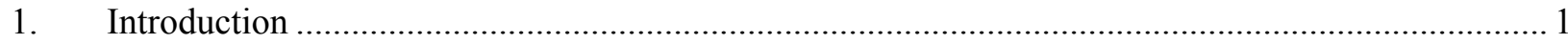

1.1 Why Infrasound and Low-Frequency Signals? ............................................................. 1

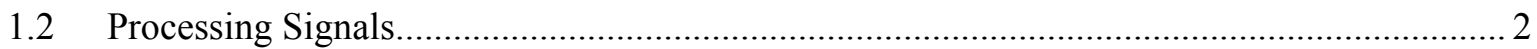

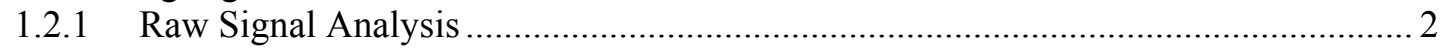

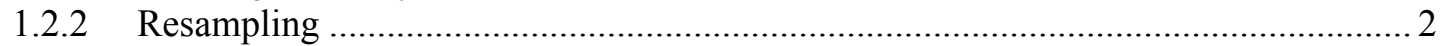

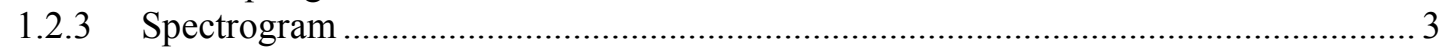

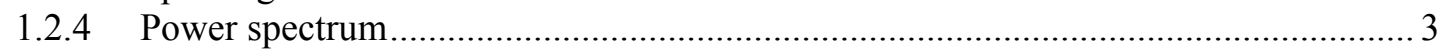

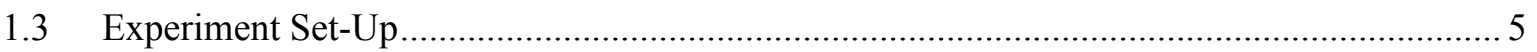

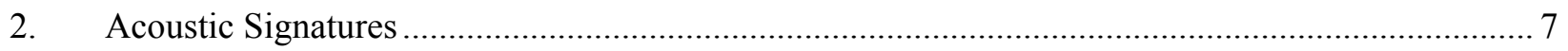

2.1 Backup Diesel Generator Startup/Shutdown............................................................. 7

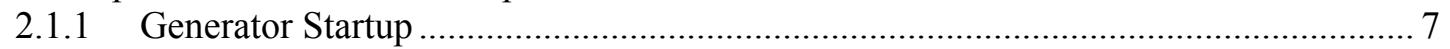

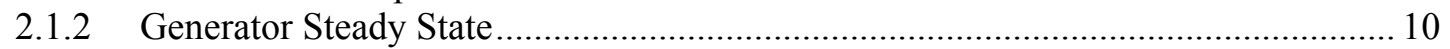

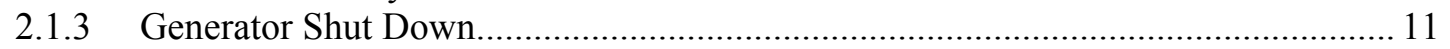

2.2 Manipulator Operations in Hot Cells ....................................................................... 14

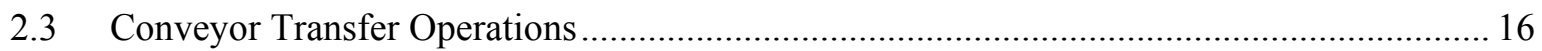

2.4 Cell Off-Gas \& Vessel Off-Gas Ventilation Trains ............................................................. 21

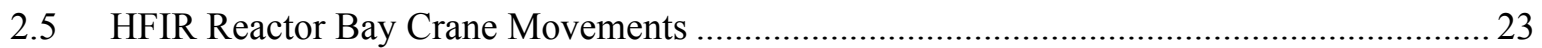

2.5.1 12-Ton Unloaded Crane Bridge Movements .............................................................. 23

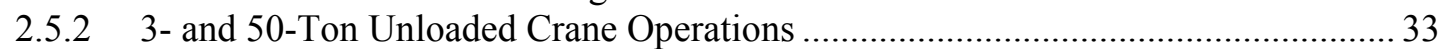

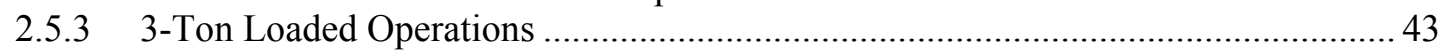

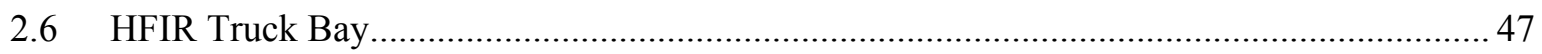

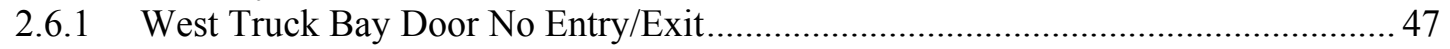

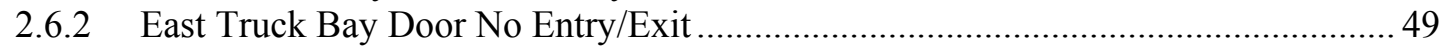

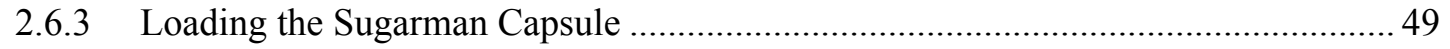

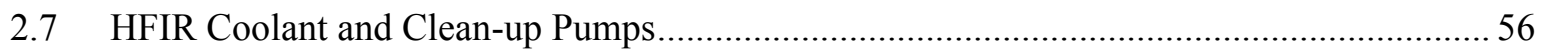

2.8 HFIR Air Conditioning and Cooling Operations ................................................................5 57

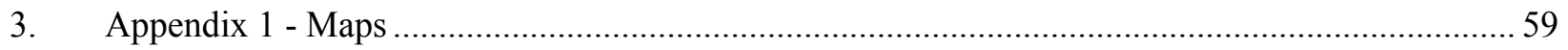

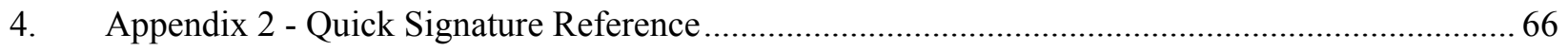

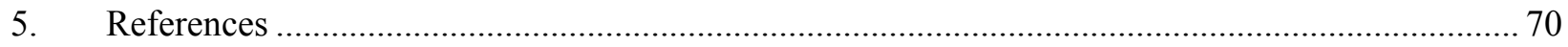




\section{FIGURES}

Figure 1. Raw data signal spanning a 10 minute time range. ................................................................ 2

Figure 2. Power spectrum with $1 / \mathrm{f}$ noise indicated with a red arrow........................................................ 4

Figure 3. Power spectrum showing frequencies affected by $1 / \mathrm{f}$ ("one over $\mathrm{f}$ ") noise................................. 4

Figure 4. Brüer and Kjaer high-performance audio recorder affixed atop a variable-length tripod. ........... 6

Figure 5. Raw signal showing an obvious increase in voltage starting between 09:34 and 09:36. ............ 8

Figure 6. Spectrogram showing an increase in the frequency intensity starting at approximately 09:35 at the onset of diesel generator operation. 8

Figure 7. Power spectra comparison between the time before (blue) and including (orange) diesel generator startup.

Figure 8. Power spectra with dominant peaks annotated. The time period before generator startup (blue) is plotted against time that includes the generator operation startup (orange). 9

Figure 9. Power spectra with dominant peaks annotated. The time period during generator startup (orange) is plotted against time for generator steady state operation (blue)..... 10

Figure 10. Acquired signal for diesel generator shut down.

Figure 11. Spectrogram of diesel generator shut down.

Figure 12. Power spectra for the time period including (orange) and following generator shut down (blue).

Figure 13. Power spectra matching data of Figure 11 with dominant peaks annotated.

Figure 14. Raw signal measured from recorder near hot cell manipulators.

Figure 15. Spectrogram of manipulator operations showing high intensity frequency bands below approximately $30 \mathrm{~Hz}$.

Figure 16. Power spectrum of manipulator operations with persistent peaks at 23, 30, 44, 60, and $82 \mathrm{~Hz}$ annotated.

Figure 17. Raw signal recording hot cell conveyor belt movements towards and away from the stationary sound recorder.

Figure 18. Spectrogram showing frequencies related to movement of the conveyor belt system between hot cells 4 and 7 .

Figure 19. Power spectrum comparing conveyor movement toward the sound recorder (orange) with the background signal (blue).

Figure 20. Power spectrum comparing conveyor movement away from the sound level meter (orange) with the background signal (blue)

Figure 21. Power spectrum comparing conveyor movement toward (blue) and away from the sound level meter (blue).

Figure 22. Spectrogram displaying cell off-gas signals. 22

Figure 23. Spectrogram displaying vessel off-gas signals.

Figure 24. Raw signal acquired from movement of a 12-ton crane over the spent fuel pool for the time period starting at 1:05 $\mathrm{pm}$. 
Figure 26. Raw signal acquired from movement of a 12-ton crane over the spent fuel pool for the time period starting at $1: 35 \mathrm{pm}$.

Figure 27. Spectrogram recorded in position 6 covering time period starting at 1:05 pm......................26

Figure 28. Spectrogram recorded in position 6 covering time period starting at $1: 15 \mathrm{pm} \ldots \ldots \ldots \ldots \ldots \ldots \ldots \ldots . . . . . . . .26$

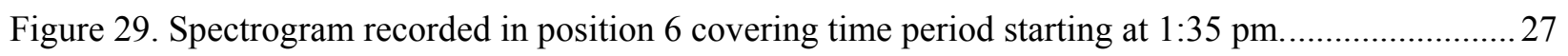

Figure 30. Spectrogram showing a close up of the time period surrounding the pattern indicated

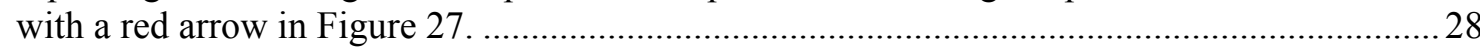

Figure 31. Spectrogram showing close-up of time period surrounding the unknown burst indicated in Figure 27.

Figure 32. Spectrogram showing a close up of the time period surrounding the pattern and unknown burst indicated with a red arrow in Figure 28.

Figure 33. Power spectra for times including similar intensity profiles shown in Figures 26 (orange) and 28 (yellow) in comparison to periods of background signals extracted from Figures 26 (blue) and 28 (purple). .31

Figure 34. Power spectra displaying signals including the pattern (blue) and unknown burst (orange) indicated in Figure 27. 32

Figure 35. Raw signal recording of HFIR reactor bay crane movements. .33

Figure 36. Spectrogram that indicates 3- and 50-ton crane movements in the HFIR reactor bay. The red arrows point to specified crane movements with "South" and "North" referring to the crane housing that includes both 3- and 50-ton hooks and "East" and "West" referring to crane bridge movements.

Figure 37. Power spectra that includes a background time period from 10:19 to 10:19:30 (blue), upward 3-ton crane movements (orange), and downward 3-ton crane movements (yellow) for frequencies that range to $100 \mathrm{~Hz}$.

Figure 38. Power spectra that includes a background time period from 10:19 to 10:19:30 (blue), upward 3-ton crane movements (orange), and downward 3-ton crane movements (yellow) for frequencies that range from 100 to $300 \mathrm{~Hz}$.

Figure 39. Power spectra that includes a background time period from 10:19 to 10:19:30 am (blue), downward 50-ton crane movements (orange), and upward 50-ton crane movements (yellow) for frequencies that range to $100 \mathrm{~Hz}$.

Figure 40. Power spectra that includes a background time period from 10:19 to 10:19:30 am (blue), downward 50-ton crane movements (orange), and upward 50-ton crane movements (yellow) for frequencies that range from 100 to $300 \mathrm{~Hz}$. The red arrow points to peaks at approximately $240 \mathrm{~Hz}$.

Figure 41. Power spectra that includes a background time period from 10:19 to 10:19:30 am (blue) and translations of the crane housing south (orange) and north (yellow) for frequencies that range to $100 \mathrm{~Hz}$.

Figure 42. Power spectra that includes a background time period from 10:19 to 10:19:30 am (blue) and translations of the crane housing south (orange) and north (yellow) for frequencies that range from $100-300 \mathrm{~Hz}$.

Figure 43. Power spectra showing time periods for the crane bridge east movement (orange) occurring between 10:24:22 and 10:24:52 am, the bridge west movement (yellow) 
occurring between 10:24:53 and 10:25:29 am; both in comparison to the background (blue) (10:19 to 10:19:30 am). The spectra extend to $100 \mathrm{~Hz}$.

Figure 44. Power spectra showing time periods for the crane bridge east movement (orange) occurring between 10:24:22 and 10:24:52 am, the bridge west movement (yellow) occurring between 10:24:53 and 10:25:29 am; both in comparison to the background (blue) (10:19 to 10:19:30 am). The spectra extend from 100 to $300 \mathrm{~Hz}$. 42

Figure 45. Raw signal recorded from 10:38 to 10:48 that includes signals from the 3-ton crane moving a $5^{\prime}$ flange. The time period within the black dashed lines indicates the duration of crane movement. 44

Figure 46. Spectrogram covering duration of 3-ton crane moving a 5 ' flange. 45

Figure 47. Power spectra comparing time periods for the 3-ton crane moving a $\sim 5$ ' flange (orange) occurring between 10:40:29 and 10:42:31 am against a background (blue) time period (10:42:45 to10:43:19). The black dashed line is located at approximately 7 $\mathrm{Hz}$.

Figure 48. Power spectra comparing time periods for the 3-ton crane moving a 5' flange (orange) occurring between 10:40:29 and 10:42:31 am against a background (blue) time period $(10: 42: 45$ to $10: 43: 19)$. 46

Figure 49. Spectrogram displaying east and west truck bay doors opening and closing as indicated with red arrows. 48

Figure 50. Power spectra for the west truck bay door opening and closing between 10:26:43 and 10:27:29 (blue) and opening and closing between 10:28:23 and 10:29:19 (orange) compared to a background period (yellow) measured between 10:19 and 10:19:30 for frequencies up to $100 \mathrm{~Hz}$.

Figure 51. Power spectra for the west truck bay door opening and closing between 10:26:43 and 10:27:29 (blue) and opening and closing between 10:28:23 and 10:29:19 (orange) compared to a background period (yellow) measured between 10:19 and 10:19:30 for frequencies between 100 and $300 \mathrm{~Hz}$.

Figure 52. Raw signal that includes Sugarman capsule loading operations from 1:28 to 1:38 pm. .51

Figure 53. Spectrogram of time period that covers Sugarman capsule loading operations from 1:28 to 1:38 pm. "West opened 10', West closed, and West opened" refers to the west truck bay door operations. "Bridge, Hook, and Housing" refers to the 50-ton bridge and 3-ton crane hook movements.

Figure 54. Power spectra showing time periods when the west truck door bay opens 10' (orange), closes $10^{\prime}$ (yellow), and a background period (blue).

Figure 55. Power spectra with time periods including the west truck bay door opened 10' (blue) and opened completely with the truck passing through (orange) displayed.

Figure 56. Power spectra comparing the partial openings of the west truck bay door without entry or exit through the door.

Figure 57. Power spectra comparing the background time periods that were analyzed against each partial west truck bay door opening without entry or exit through the door.

Figure 58. Power spectra comparing the complete openings of the west truck bay door. The opening occurring during preparation for movement of the Sugarman capsule had a truck exit the bay. 
Figure 59. Raw signal acquired covering 10 minute period that includes duration of power cycling for air conditioning units 10-14 located on the south wall of HFIR reactor bay.

Figure 60. Spectrogram including power cycling of air conditioning units located in HFIR reactor bay. The red arrows point to changes in the power in the infrasound region.

Map 1. Area near 7900 building. .59

Map 2. Full aerial view with access roads. 60

Map 3. Full aerial view with access roads and markings indicating positions of audio recorders. 61

Map 4. Detailed schematic of the first floor in building 7920. 62

Map 5. Aerial photo of HFIR and REDC area. 63

Map 6. Detailed schematic of the second level in building 7900. 64

Map 7. Detailed schematic of the third level in building 7900. .65

\section{TABLES}

Table 1. Signature guide 66 


\section{ACRONYMS}

\begin{tabular}{|c|c|}
\hline Written & Definition \\
\hline AC & Air Conditioner \\
\hline dB & Decibel \\
\hline DFT & Discrete Fourier Transform \\
\hline FIR & Finite Impulse Response \\
\hline HFIR & High Flux Isotope Reactor \\
\hline INL & Idaho National Laboratory \\
\hline MINOS & Multi-Informatics Nuclear Operation Scenarios \\
\hline ORNL & Oak Ridge National Laboratory \\
\hline PCS & Primary Coolant System \\
\hline PPS & Plant Protective System \\
\hline REDC & Radiochemical Engineering Development Center \\
\hline TSR & Technical Safety Requirement \\
\hline UH & University of Hawai'i \\
\hline
\end{tabular}




\section{Compendium of HFIR and REDC Infrasound and Low-Frequency Acoustic Emissions}

\section{Introduction}

Current efforts by the nuclear nonproliferation community to develop detection schemes that may indicate deleterious activities have broadened in scope to include the detection of more subtle activities. While innocuous events alone may not signify proliferation, when in concurrence with other relevant events they may indicate the potential for proliferation. The Multi-Informatics Nuclear Operation Scenarios (MINOS) project is developing technologies to address the broadened scope set out by the nuclear nonproliferation community. Researchers are exploring a diverse collection of data sets including electromagnetic, seismo-acoustic, effluents, thermal, biota, and radiation signals to develop signatures that characterize these benign activates. With that in mind, independent groups working on the MINOS project are currently using their expertise to measure and characterize signals emanating from nuclear fuel-cycle facilities. Ultimately, signatures collected from individual data sets will be analyzed concurrently with the hope that the combined effort will provide useful information on the state of these nuclear facilities and their operations.

The goal of the studies presented here is to determine if infrasound and low-frequency acoustic signals emitted from nuclear facilities can be developed into reliable signatures of declared and/or undeclared operations. Although the goal is to characterize expected nuclear operations, the expectation is that maintaining a broad and detailed collection of signatures from known events will make signals from unexpected events more apparent. These unexpected or "abnormal" signals would in essence become notification signatures signifying a need for further evaluation.

This document is a compilation of infrasound and low-frequency signatures that characterize various nuclear reactor events. This compendium is meant to be updated as more data is analyzed and additional signals are recorded. An initial set of sound signals were collected at Oak Ridge National Laboratory's (ORNL's) High Flux Isotope Reactor (HFIR) and Radiochemical Engineering Development Center (REDC) during the week of June 18, 2018. HFIR is a high-flux reactor and is used as a research reactor for a variety of experiments. Chemical separations, production of irradiation targets, target purification, and a variety of other radiochemical processes and research occur at REDC, which is adjacent to HFIR. The team performing this research includes participants form Idaho National Laboratory (INL), the University of Hawai'i (UH), and ORNL.

\subsection{Why Infrasound and Low-Frequency Signals?}

Sound results from the transfer of energy in air, or other media, originating from a vibrating body. The vibrating body in turn vibrates particles in the surrounding medium with those vibrating particles, transferring energy to additional nearby particles. The transference of energy creates pressure changes that ripple to additional nearby particles, this results in a propagating sound wave.[1] An audible sound is perceived as these pressure ripples vibrate the eardrum. Audible sound waves are typically defined as having frequencies between approximately 20 hertz (Hz) and $20 \mathrm{kHz} \cdot[2,3]$ Sound waves with frequencies higher and lower than the audible range are defined as ultrasound and infrasound, respectively.[4] Lower frequency sounds are attenuated less through air and can therefore travel farther distances making them a useful signal for long distance observation.[4] In addition, the feasibility of measuring infrasound signals 
from nuclear fuel-cycle operations is preceded by research showing observable signals from man-made sources including heavy machinery.[6,7]

\subsection{Processing Signals}

Raw acoustic signals used in this report include all frequencies recorded from the infrasound to the audible range. After a raw signal is acquired, signal processing is used to analyze the input and modify it into a form that allows for easier access to infrasound component frequencies. The MATLAB ${ }^{\circledR}$ Signal Processing Toolbox was utilized for this analysis; there are many techniques available, this section describes the processes performed to the data included in this compilation.

\subsubsection{Raw Signal Analysis}

Analysis of raw signals, similar to the data shown in Figure 1, is useful if the relevant event has both audible and infrasound components. In addition, known audible events closely preceding or latter than the relevant signal can also be useful in identifying the time period when the relevant signal occurred. As such, the audible frequencies may provide a time stamp to the initiation of the event similar to the notable increase in voltage shown in the figure at approximately 5 minutes.

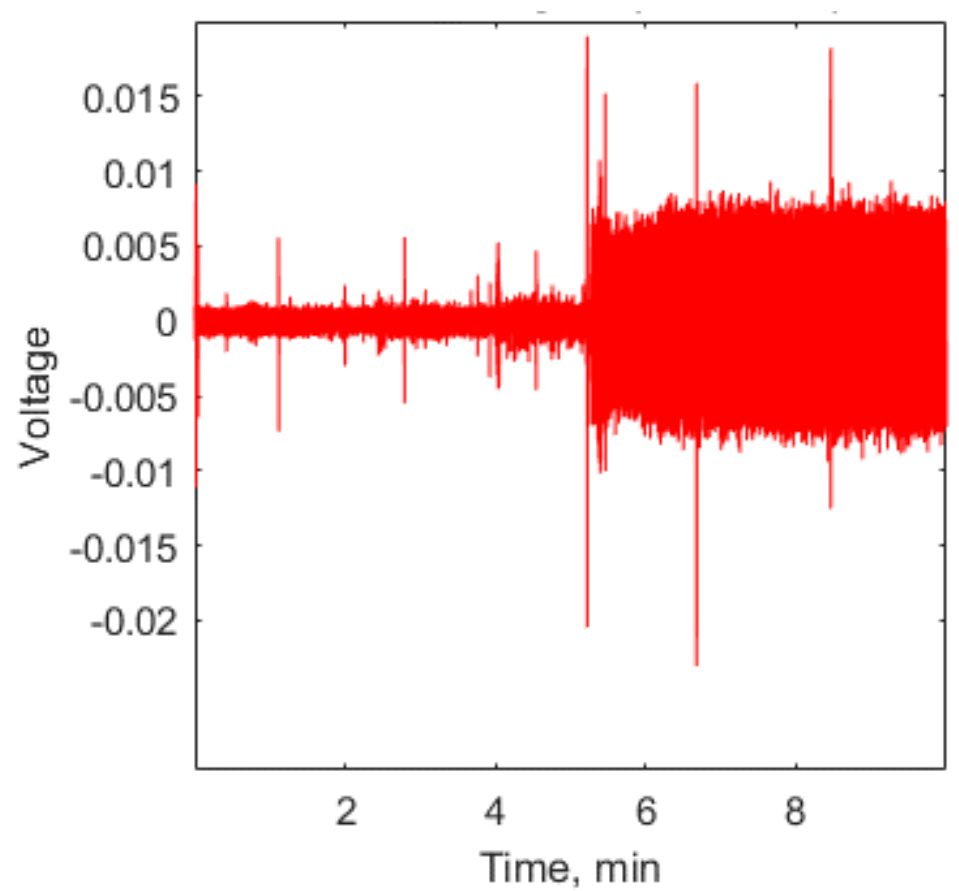

Figure 1. Raw data signal spanning a 10 minute time range.

\subsubsection{Resampling}

Following raw signal analysis, signals are resampled to include only frequencies at and below $100 \mathrm{~Hz}$. Although the focus of this research is to acquire infrasound and low-frequency signatures, including frequencies in the audible range may be useful in pinpointing the initiation of events as well as allowing for a greater characterization of signatures that include frequencies in both ranges. The resampling function, included in $\mathrm{MATLAB}^{\circledR}$, applies a low-pass filter prior to minimize aliasing. The filter has a finite number 
of samples and is designed to be of lower frequency than the signal, therefore, convolution of the filter with the signal attenuates high-frequency components. The frequencies present in the resampled data are then analyzed graphically by spectrogram and power spectrum.

\subsubsection{Spectrogram}

A spectrogram shows changes in the power intensity over a range of frequencies as a function of time. Spectrograms are useful because variations in the power over time are visualized making signatures easier to define. The component sinusoidal frequencies are identified by applying a discrete Fourier transform (DFT) over portions of a signal corresponding to short time bins equally spaced over the total input time. A DFT is suited for periodic data and in a best-case scenario the incremented time bins would "cut" the signal at the beginnings and ends of a period; however, this is not likely the case in typical signals. Therefore, to minimize the effects of non-periodic transitions between time increments, windowing operations are performed. A Hann window is a symmetric waveform that decreases in amplitude rapidly to zero towards the edges. The window is convolved with the signal to minimize discontinuities created between adjacent non-periodic time bins. Time bins are set to 15 second increments and a Hann window is applied to each bin for the data detailed within this compilation unless otherwise noted.

\subsubsection{Power spectrum}

The power spectrum gives the power of the signal for all frequencies given in a specific time period. Component frequencies are identified by applying a DFT over the time period of interest. The power spectrum of Figure 2 shows a signal with high intensity peaks at various frequencies within the range of approximately 20 to $75 \mathrm{~Hz}$. These high intensity peaks are useful for signal characterization and identification of events. When multiple time periods are examined concurrently frequency changes can be readily identified utilizing power spectra. Note that a rapidly decreasing curve is present in all power spectra in the ultralow frequency range starting near $0 \mathrm{~Hz}$, as depicted in Figure 2 and Figure 3. The ubiquitous nature of the curve has prompted its naming as $1 / \mathrm{f}$ ("one over $\mathrm{f}$ ") noise. The source of $1 / \mathrm{f}$ noise is unknown and its presence makes analysis in this region difficult.[3-9] 


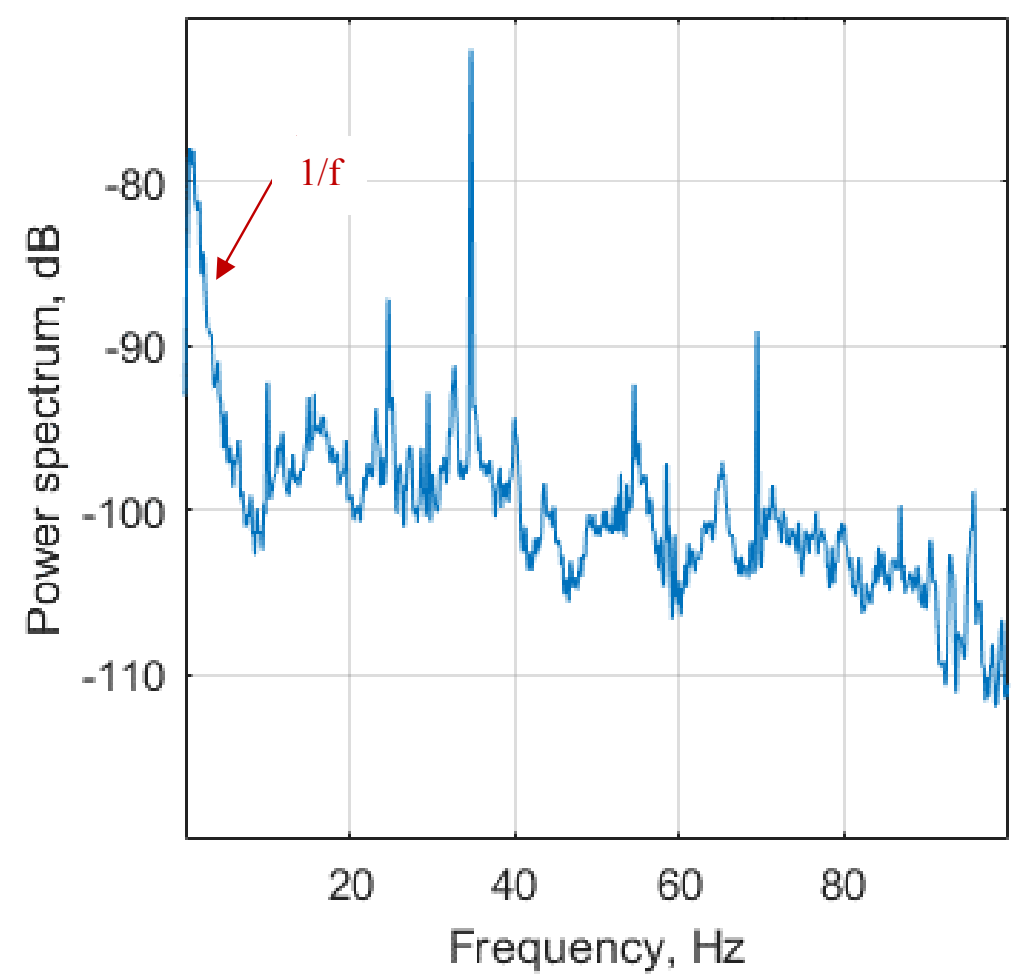

Figure 2. Power spectrum with $1 /$ f noise indicated with a red arrow.

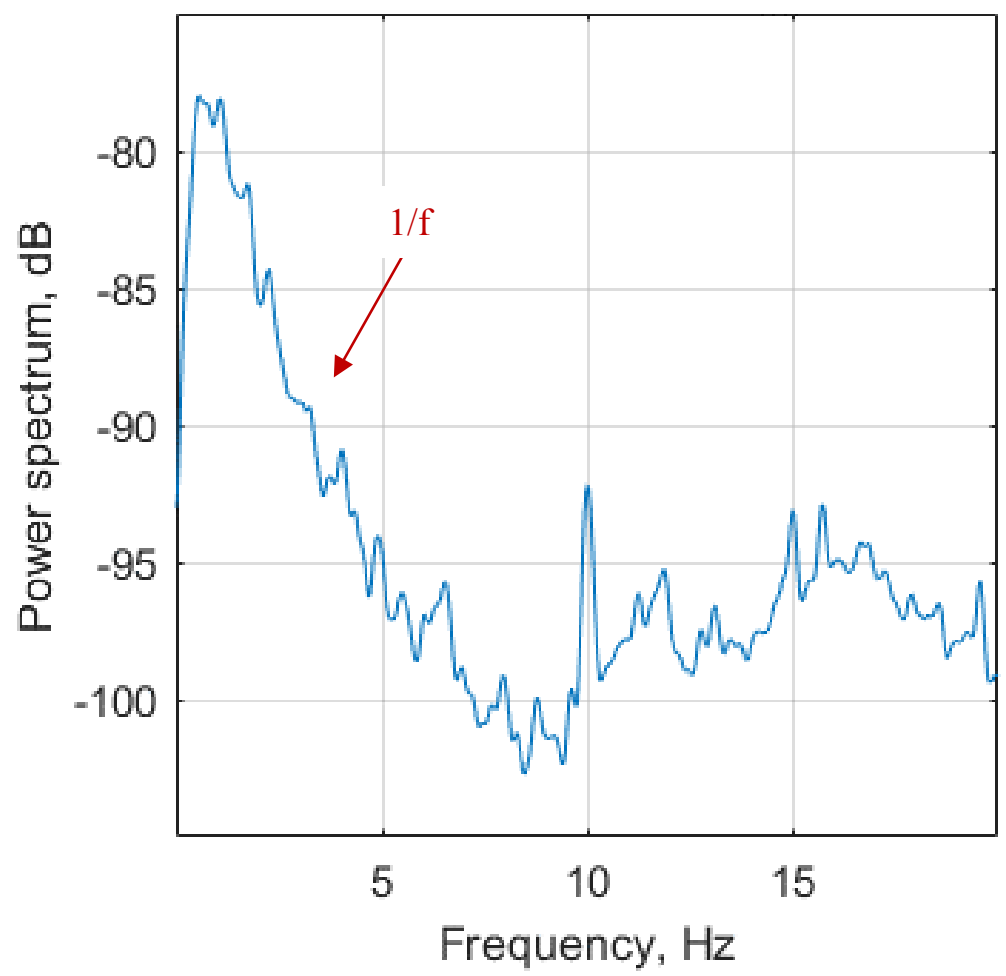

Figure 3. Power spectrum showing frequencies affected by $1 / \mathrm{f}\left(\right.$ "one over $\left.\mathrm{f}^{\prime \prime}\right)$ noise. 


\subsection{Experiment Set-Up}

Teams from INL and UH visited ORNL's HFIR and REDC facilities to record acoustic signals associated with background activities and targeted actions, in each case noting an event description and time stamp. Two Brüer and Kjaer (B\&K) 2250 class 1 high-performance sound level meters and associated data logging software were used to record audio data. One of these recorders positioned on a variable-length tripod is shown in Figure 4. Low-frequency type 4964 microphones, each with a matched pre-amplifier recording setup, were used with the reorders, allowing the recording range to extend from 0.8 to $500 \mathrm{~Hz}$ at an $8-\mathrm{kHz}$ sampling rate. A B\&K UA-1650 90-mm wind screen was placed over each microphone to eliminate unwanted ambient indoor/outdoor environmental noise during event collection. Events were either performed specifically for the experiment or recorders were placed in locations where events were ongoing and/or persistent. Some activities were recorded inside facilities with additional measurements synchronously taken outside if feasible. Other events were only recorded inside or outside a particular facility with each recorder positioned in strategic locations. Longer persistent measurements were noted with start and end times, however, specific events occurring within these time periods were not logged. Signals were recorded generally every 10 minutes unless the recorder was turned off prior to the end of a 10 minute recording block. Activities were recorded in and around 7 different buildings $(7900,7912,7920$, 7922, 7923, 7930, and 7939) at ORNL's HFIR and REDC facilities. Detailed events, described in section 2, are in accordance with the laboratory notebook taken to ORNL by MINOS team members.

The recorders were calibrated prior to arrival at ORNL using a traceable $1 \mathrm{kHz} \pm 0.1 \%$ sound calibrator, type 4231, provided by the manufacturer specifically designed for the 2250 sound level meters. The calibrator conforms to EN/IEC 60942 (2003) class 1 and ANSI S1.40-2006 and has an accuracy of \pm 0.2 decibels $(\mathrm{dB})$ that is valid for one year from the purchase date. The recorded pressure is updated once per second and is referenced to $20 \mu \mathrm{Pa}$. Conversion to $\mathrm{dB}$ occurs through weighting filters processed through the analyzer's onboard software. 


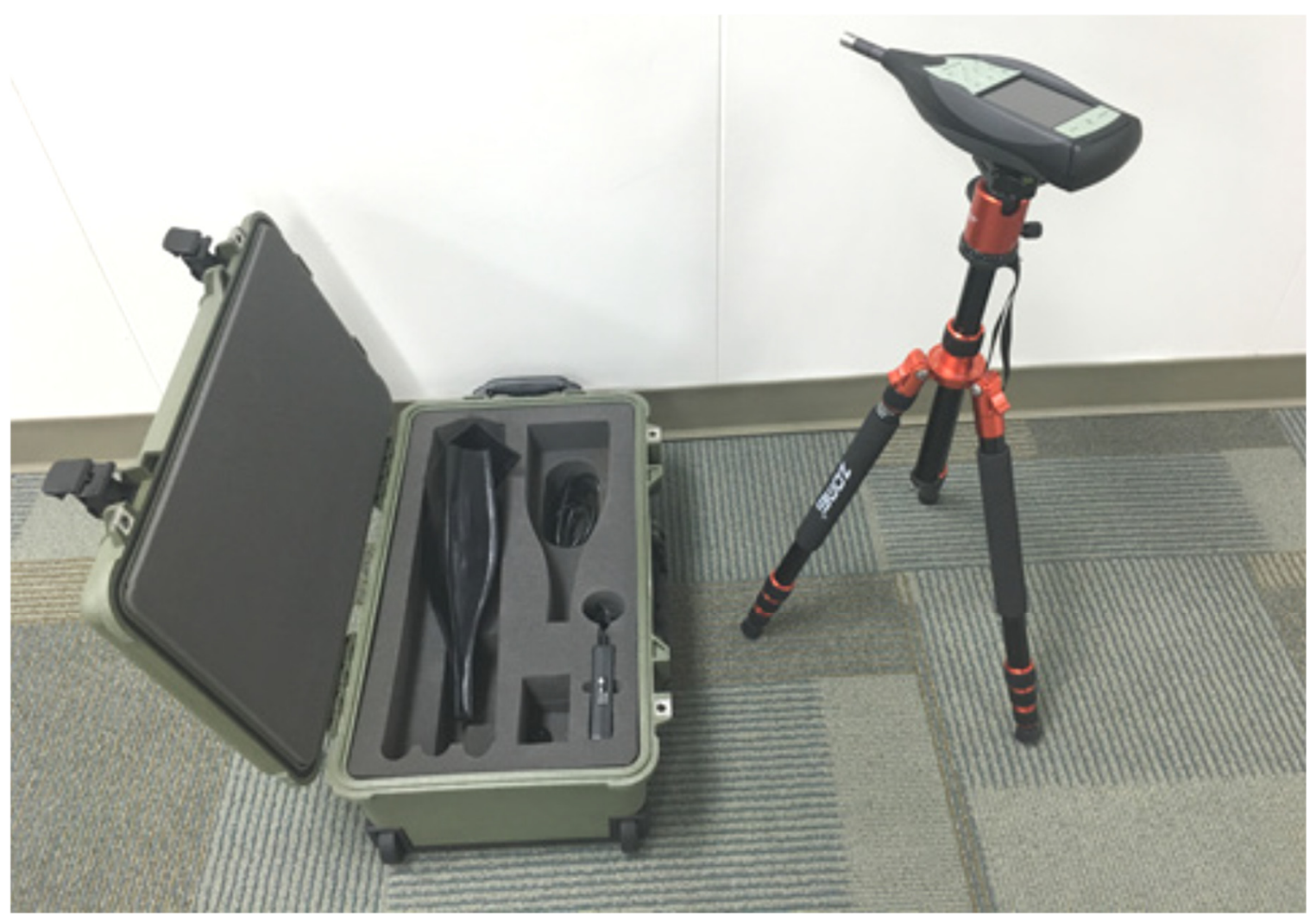

Figure 4. Brüer and Kjaer high-performance audio recorder affixed atop a variable-length tripod. 


\section{Acoustic Signatures}

This section describes mechanical events that commonly occur at nuclear reactor and radioactive handling facilities. The sound-level meters were placed strategically or, in some cases, positioned in locations that did not interfere with normal operations of ORNL personnel. Events were annotated by INL team members when possible. In many cases, the event was performed off schedule specifically for these studies.

\subsection{Backup Diesel Generator Startup/Shutdown}

Start-up and shut-down operations of a backup diesel generator to power building 7939 in the event of power loss were recorded by both sound level meters. The test was initiated by shutting off a breaker to the air supply system marked at location "A" appearing in Map 3 in Appendix 1. Meters were positioned outside of building 7939 at positions marked 1 and 2 on Map 3. Signals were recorded for approximately 35 to 40 minutes (recorder dependent).

\subsubsection{Generator Startup}

The raw signal acquired from the sound level meter positioned at mark 1 shows a clear increase corresponding with the startup, beginning at approximately 09:35:30 as displayed in Figure 5. Although, the INL notebook does not specify an exact time for generator startup, the startup time was verified by listening to the raw signal. The time of this voltage increase matches the time observed in the spectrogram of Figure 6 where a clear increase in the intensity for the frequency band from approximately $20 \mathrm{Ho} 100 \mathrm{~Hz}$ begins. This increase in intensity is also visible in the power spectra of Figure 6 beginning at approximately $20 \mathrm{~Hz}$. In Figure 7 the power spectra for the time period before the generator begins operation and continuing to 09:35 is compared against the time period during start up from 09:35 to 09:36. As observed in the figure, the base line frequency level in the time period during generator startup pulls away from the base line frequency of the time period before generator startup. The dominant peaks are annotated in the power spectra of Figure 8. Dominant peaks that are generated during generator startup include those at 15, 27, 30, 45, 60, 63, 75, 82, and $90 \mathrm{~Hz}$. Harmonics occur for the fundamental $15 \mathrm{~Hz}$ frequency at 30, 45, 60, 75, and $90 \mathrm{~Hz}$. Other harmonics include 27 and $82 \mathrm{~Hz}$. The frequency of these peaks match high intensity lines shown in the spectrogram (Figure 6) after generator operation begins. In addition, high intensity frequency bands appear in the data during generator startup at approximately $18-20 \mathrm{~Hz}$, approximately 38 $52 \mathrm{~Hz}$, and approximately $62-69 \mathrm{~Hz}$.

Data for the recorder positioned at mark 2 was not included in this compendium; however, signature information agrees for both recorders. In addition, both recorders show an increase in signal during the same time period with the recorder at position 1 showing a larger increase likely due to the proximity of the sound level meter to the generator. 


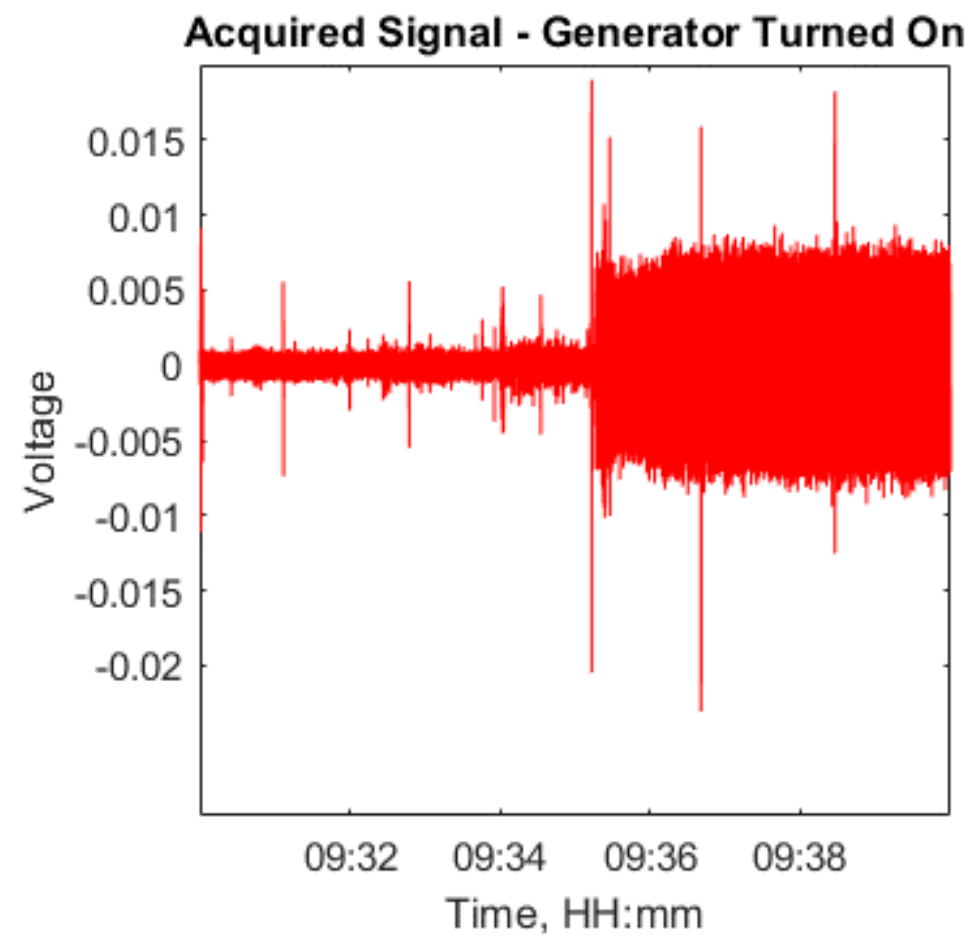

Figure 5. Raw signal showing an obvious increase in voltage starting between 09:34 and 09:36.

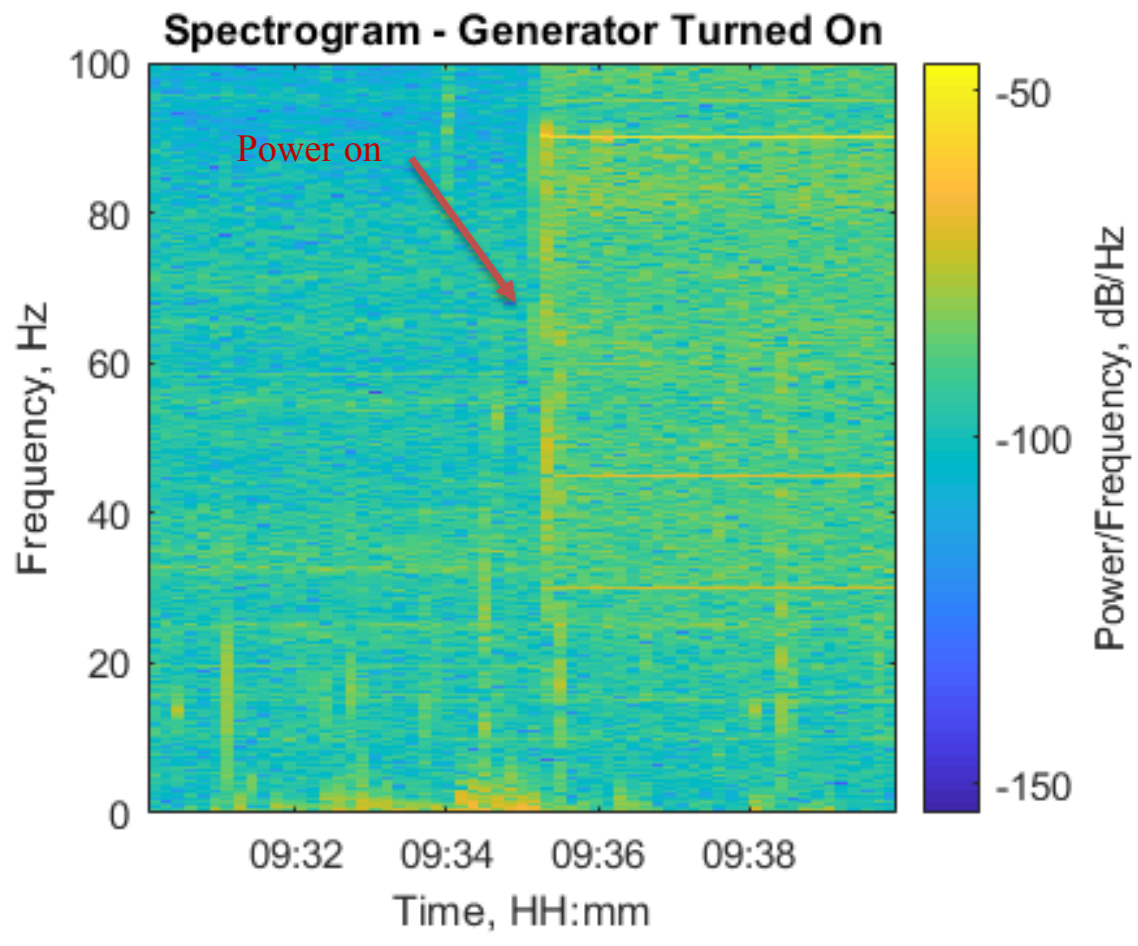

Figure 6. Spectrogram showing an increase in the frequency intensity starting at approximately 09:35 at the onset of diesel generator operation. 


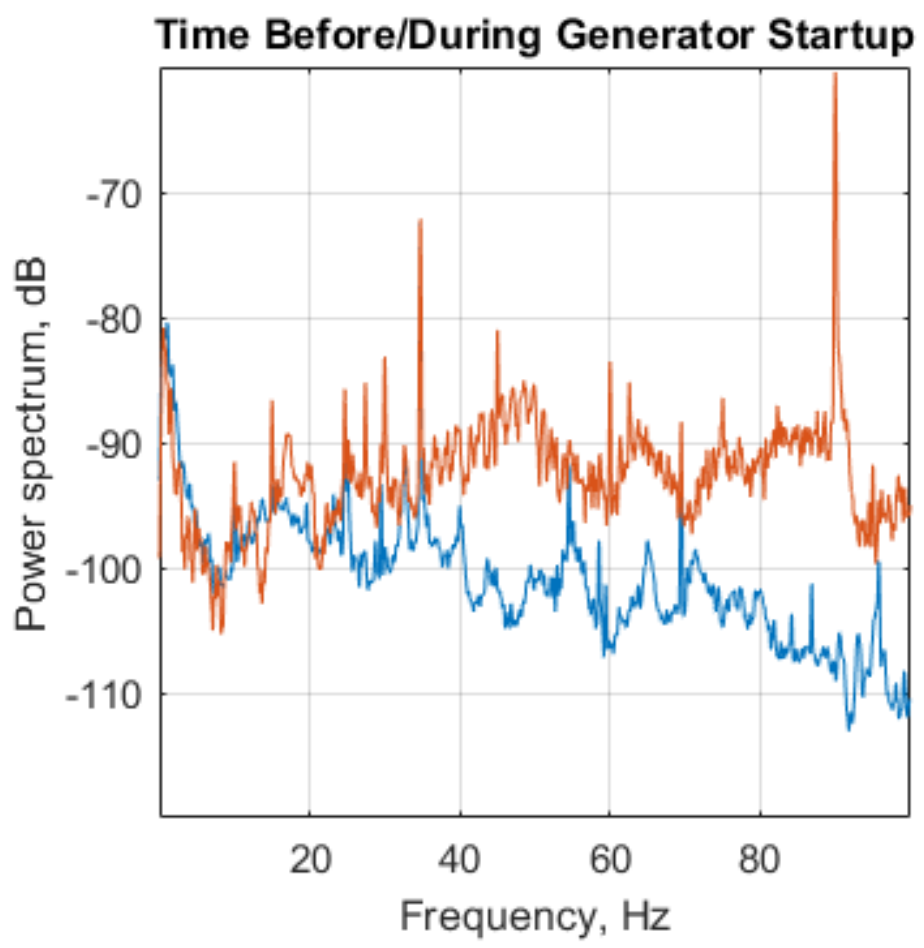

Figure 7. Power spectra comparison between the time before (blue) and including (orange) diesel generator startup.

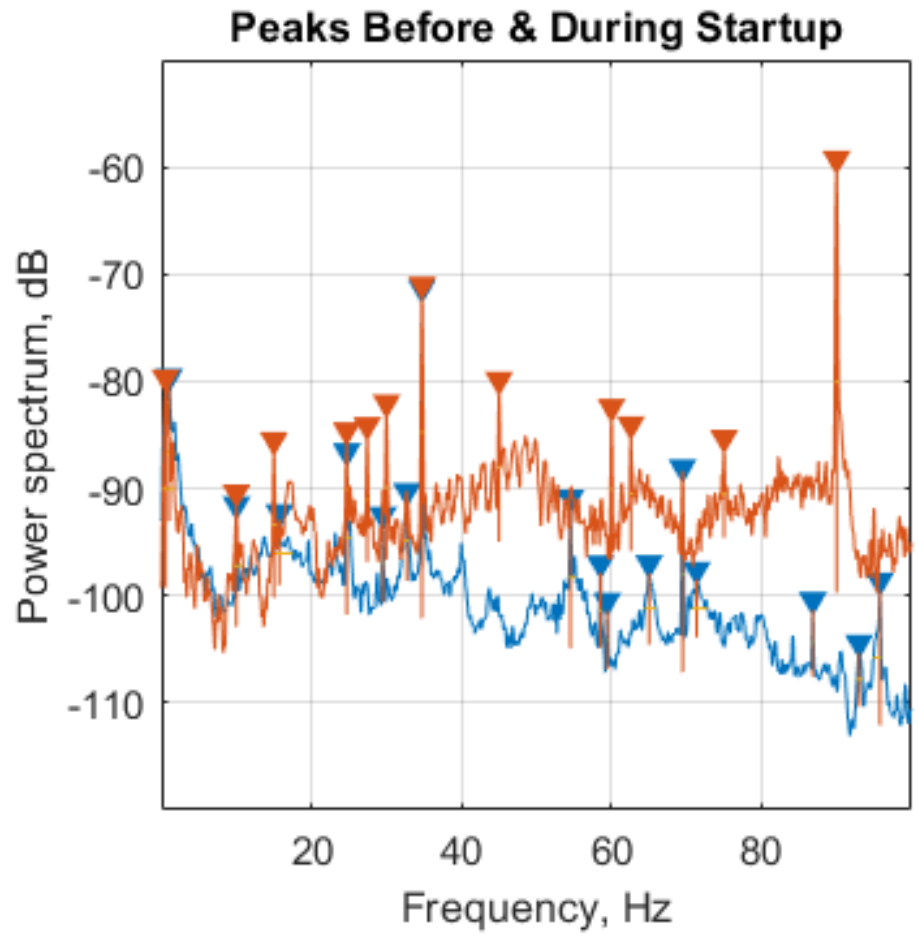

Figure 8. Power spectra with dominant peaks annotated. The time period before generator startup (blue) is plotted against time that includes the generator operation startup (orange). 


\subsubsection{Generator Steady State}

The intensity of the frequency band from approximately 38 to $80 \mathrm{~Hz}$ decreases from the time period that includes generator startup, from 09:35 to 09:36, and following startup, during steady state operation, from 09:36 to 09:40. The power spectra of Figure 9 shows that the intensity of frequencies during startup for the frequency band from approximately 38 to $80 \mathrm{~Hz}$ is greater on average than during steady state operation. All dominant peaks that were generated during startup continue to persist during steady-state operation.

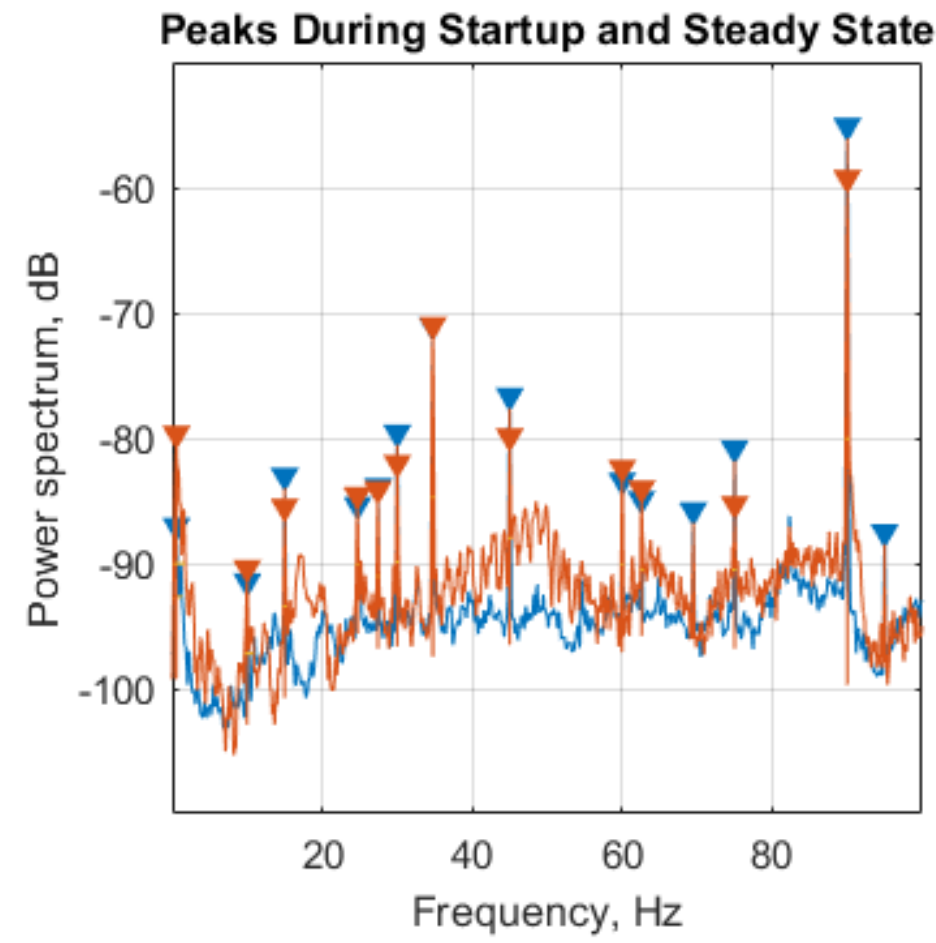

Figure 9. Power spectra with dominant peaks annotated. The time period during generator startup (orange) is plotted against time for generator steady state operation (blue). 


\subsubsection{Generator Shut Down}

Signature development for generator shut off is similar to that described for startup. The acquired signal of Figure 10 shows a similar, but opposite change in intensity in comparison to operation startup. The source of the high intensity peak at the end of the recorded period, beyond 10:13, is unclear, but seems to be unlikely due to generator shut down. All peaks and harmonics described for startup operations remain prior to shut down but are not present after shut down, as observed in the spectrogram of Figure 11. The power spectra of Figure 12 and Figure 13 display time during generator shut down and directly following shut down. The same peaks are identified during shut down as startup.

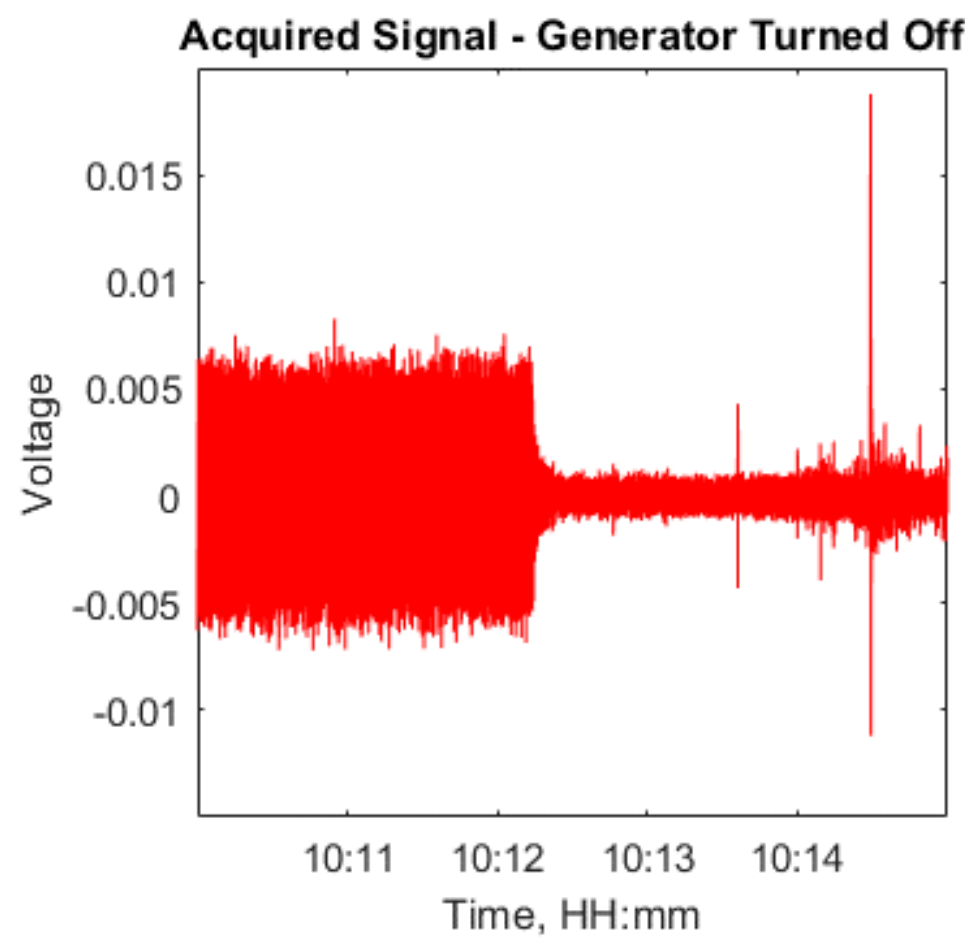

Figure 10. Acquired signal for diesel generator shut down. 


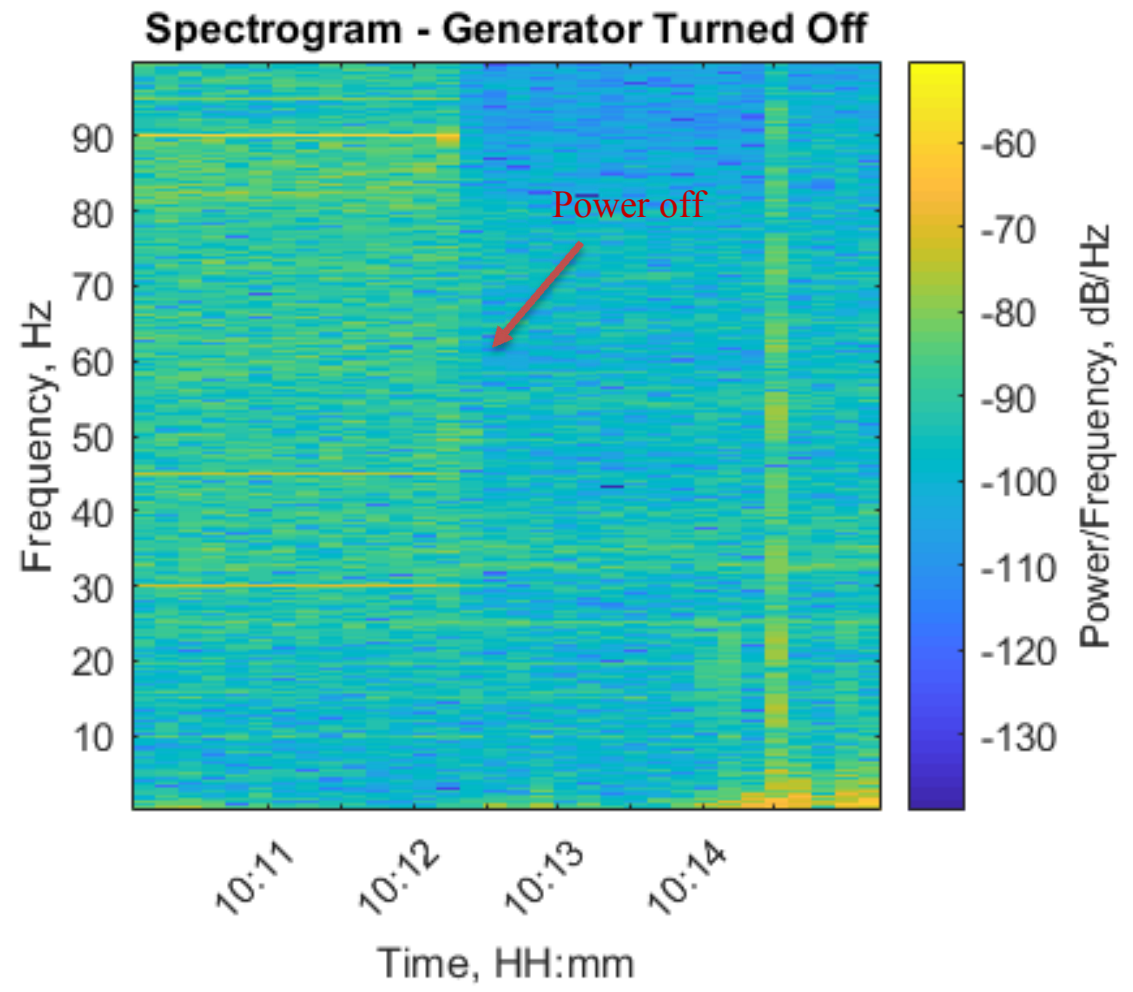

Figure 11. Spectrogram of diesel generator shut down.

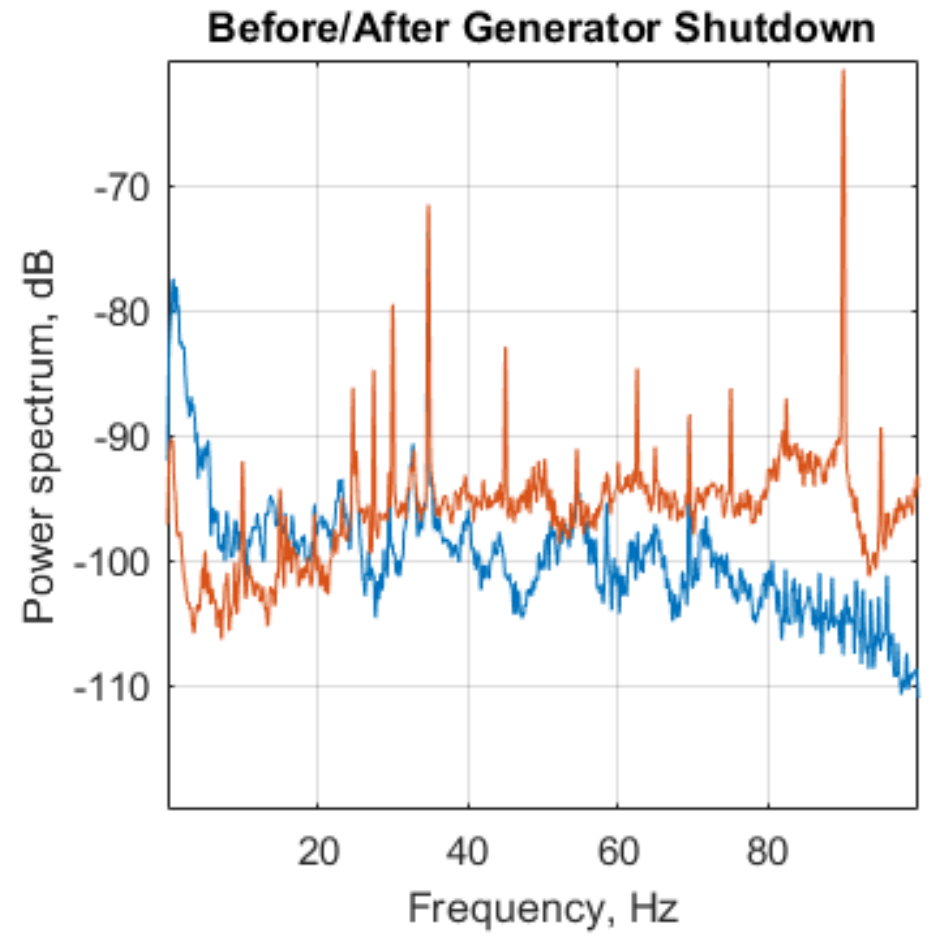

Figure 12. Power spectra for the time period including (orange) and following generator shut down (blue). 


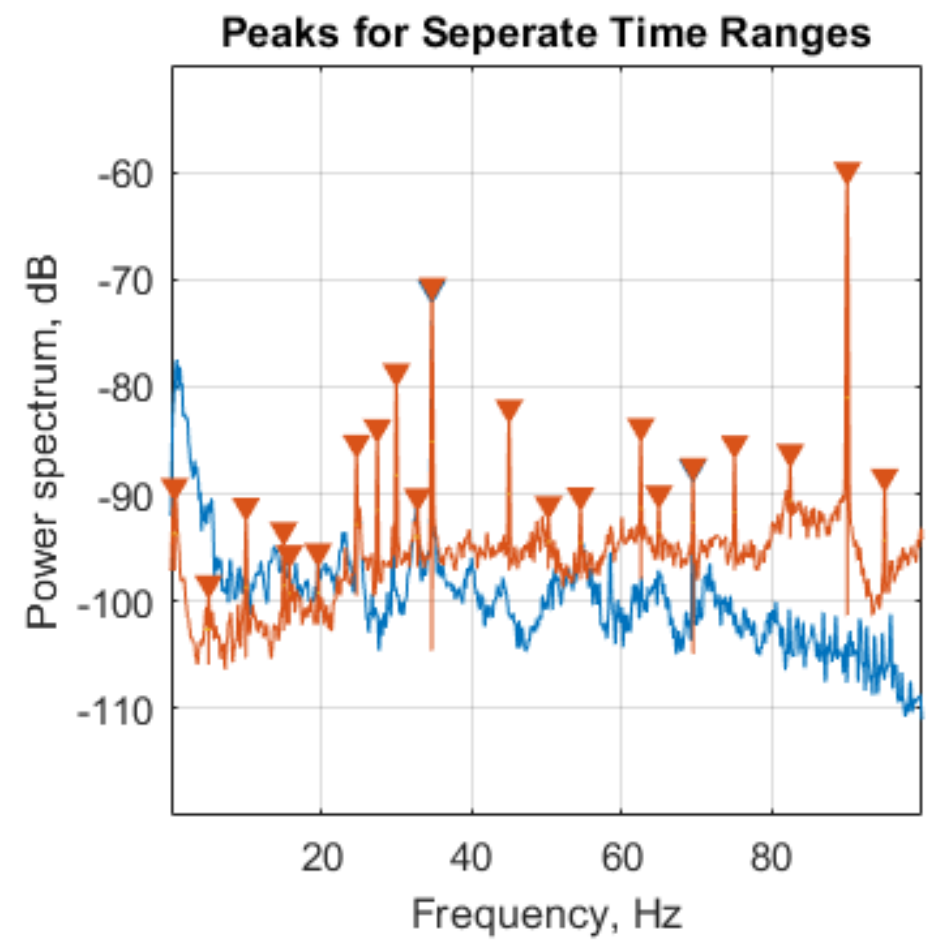

Figure 13. Power spectra matching data of Figure 11 with dominant peaks annotated. 


\subsection{Manipulator Operations in Hot Cells}

Hot cells are shielded environments designed to protect skilled workers from radioactive materials located inside the cell. Manipulators are robotic arms that extend from outside to inside a hot cell and are used for remote handling of the radioactive materials. Robotic pincers are fastened to the inside end of the manipulator and connected through the length of the arm to a remote control utility fastened on the outside end.

Signals were recorded of manipulator operations performed by ORNL personnel in room 116 of building 7920. The manipulator studied here is marked with a " $\mathrm{B}$ " on Map 4, appearing in Appendix 1. A signal recorder was placed approximately 10 feet behind the hot cell manipulators, marked with a 3 on Map 4, for 26 minutes (without MINOS team members present to note operations or time stamps). The raw signal displayed in Figure 14 was analyzed through an audio device to determine if manipulator operations could be heard. The sound recording was playing simultaneously while conducting a visual examination of the spectrogram in Figure 15. The visual examination includes an indicator on the spectrogram of the position of the sound during playback. The high-intensity frequency bands below approximately $30 \mathrm{~Hz}$ were separated into time periods and examined individually and in comparison to one another. No distinguishing frequencies were identified between the bands. In addition, it was difficult to identify audible sounds as manipulator operations; therefore, more sound signals must be recorded in the future for manipulator acoustic characterization. Although a frequency signature could not definitively be attributed to hot cell manipulator operations, persistent frequencies were identified in the environment near the manipulators as shown in the power spectrum of Figure 16. Dominant peaks are located at 23, 30, 44, 60, and $82 \mathrm{~Hz}$. The $60 \mathrm{~Hz}$ frequency likely results from commercial electrical power; however, more tests would need to be performed to determine the direct cause of the additional observed frequencies.

\section{Acquired Signal-Manipulator Operations}

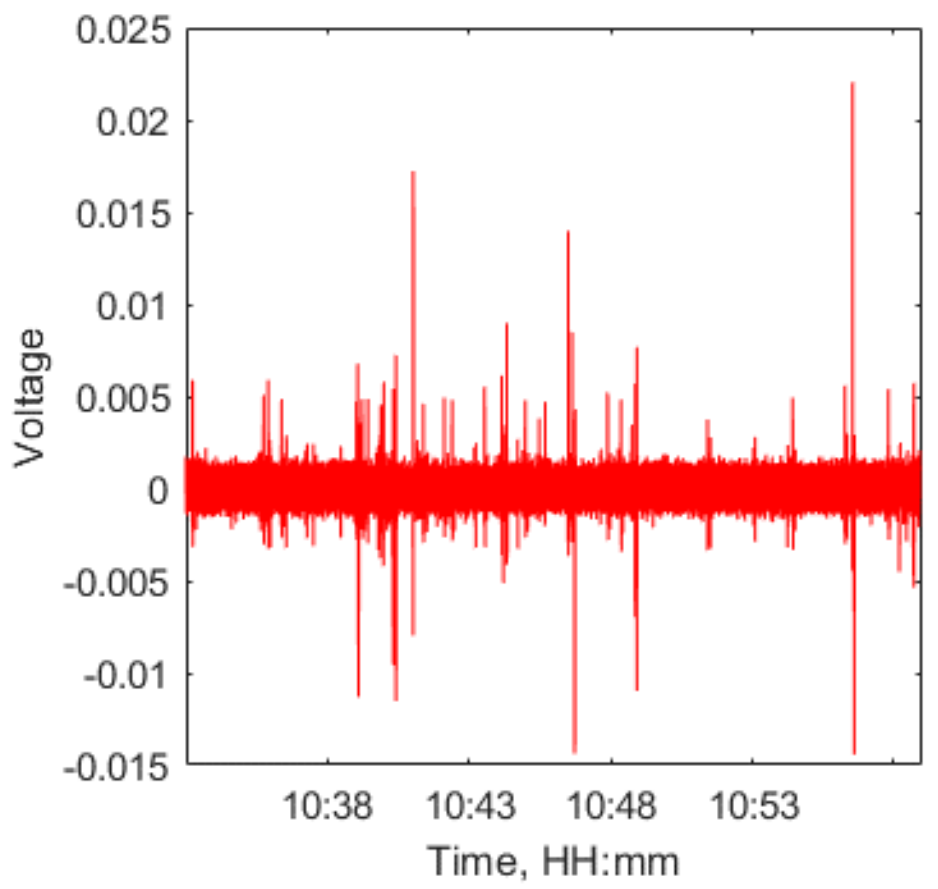

Figure 14. Raw signal measured from recorder near hot cell manipulators. 


\section{Spectrogram-Manipulator Operations}

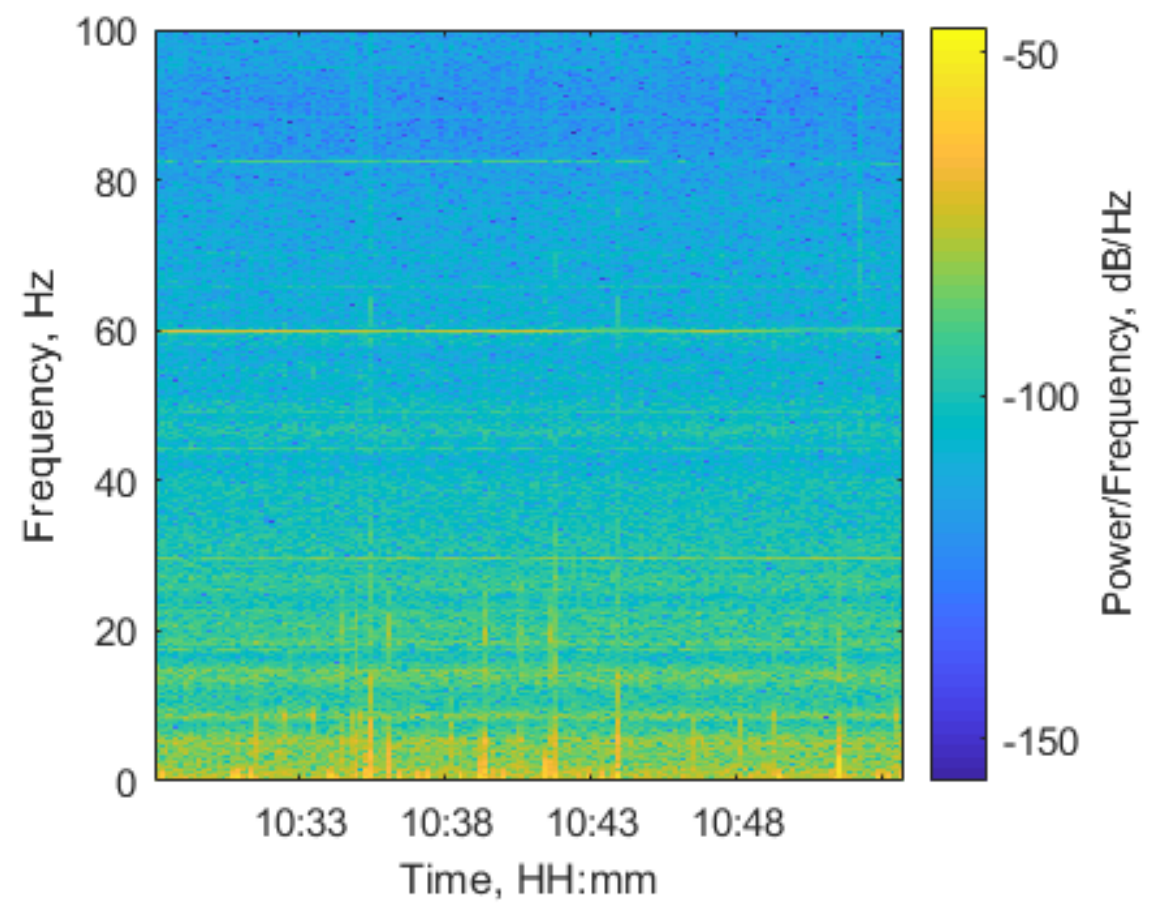

Figure 15. Spectrogram of manipulator operations showing high intensity frequency bands below approximately $30 \mathrm{~Hz}$.

\section{Peaks-Manipulator Operations}

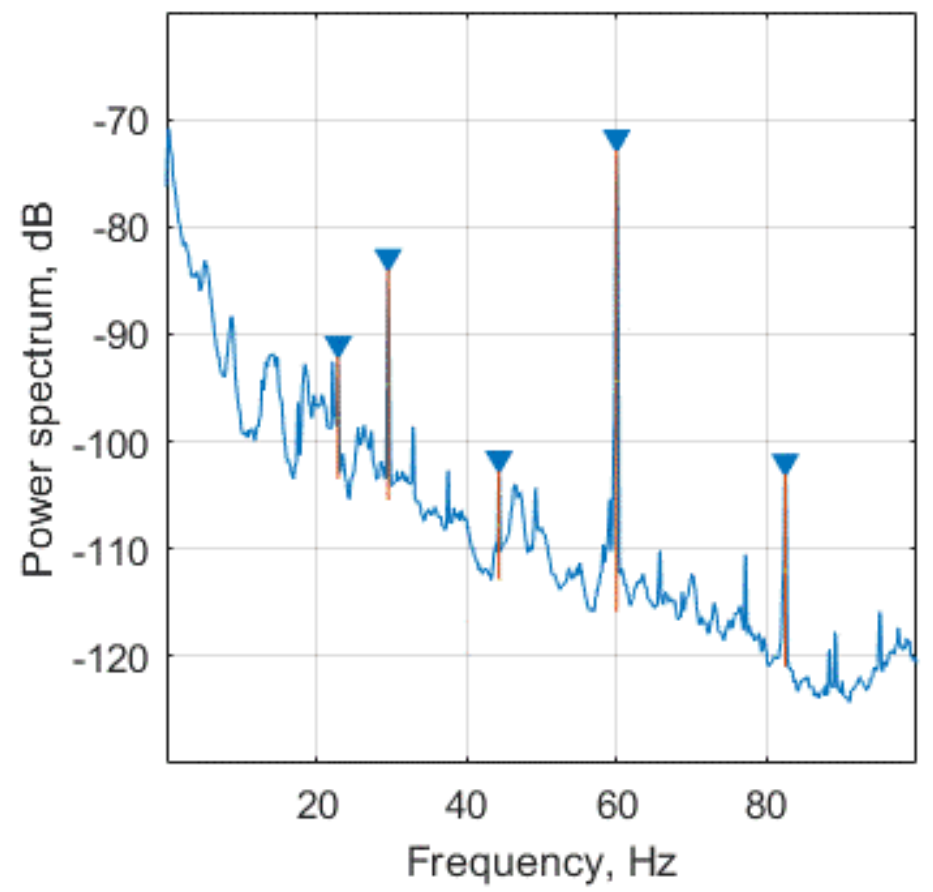

Figure 16. Power spectrum of manipulator operations with persistent peaks at $23,30,44,60$, and $82 \mathrm{~Hz}$ annotated. 


\subsection{Conveyor Transfer Operations}

The ORNL conveyor system transfers radioactive materials between hot cells and a control room adjacent to the hot cells. The conveyor system is located in building 7920 and controlled by switches located near each hot cell in room 116, 120, or in control room 122 labeled on Map 4 of Appendix 1. Sound signals were measured at marker ' $3 \mathrm{a}$ ", indicated on Map 4, in the control room which contains a 4' $\times 10$ ' by 6 ' tall lead shielding wall located between the recorder and the conveyor belt. Pneumatic equipment, located in control room 122, power conveyor belt movements through pressure differentials controlled by compressor valves. The conveyor was moved toward the recorder from hot cell 4 to hot cell 7, labeled "B1" and "B2" respectively on Map 4. The movement time was annotated by INL team members at 10:41 am. The conveyor moved away from the sound recorder from hot cell 7 to 4 with the transfer start time annotated at $10: 42 \mathrm{am}$.

The raw signal displayed in Figure 17 was recorded in a 4 minute 28 second time frame from 10:4010:44:28 am. Audio analysis revealed a loud thump at 10:41, this is observed in the figure as the large voltage difference ranging from approximately -0.07 to $0.04 \mathrm{~V}$, however, the sound does not seem to be related to the conveyor movement between hot cells 4 and 7 . The start time of conveyor movement is approximately 10:42 am as determined by listening to the file. Note that the time determined by listening to the file is different from the time annotated. Differences in time stamps are likely due to an inability to synchronize the time stamp in the sound meter to the experimenter's time in seconds.

The conveyor belt movement start time, determined by listening to the raw signal, was confirmed through the spectrogram shown in Figure 18. Note that spectrogram time bins were adjusted to 5 second increments to focus on the signal that occurs over the short time period during conveyor movements. The spectrogram shows a brief intensity burst in frequencies ranging from approximately 44 to $100 \mathrm{~Hz}$ at approximately 10:42 am; however, a persistent frequency band ranging from approximately 50 to $60 \mathrm{~Hz}$ occurring throughout the time period partially conceals the signal over the band range. Directly following the burst, a frequency component at approximately $84 \mathrm{~Hz}$ is intensified. Over the next approximately 25 seconds, frequency components are intensified in an upward sloping curve maximizing at approximately $92 \mathrm{~Hz}$ followed by a slight lowering of the curve that ends at approximately $90 \mathrm{~Hz}$. The time period spanning the signal ranges from approximately 10:42:00 to 10:42:25. The movement ends in an intensity burst including frequencies ranging from approximately 44 to $96 \mathrm{~Hz}$. Conveyor belt movement away from the sound recorder from hot cell 7 to 4 gives a similar slope increase in frequency intensities sandwiched between intensity bursts at the start and end of operation, however, the range of frequencies in the slope region begins at approximately $70 \mathrm{~Hz}$, achieves a maximum at approximately $78 \mathrm{~Hz}$, and curves down slightly at end of the time period to approximately $76 \mathrm{~Hz}$. Belt movement away from the recorder occurs from approximately 10:42:40 to 10:43:08 as seen in the spectrogram. The difference in the intensity of frequency components measured between hot cell movements going towards or away from cell 7 and 4 are likely caused by the pneumatic controls rather than from the movement of the conveyor belt itself. However, follow-up measurements of conveyor belt movements are required to ascertain the origin of the signal. In addition, the duration of the intensified power measured likely corresponds with the distance the conveyor belt travels.

The power spectra of Figure 19 displays the time period from 10:42 to 10:42:30 which includes conveyor movement from hot cell 4 to 7 . This spectrum is compared to a background signal which consists of time occurring from 10:41:15 to 10:42. The background time period was chosen because it excludes frequencies associated with the loud thump occurring at approximately 10:41. The conveyor movement power spectrum shows a slight increase in the intensity of frequencies ranging from approximately 40 to $50 \mathrm{~Hz}$. The most notable difference between the spectra occurs between the frequency range starting at approximately $70 \mathrm{~Hz}$ and continuing to nearly $100 \mathrm{~Hz}$. The largest power observed from the conveyor belt signal is approximately $-95 \mathrm{~dB}$ with the background power minimum at approximately $-135 \mathrm{~dB}$ during this region. This frequency range includes the upward slope like increase occurring as time increases. Note that 
no significant power differences are observed between the background and the conveyor system in the infrasound region.

The power spectra of Figure 20 shows the same background signal as Figure 19 in comparison to the signal over the time period that includes the conveyor belt moving from hot cell 7 to $4,10: 42: 30$ to 10:43:15. Again the power in the range of approximately 40 to $50 \mathrm{~Hz}$ is slightly higher for conveyor system movement and it is also slightly greater just beyond approximately $50 \mathrm{~Hz}$ to $60 \mathrm{~Hz}$. The most significant differences to the power occur in the range of frequencies that includes approximately 62 to $100 \mathrm{~Hz}$. The maximum power value for the conveyor signal is approximately $-89 \mathrm{~dB}$ during this time period. As described above, there are no significant power differences observed between the background and the conveyor system in the infrasound region.

The power spectra of Figure 21 shows the signal from the conveyor belt moving from hot cell 4 to 7 compared to movement from hot cell 7 to 4 during the same time periods described for Figure 19 and Figure 20. The figure shows the power differences associated with frequency components that are intensified as a result of conveyor system operation as described in previous paragraphs. Belt movements from hot cells 4 to 7 show larger power in the frequency band ranging from approximately 82 to $98 \mathrm{~Hz}$, while movement from hot cells 7 to 4 shows larger power from approximately 68 to $80 \mathrm{~Hz}$.

\section{Acquired Signal-Conveyor Belt System}

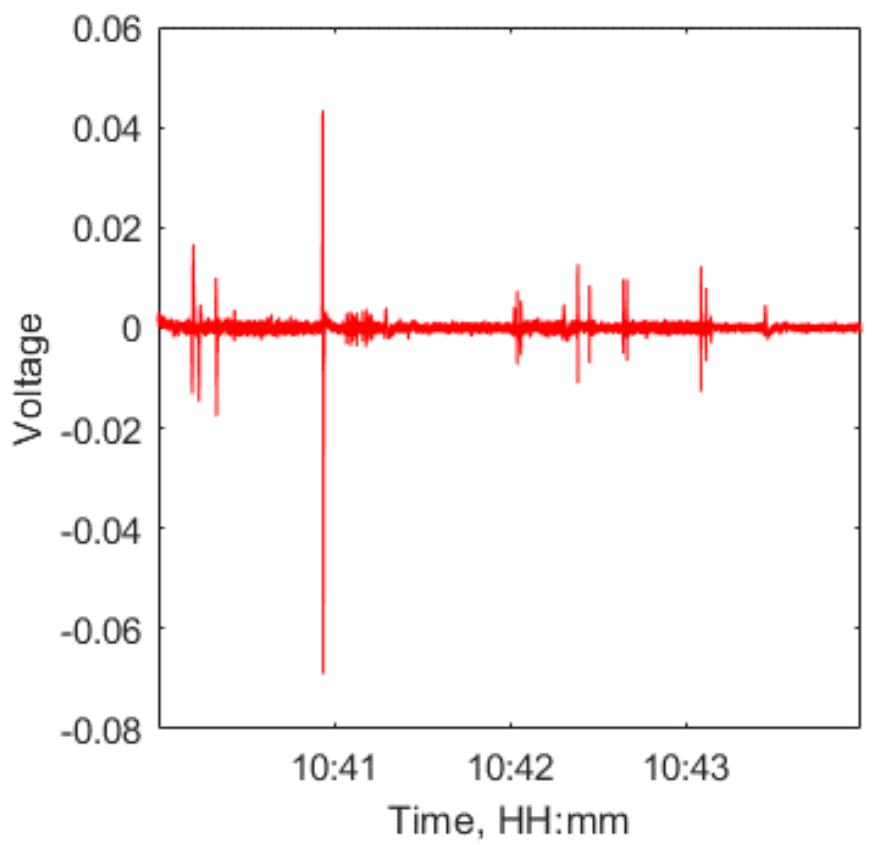

Figure 17. Raw signal recording hot cell conveyor belt movements towards and away from the stationary sound recorder. 


\section{Spectrogram-Conveyor Belt System}

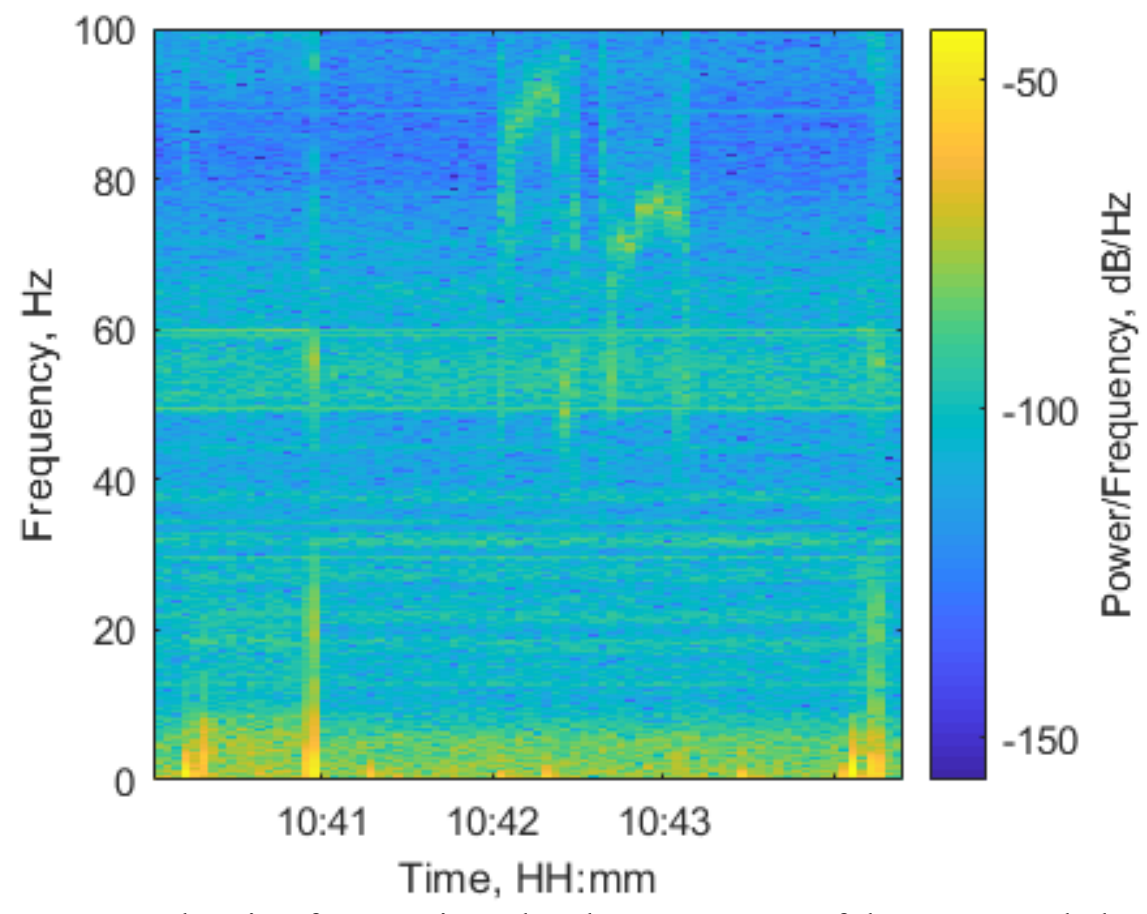

Figure 18. Spectrogram showing frequencies related to movement of the conveyor belt system between hot cells 4 and 7.

\section{Conveyor Belt System \\ Movement from cubicle \#4 to \#7}

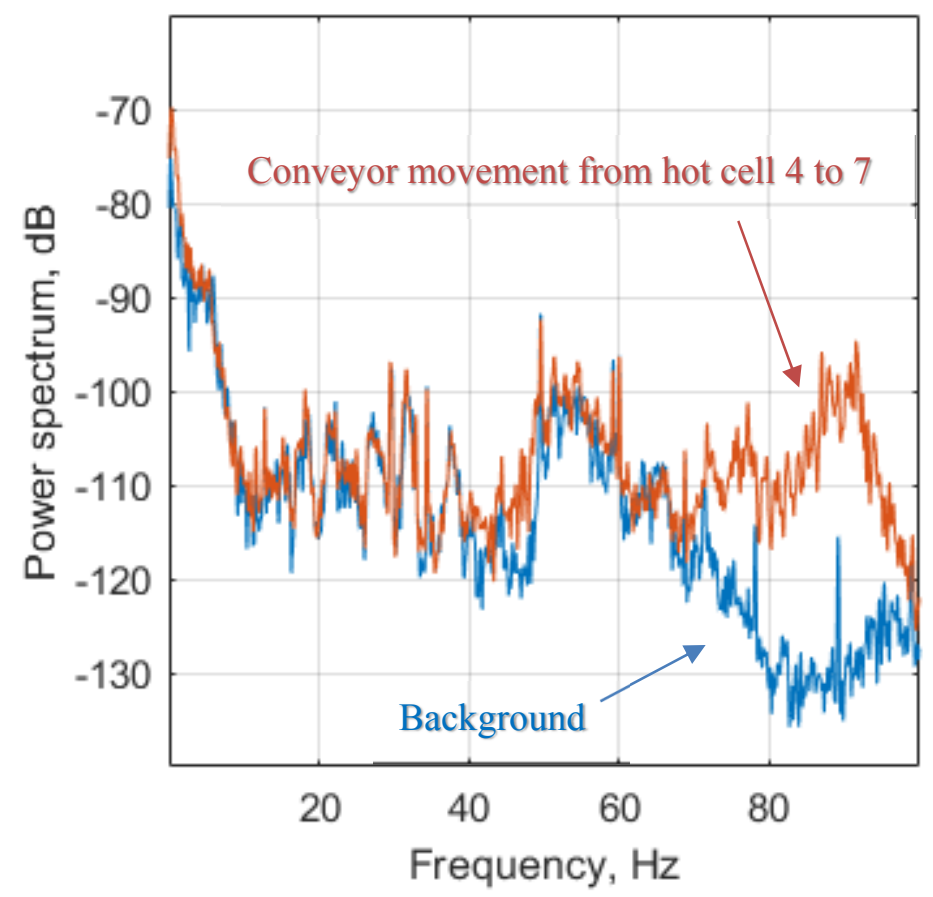

Figure 19. Power spectrum comparing conveyor movement toward the sound recorder (orange) with the background signal (blue). 


\section{Conveyor Belt System \\ Movement from cubicle \#7 to \#4}

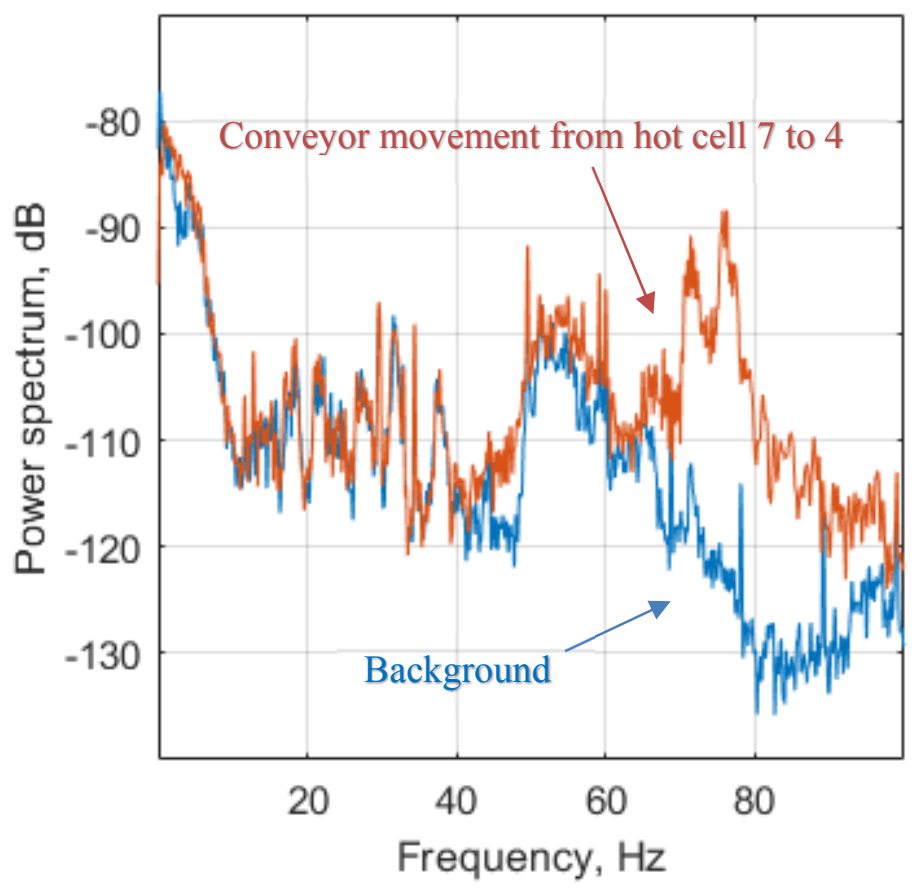

Figure 20. Power spectrum comparing conveyor movement away from the sound level meter (orange) with the background signal (blue). 


\section{Conveyor Belt System \\ Movement from cubicle}

\#4 to \#7/ \#7 to \#4

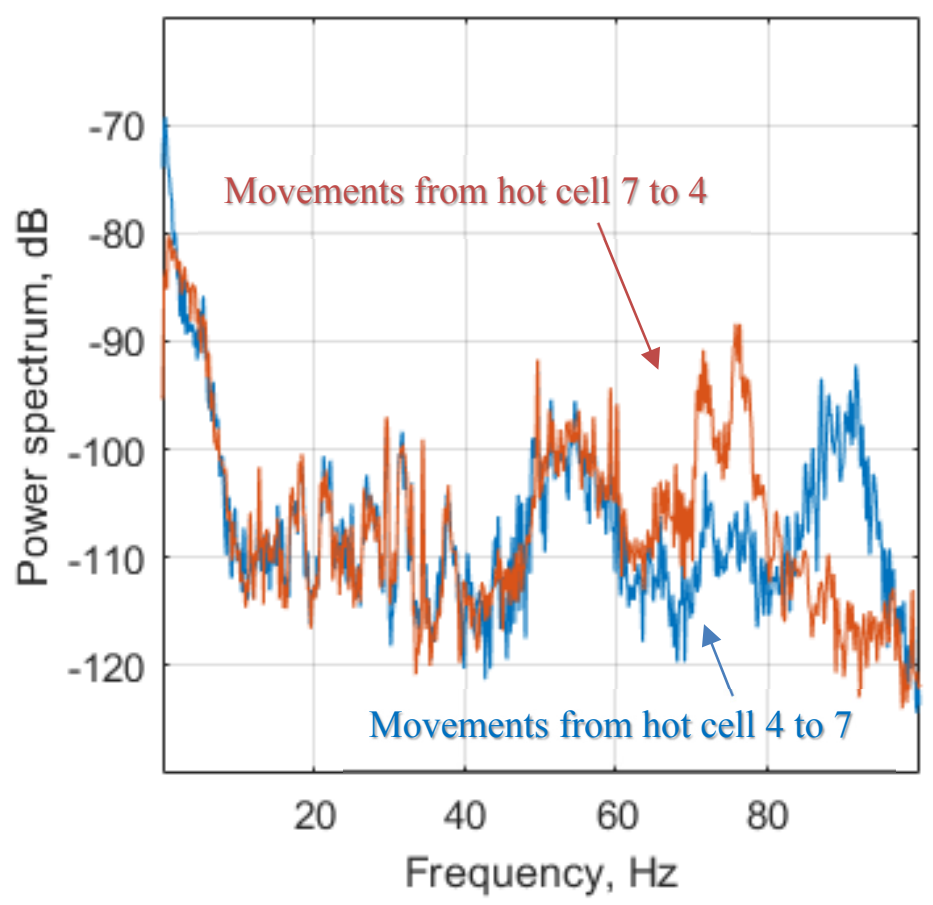

Figure 21. Power spectrum comparing conveyor movement toward (blue) and away from the sound level meter (blue). 


\subsection{Cell Off-Gas \& Vessel Off-Gas Ventilation Trains}

As a safety feature, the ventilation system for the REDC facility has two ventilation trains; the cell offgas and vessel off-gas trains. Pumps, located in an open shed (building 7922), pull vacuum separately through two large pipes; one pipe starts flow for the cell off-gas train and the other for the vessel off-gas train. The pipes branch off to alternate areas of the REDC facility. The cell off-gas train flows from hot cells and gloveboxes and may include radioactive gases. The vessel off-gas train includes air that flows from chemical hoods or laboratories that do not contain radioactive gases. A vacuum is pulled separately for each train so that radioactive gases can never flow into a nonradioactive area. Both trains come together, are filtered, and ultimately vented out of the stack, the tall tower labeled 7911 in Map 1 located in Appendix 1. Vacuum pumps and fans are housed in building 7922 located near the stack, also shown in Map 1. INL team members left both recorders unmanned in building 7922 for about an hour and a half and during that time it was assumed that both trains were in steady-state operation.

Recording of the cell off-gas train began at 11:17 am and ended at 12:43 pm. Vessel off-gas recording also started at 11:17 am, but ended at 12:45 pm. Sound level meters were placed at positions 4 and 5, labeled in Map 3 and Map 5 in Appendix 1, to record data for the vessel off-gas and cell off-gas trains, respectively. Raw signals, spectrograms, and power spectra were analyzed for each data file recorded. The spectrograms showed a multitude of frequency bands that were present throughout the entire recording period for both ventilation trains. The most notable frequency component which persisted throughout the entire recoding time window was observed at approximately $44 \mathrm{~Hz}$ and measured approximately $-71 \mathrm{~dB}$ and $-75 \mathrm{~dB}$ for the cell and vessel off-gas trains, respectively. The frequency line at approximately $44 \mathrm{~Hz}$ is apparent in the spectrograms of Figure 22 and Figure 23 that cover a 20 minute period ranging from 11:56 am to $12: 16 \mathrm{pm}$ and 12:25 to $12: 45 \mathrm{pm}$, respectively. Figures 21 and 22 show data that was recorded near the cell and vessel off-gas pipes, respectively. Both spectrograms also display a defined frequency component at approximately $28 \mathrm{~Hz}$ that measures approximately -95 and $-88 \mathrm{~dB}$ for the cell and vessel off-gas trains, respectively. No significant changes in the data were observed over the entire recording period with the exception of a frequency component at approximately $8.6 \mathrm{~Hz}$ that intensifies at approximately 12:03:20 pm, continues to 12:05:48 pm, resumes again at approximately 12:29:41 pm, and continues until approximately 12:37:03 pm. Sound level meters positioned near both ventilation trains recorded the approximately $8.6 \mathrm{~Hz}$ frequency component at the exact same times with the signal observable in the spectrograms of Figure 22 and Figure 23. It is unclear what generated the $8.6 \mathrm{~Hz}$ frequency component; however, it may be that the signal was caused from a source external to the open air shed that the recorders were housed in. More experiments would need to be conducted for confirmation. 


\section{Spectrogram-Cell Off Gas}

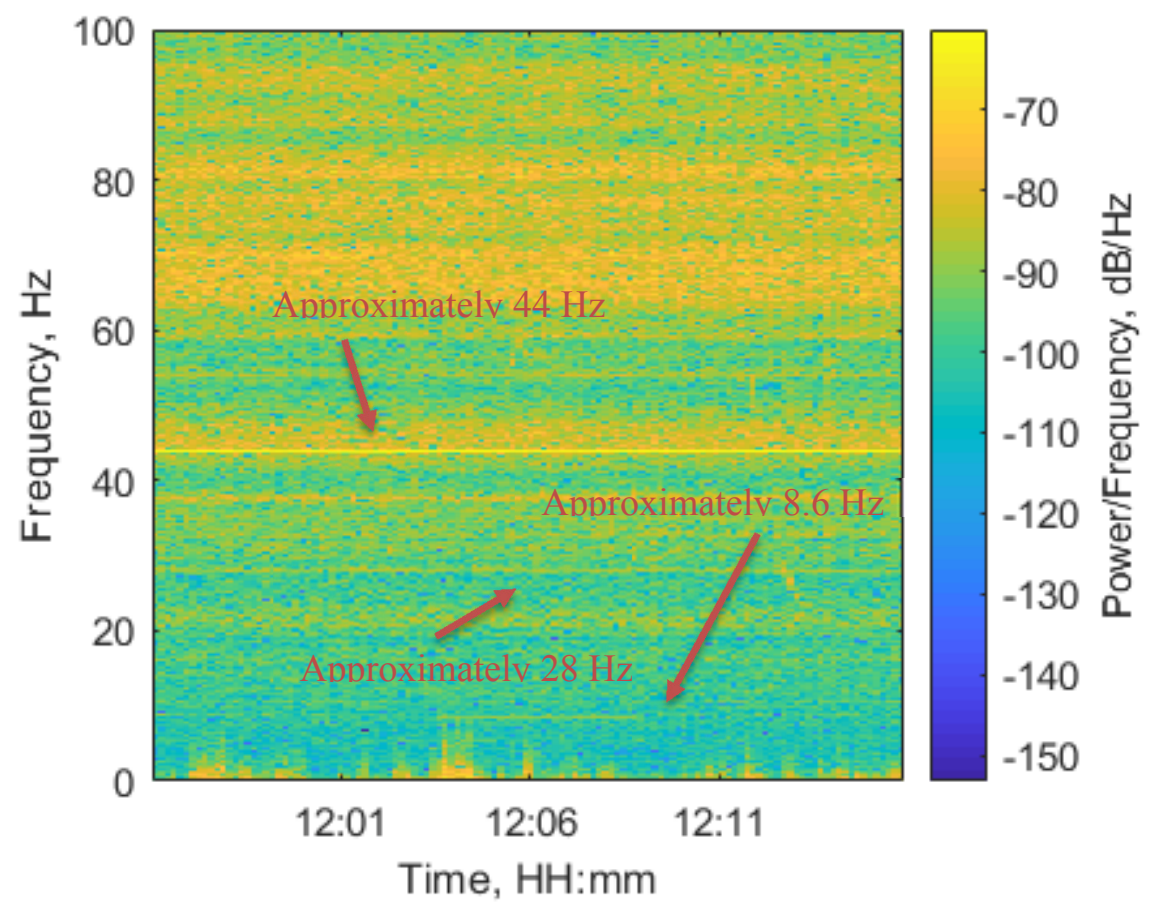

Figure 22. Spectrogram displaying cell off-gas signals.

\section{Spectrogram-Vessel Off Gas}

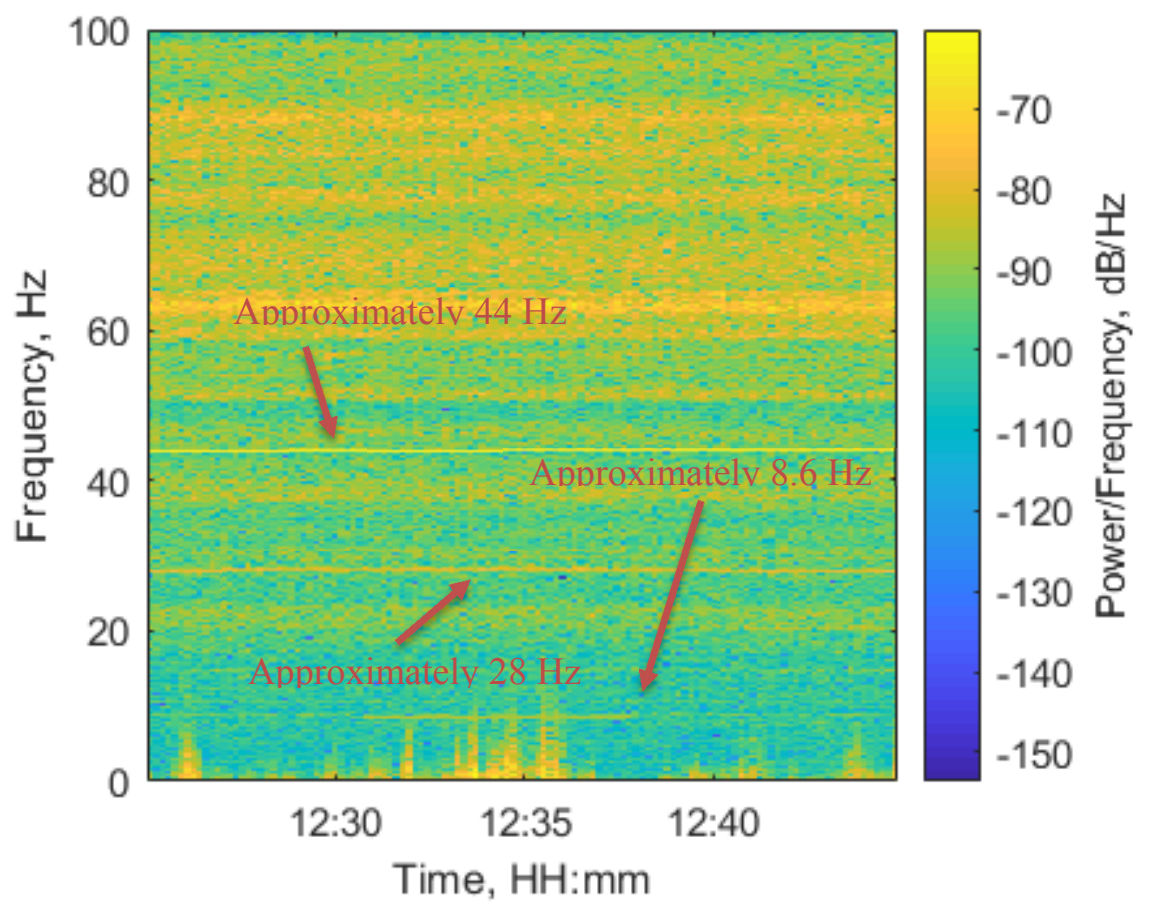

Figure 23. Spectrogram displaying vessel off-gas signals. 


\subsection{HFIR Reactor Bay Crane Movements}

The HFIR reactor bay, room 210 in building 7900 labeled in Map 6 of Appendix 1, houses two overhead crane bridges with access to the second floor. A 12-ton crane bridge spans the width of the spent fuel pool, as noted in Map 6. An additional crane bridge spans the north/south width of the entire reactor bay that is approximately $125 \times 100 \times 60$ feet high, therefore movements occur in the east/west direction. This bridge holds two crane hooks, 3 - and 50-ton, which translate in the crane housing north and south.

\subsubsection{2-Ton Unloaded Crane Bridge Movements}

Sound level meters were placed on a viewing deck on the third floor of building 7900, which views the second floor below through a window. The recorders were positioned near the spent fuel bridge (indicated by a purple rectangle) at positions 6 and 7 labeled on Map 7 in Appendix 1. Sound recording began at 1:06 and 1:08 pm for meters at positions 6 and 7 respectively. Measurements continued for approximately 40 minutes without INL team members present, therefore, bridge and crane movements with corresponding time stamps were not logged.

Raw signals and spectrograms for each 10 minute data block were studied concurrently. Since events were not annotated, the methodology was to look for patterns between each time block and listen to the raw data files to determine whether the signal "sounded like" a crane moving. Three 10 minute time blocks extracted from the 40 minute recording period are presented in the raw data signals of Figure 24, Figure 25, and Figure 26 and spectrograms of Figure 27, Figure 28, and Figure 29 for the sound meter located at position 6. Peaks similar in shape and voltage, approximately $0.02 \mathrm{~V}$ max, were present in the raw signal data at approximately 1:11:50, 1:16:05, 1:22:04, and 1:39:17 pm in Figure 24, Figure 25, and Figure 26 respectively. These raw signal peaks correspond to strong bursts in intensity, indicated in the spectrograms, for the broad band of frequencies displayed. The intensity profile is more apparent by zooming into the time period surrounding the pattern similarities in Figure 27 and Figure 28. A close-up of the patterns indicated in Figure 27 and Figure 28 are shown in Figure 30 and Figure 32, respectively. The close-ups described in this section are displayed with the spectrogram generated with 1-second time-bin widths. The intensity profiles shown in Figure 30 and Figure 32 are very similar. A comparison of the profiles reveals a large initial increase in the intensity for frequencies ranging from 0 to approximately $20 \mathrm{~Hz}$, directly followed by a large increase in the intensity for near-zero hertz frequencies for about 1 second. This 1second intensity burst is followed by an increase in power for frequencies between approximately 4 to 21 $\mathrm{Hz}$. As this occurs, frequencies below approximately $20 \mathrm{~Hz}$ decrease immediately in concurrence with the power in frequencies at approximately 22 and $23 \mathrm{~Hz}$ intensifying. The intensity decreases to near background for a short 2 second period. After a few seconds, the intensity increases for frequencies between approximately 10 and $20 \mathrm{~Hz}$ followed by in intensity increase in the range of frequencies between 0 and approximately $20 \mathrm{~Hz}$. Simultaneous to the entire time period described, an increase in intensities over the breadth of frequencies occurs. In contrast, the intensity profile for unknown signals, indicated in Figure 27 and Figure 28, varies tremendously to the pattern profile. The unknown signals displayed in Figure 27 and Figure 28 are shown close-up in Figure 31 and Figure 32, respectively.

The power spectra of Figure 33 confirms an increase in the intensity for the broad range of frequencies analyzed over the background excluding frequencies from approximately 60 to $70 \mathrm{~Hz}$. The power spectra displays the time period including similar patterns displayed in Figure 27 and Figure 28 along with background time periods also indicated on the graphs. The background periods were chosen because they exclude significant features in the spectrograms. The most significant differences in power between the pattern data and the background occur from 0 to approximately $22 \mathrm{~Hz}$ and approximately 85 to $100 \mathrm{~Hz}$. The power spectra of Figure 34 displays the pattern matching data to the unknown profile shown in Figure 27 . The spectra show vast differences along the broad band of frequencies. 
The pattern data is likely the crane moving as verified by listening to the signal, however, it is unclear whether the movement is the crane bridge or the crane hook. The signal described as the "unknown" could also be a part of the crane moving. Also, note that the pattern signals observed using the sound level meter at position 6 cannot be verified with the meter in position 7 . There are no signals recorded by the meter at position 7 that fully match the pattern signals described above. In listening to the data recorded at position 7 it is difficult to hear the crane moving. More experiments of 12-ton crane movements need to be performed to confirm the source of the signals and whether or not reliable signatures can be developed.

\section{Acquired Signal-12-Ton Crane}

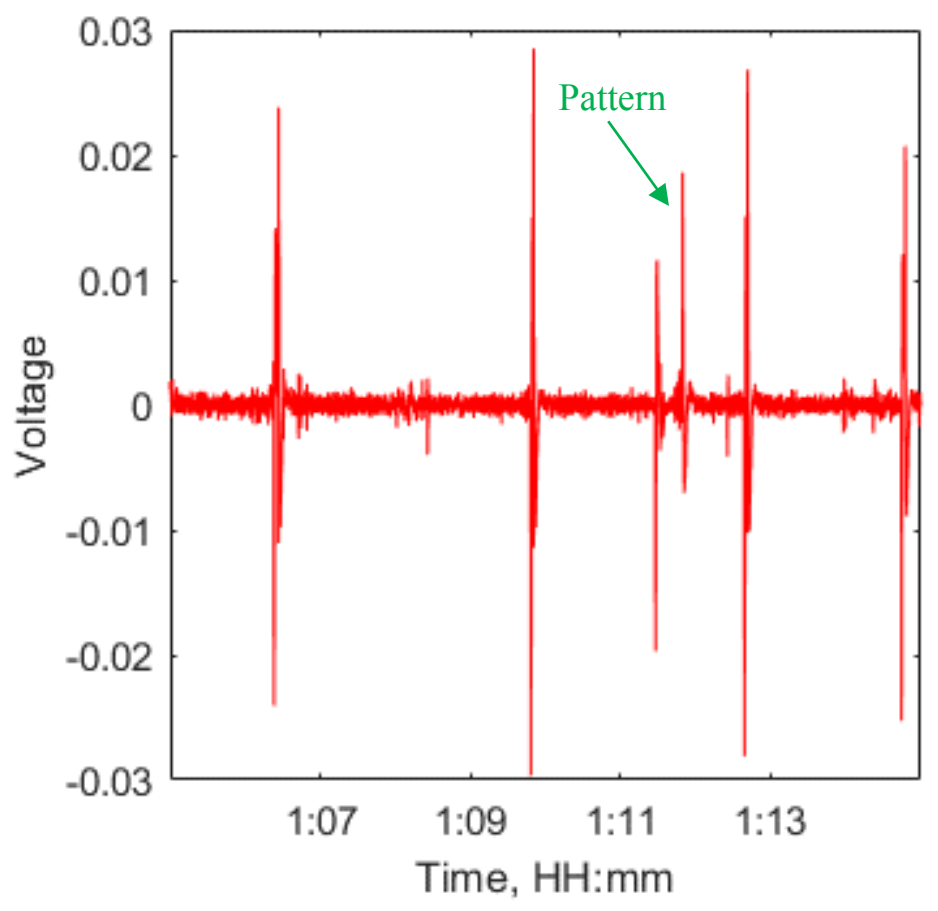

Figure 24. Raw signal acquired from movement of a 12-ton crane over the spent fuel pool for the time period starting at 1:05 pm. 
Acquired Signal-12-Ton Crane

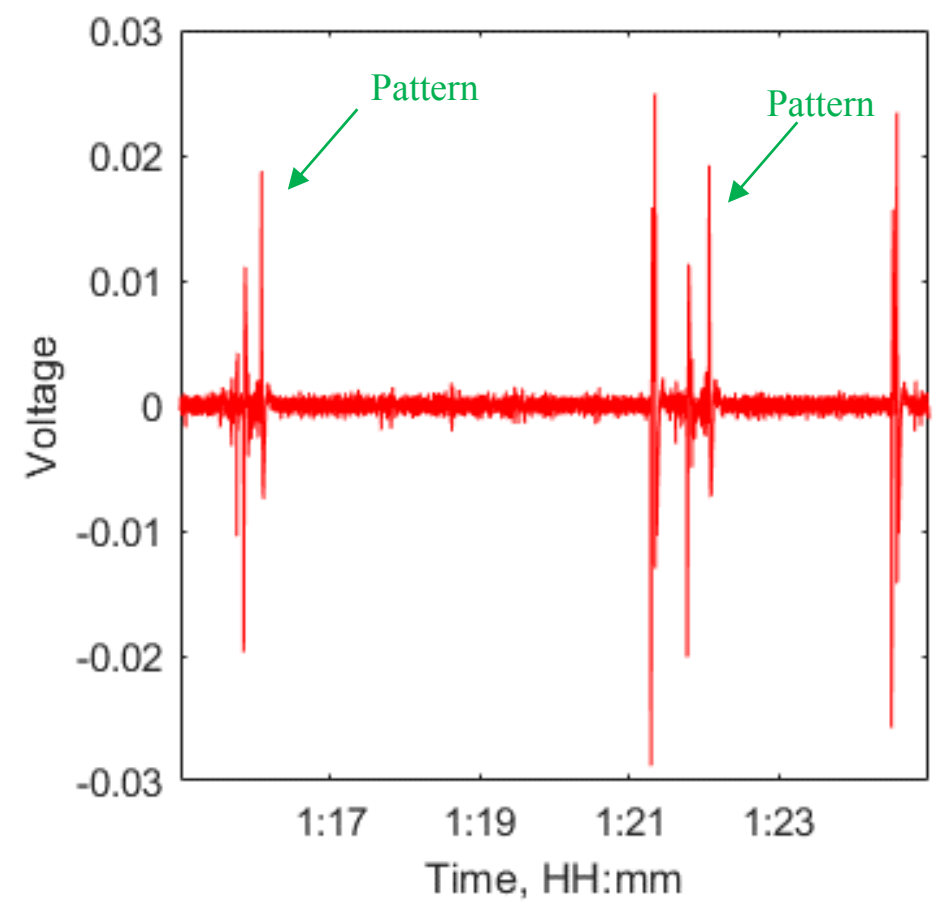

Figure 25. Raw signal acquired from movement of a 12-ton crane over the spent fuel pool for the time period starting at $1: 15 \mathrm{pm}$.

Acquired Signal-12-Ton Crane

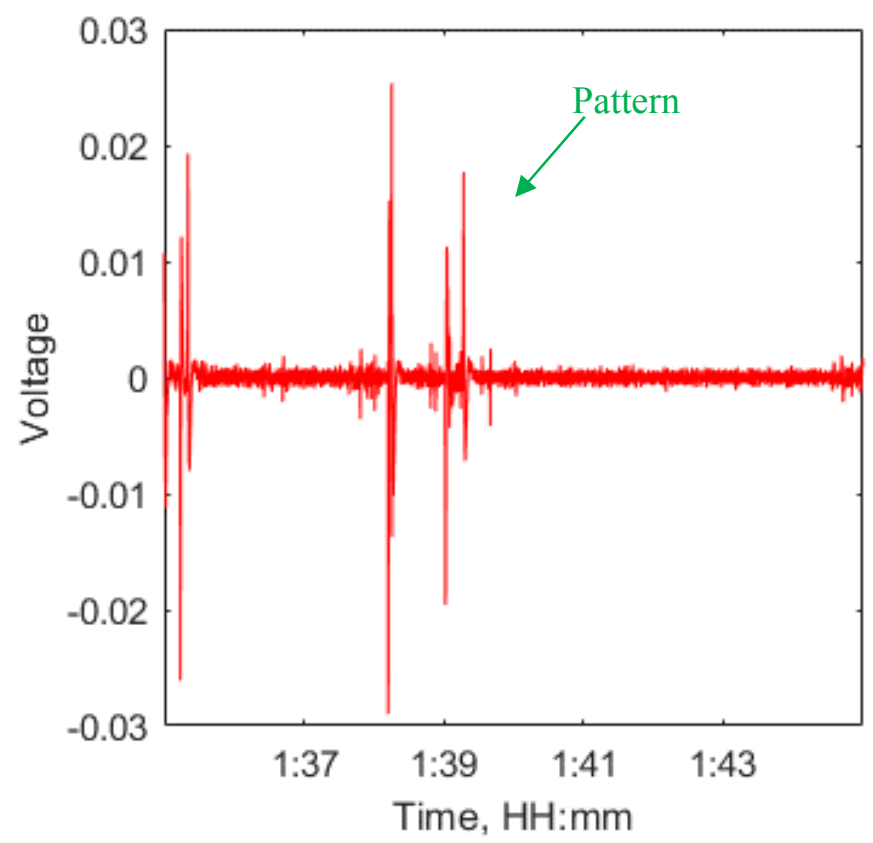

Figure 26. Raw signal acquired from movement of a 12-ton crane over the spent fuel pool for the time period starting at $1: 35 \mathrm{pm}$. 


\section{Spectrogram-12-Ton Crane}

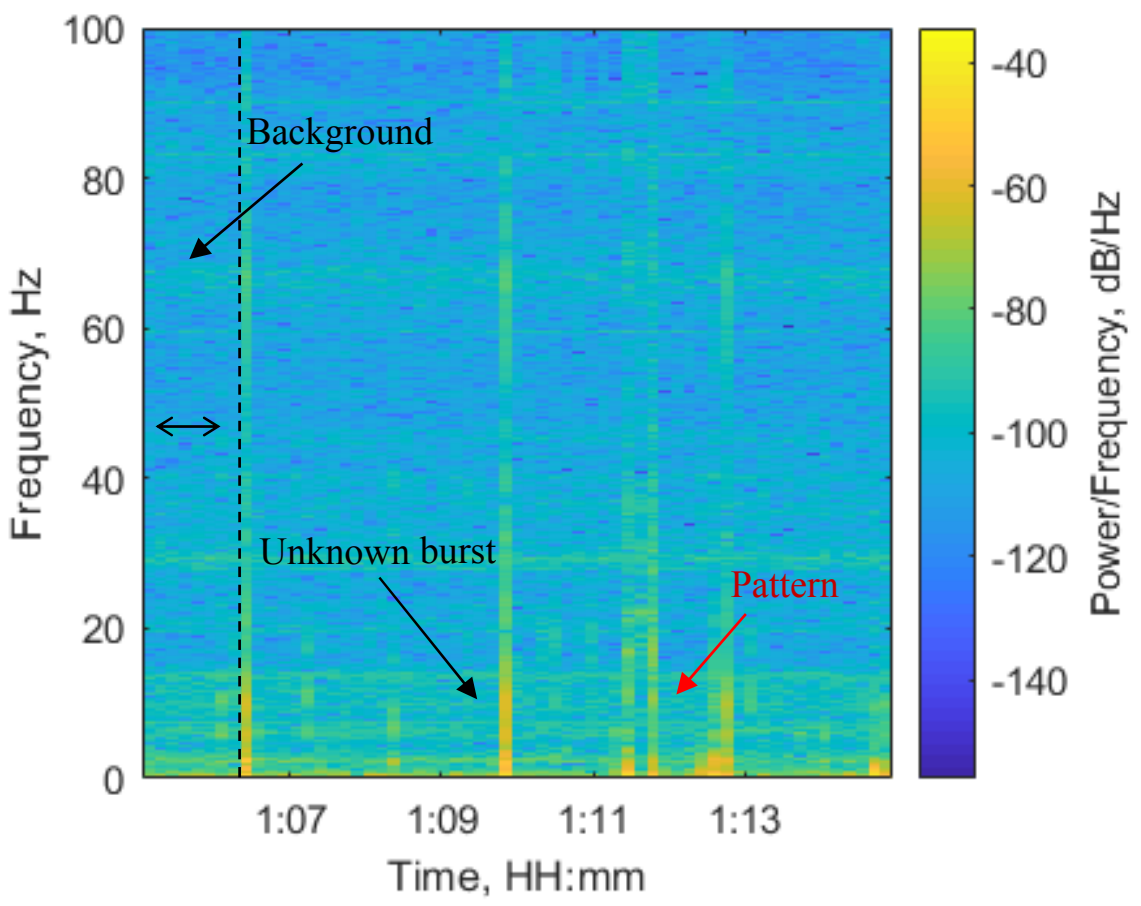

Figure 27. Spectrogram recorded in position 6 covering time period starting at 1:05 pm.

\section{Spectrogram-12-Ton Crane}

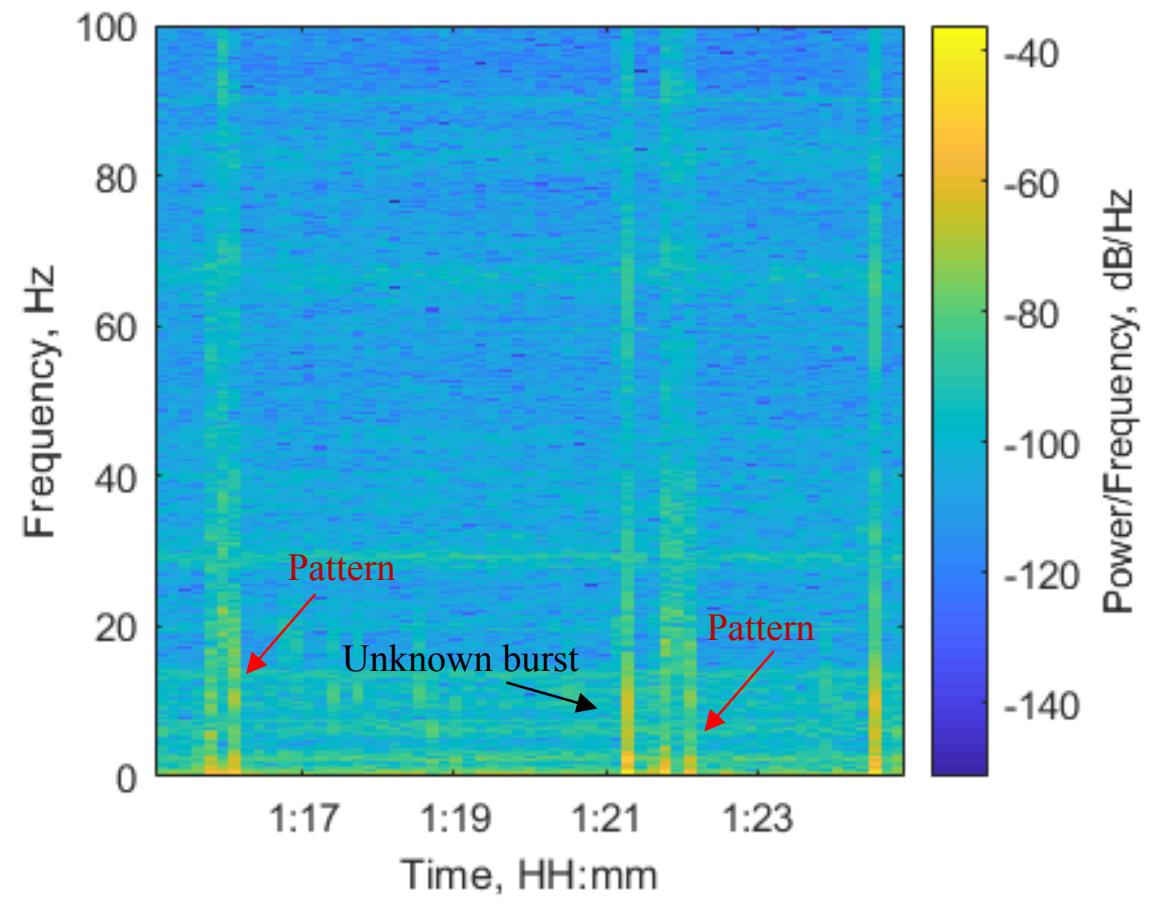

Figure 28. Spectrogram recorded in position 6 covering time period starting at 1:15 pm. 


\section{Spectrogram-12-Ton Crane}

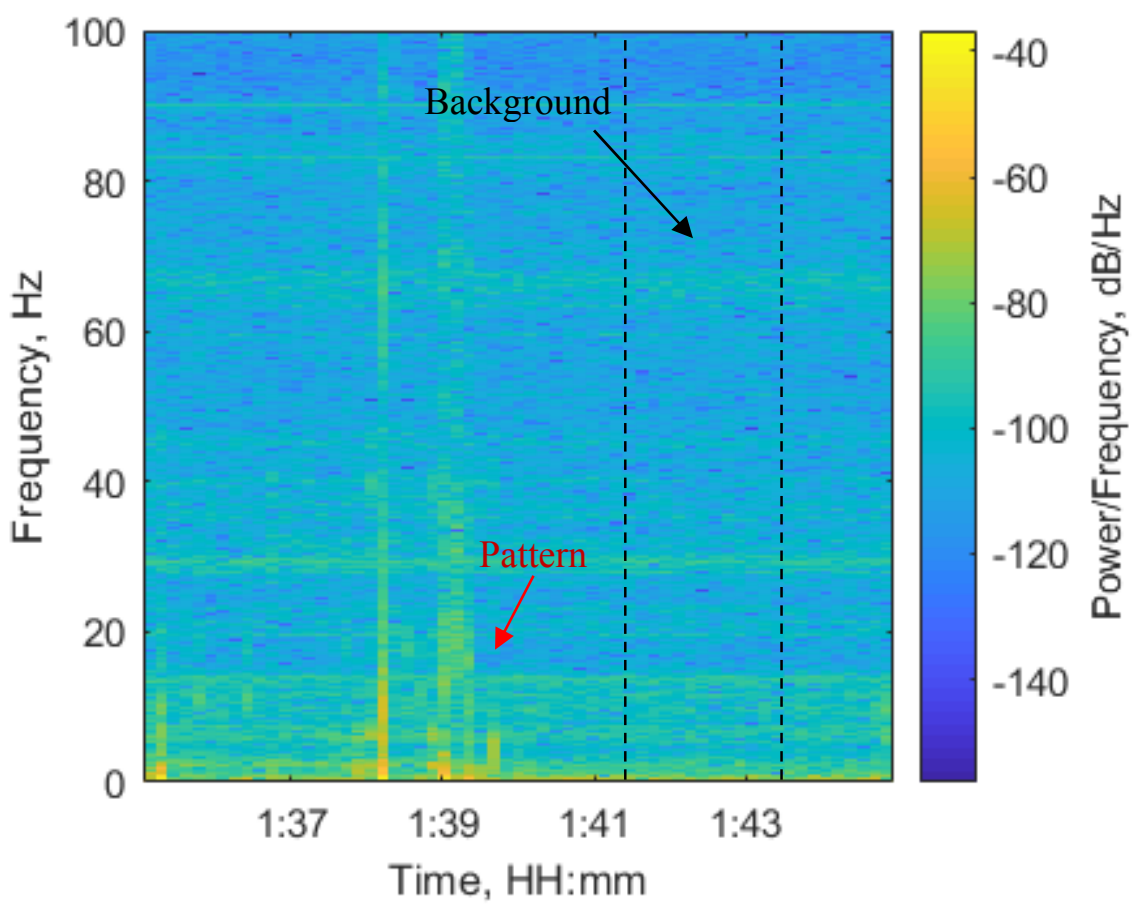

Figure 29. Spectrogram recorded in position 6 covering time period starting at 1:35 pm. 


\section{Spectrogram-12-Ton Crane Pattern Profile 1}

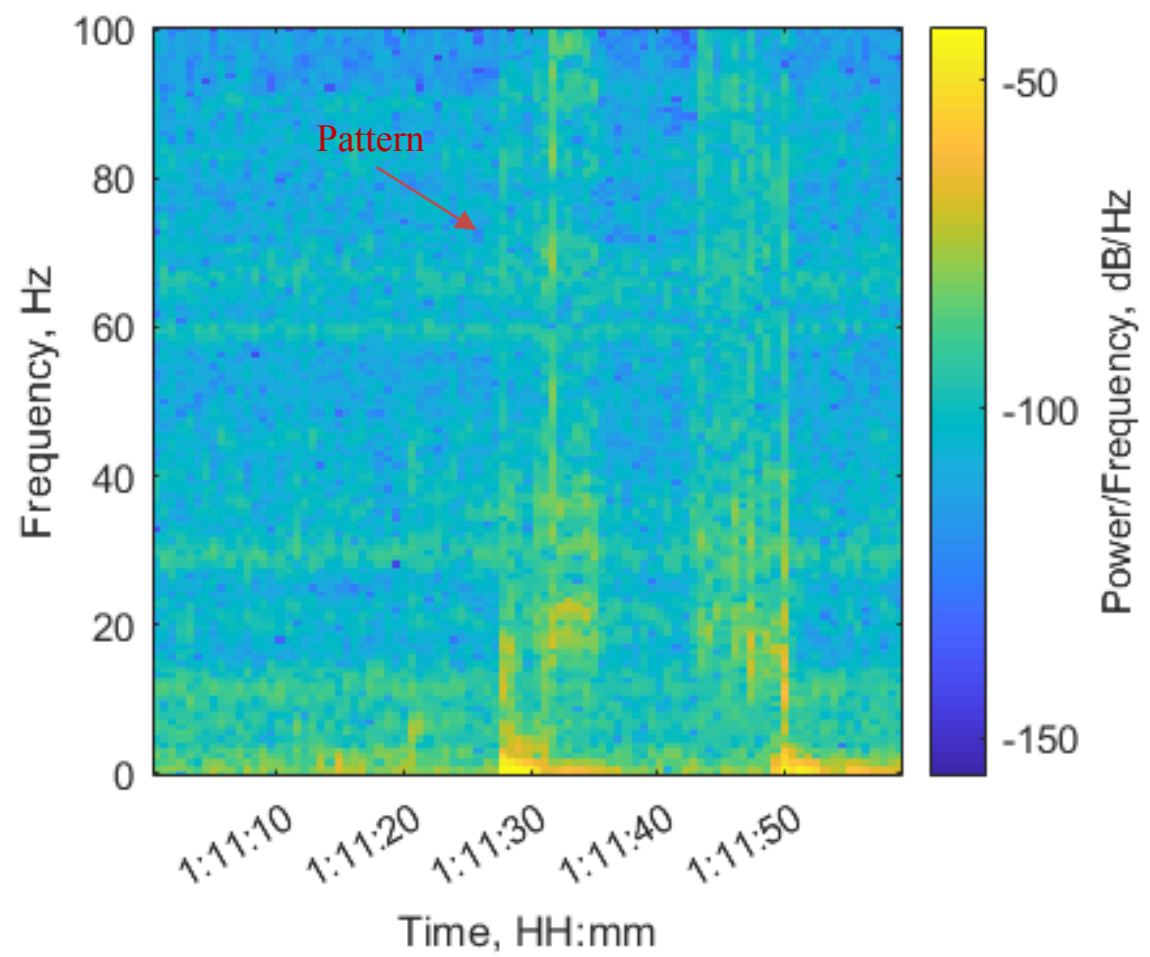

Figure 30. Spectrogram showing a close up of the time period surrounding the pattern indicated with a red arrow in Figure 27. 


\section{Spectrogram-12-Ton Crane Unknown}

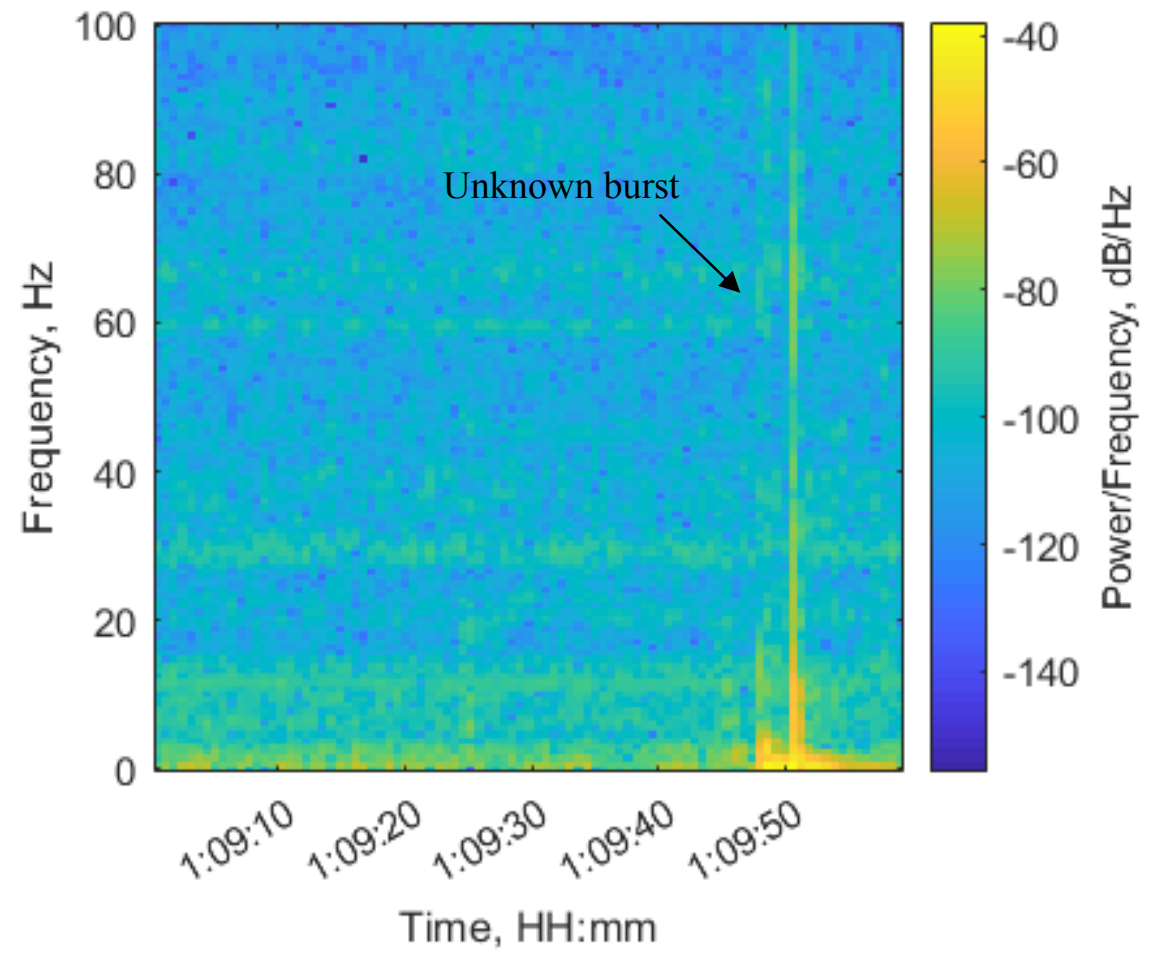

Figure 31. Spectrogram showing close-up of time period surrounding the unknown burst indicated in Figure 27. 


\section{Spectrogram-12-Ton Crane Pattern Profile 2}

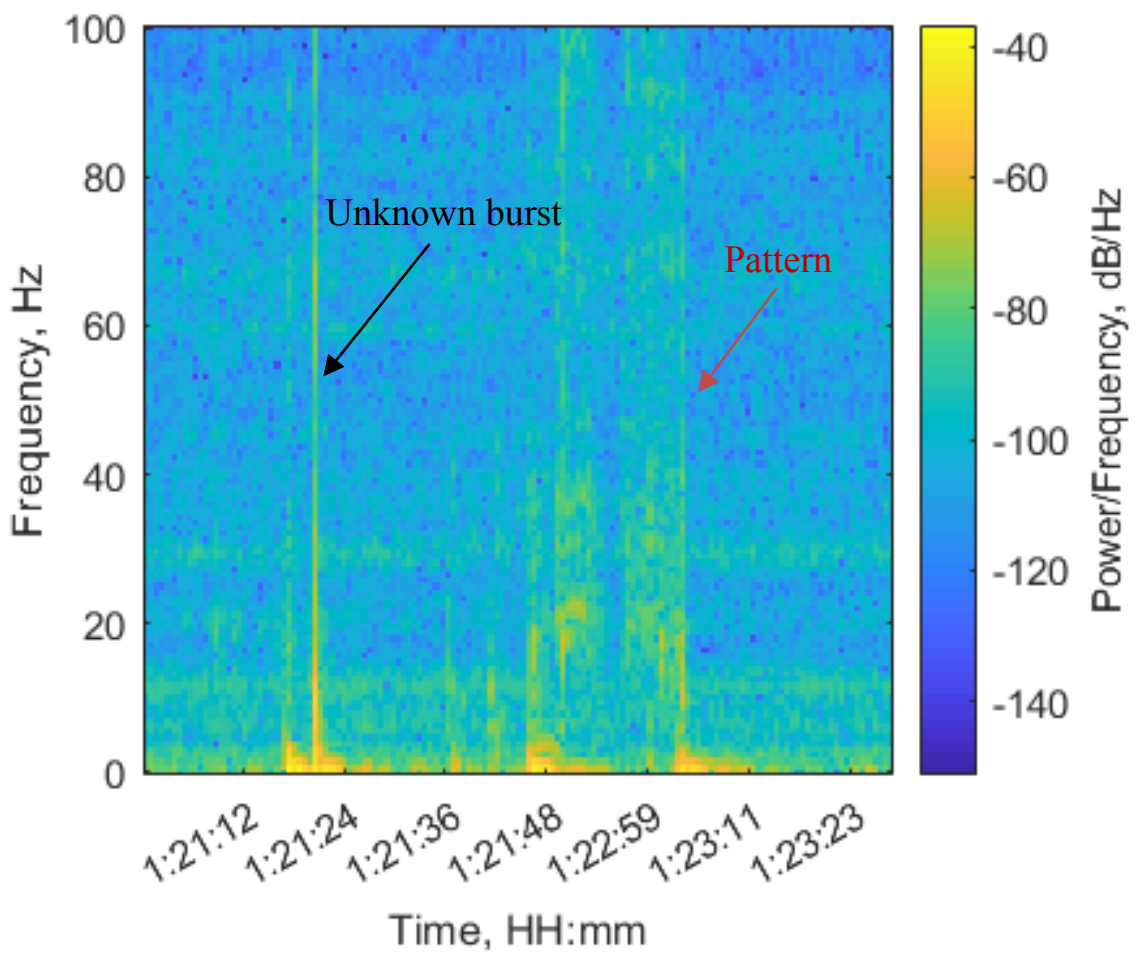

Figure 32. Spectrogram showing a close up of the time period surrounding the pattern and unknown burst indicated with a red arrow in Figure 28. 


\section{2-Ton Crane}

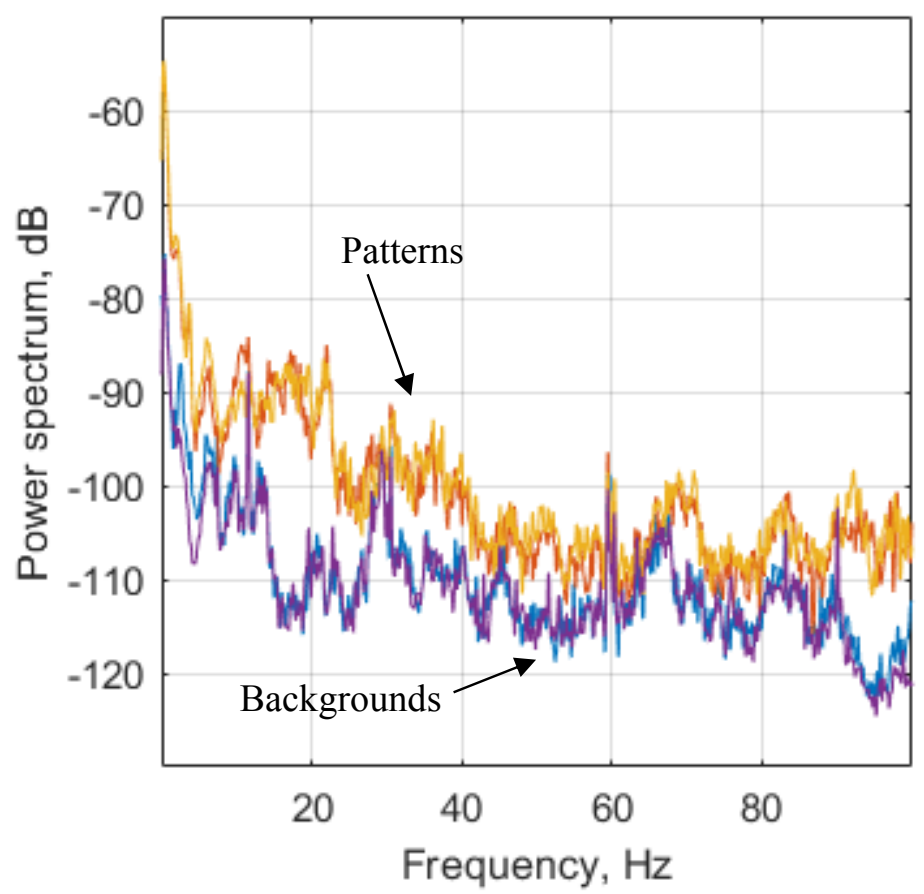

Figure 33. Power spectra for times including similar intensity profiles shown in Figures 26 (orange) and 28 (yellow) in comparison to periods of background signals extracted from Figures 26 (blue) and 28 (purple). 


\section{2-Ton Crane}

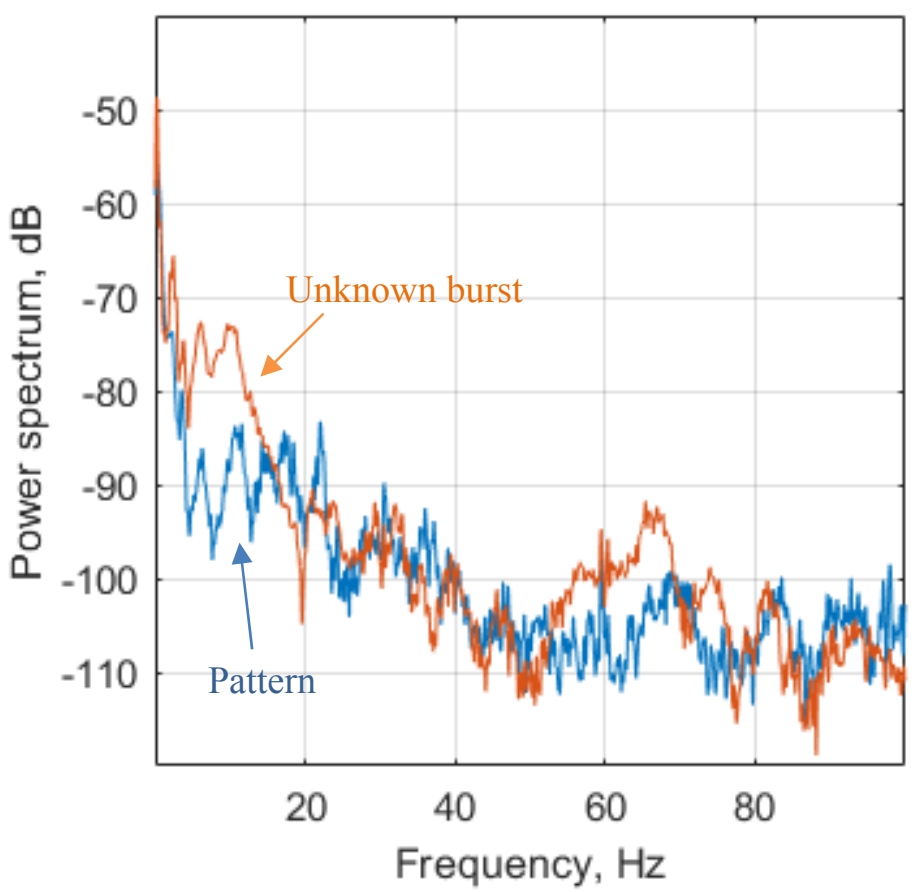

Figure 34. Power spectra displaying signals including the pattern (blue) and unknown burst (orange) indicated in Figure 27. 


\subsubsection{3- and 50-Ton Unloaded Crane Operations}

The 3- and 50-ton crane hooks are both housed in a 50-ton crane bridge with the hooks translating north and south and bridge movement going east and west, as indicated in Map 6. Sound level meters were located at positions 10 and 8 indicated on Map 6 and Map 7 in Appendix 1, respectively. Position 10 is directly above the HFIR heat exchangers and reactor coolant pumps indicated by HXs and RCPs, respectively, in Map 6. Position 8, in room 301, is approximately 50 feet from an in-use freight elevator indicated by a " $\mathrm{C}$ " on Map 7. Use of the freight elevator was not controlled, therefore, interfering signals may have been recorded throughout the measurement period. The sound level meter located at marker 8 was used to monitor sounds occurring overnight and began recording on 6/18/2018 at 2:37 pm and continued until $6 / 19 / 2018$ at 1:54 pm. The sound level meter located at marker 10 began recording on 6/19/2018 at 9:58 am and continued until 1:58 pm. Figures shown in the following description were created by data obtained from the sound level meter located at marker 10.

The raw signal file displayed in Figure 35 covers the time period from 10:18 to 10:28 am when operations from the 3- and 50-ton cranes were performed. There are no distinguishing visual features in the raw signal, however, useful information was obtained by audio examination. Crane movements were heard in the raw file but they were not clearly seen in a spectrogram covering frequencies up to $100 \mathrm{~Hz}$, therefore the frequency range was extended to $300 \mathrm{~Hz}$ as displayed in Figure 36. By extending the frequency range, signals that occurred close to the times periods noted in the logs were observed in the spectrogram. Note that time bin widths were set to 5 seconds to account for short times associated with crane movements. Also note that the first set of signals are 3-ton crane movements which are then followed by 50-ton crane movements as indicated on the spectrogram at approximately $240 \mathrm{~Hz}$.

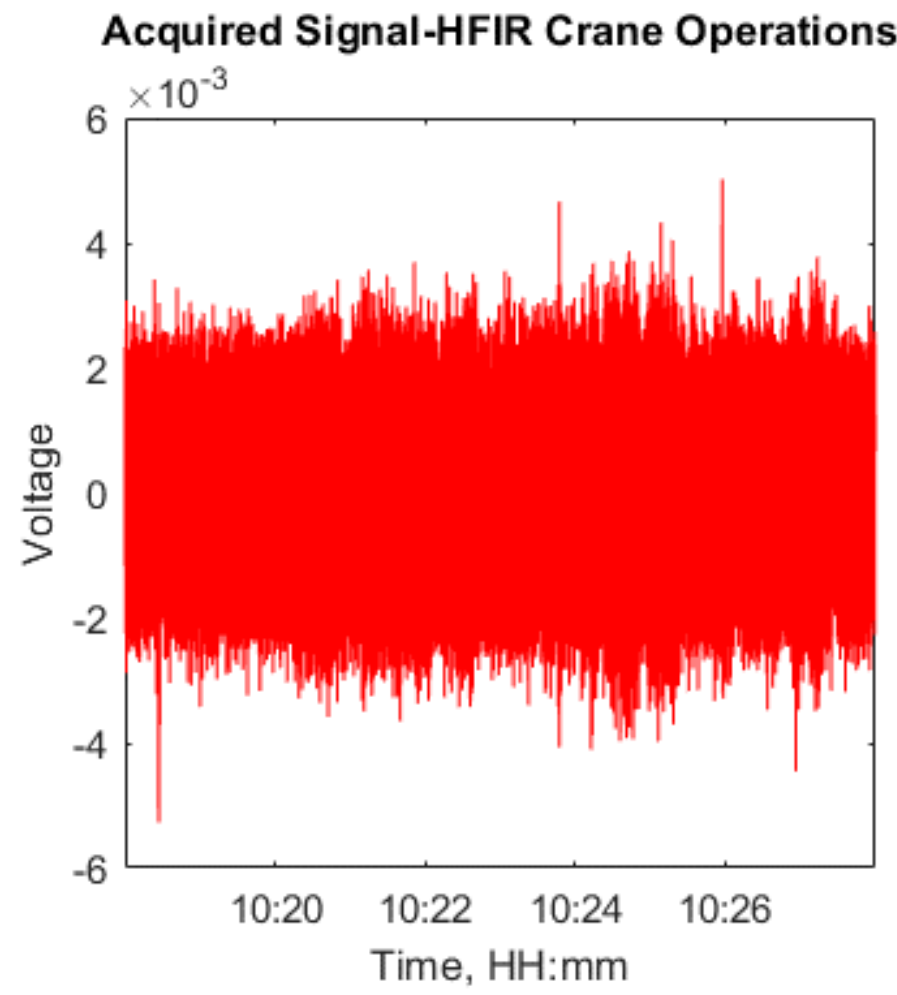

Figure 35. Raw signal recording of HFIR reactor bay crane movements. 


\section{Spectrogram-HFIR Crane Operations}

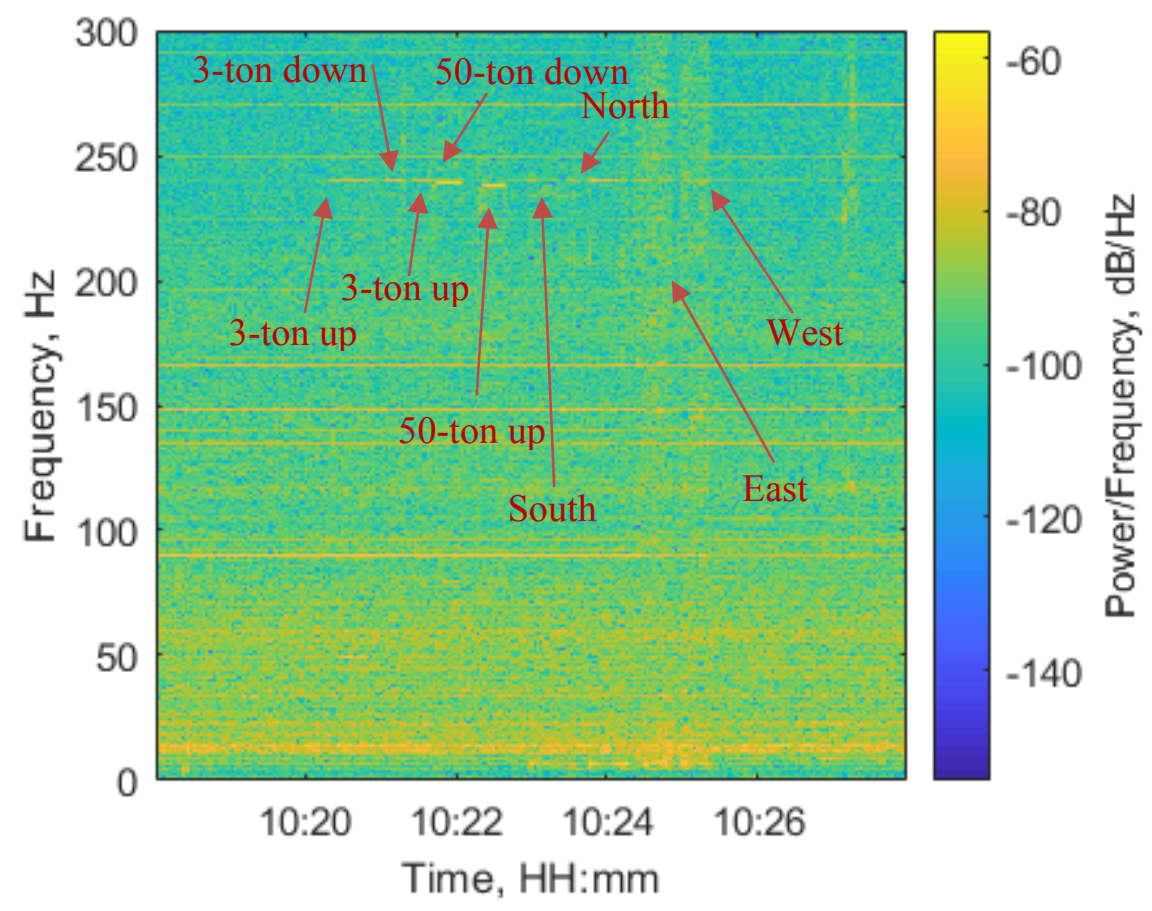

Figure 36. Spectrogram that indicates 3- and 50-ton crane movements in the HFIR reactor bay. The red arrows point to specified crane movements with "South" and "North" referring to the crane housing that includes both 3- and 50-ton hooks and "East" and "West" referring to crane bridge movements. 


\subsubsection{3-Ton Up/Down Movements}

Unloaded 3-ton crane hook up movements occurred at 10:20 and 10:21 am with downward operations performed between up movements and logged at 10:21 am by INL team members. These noted times closely match intensity increases at approximately $240 \mathrm{~Hz}$ as noted in the spectrogram of Figure 36. Figure 37 and Figure 38 displays power spectra for 3-ton up and down crane movements compared to a background time period that starts at 10:19 am and ends at 10:19:30 am. Up and down crane movements are included in the time periods that range from 10:20:20 to 10:20:59 am and 10:20:59 to 10:21:21 am, respectively. Figure 37 shows frequency profiles up to $100 \mathrm{~Hz}$ with no significant differences observed in the data between the 3 time periods. Figure 38 shows frequencies that range from 100 to $300 \mathrm{~Hz}$ with an approximately $-80 \mathrm{~dB}$ peak occurring at approximately $240 \mathrm{~Hz}$ in the spectra showing the crane movements. This approximately $240 \mathrm{~Hz}$ peak is absent from the background spectrum as expected from examining the spectrogram intensity profile. Up and down crane movement power profiles do not differ significantly nor do the profiles measured for both upward movements.

\section{3-Ton Crane Up/Down}

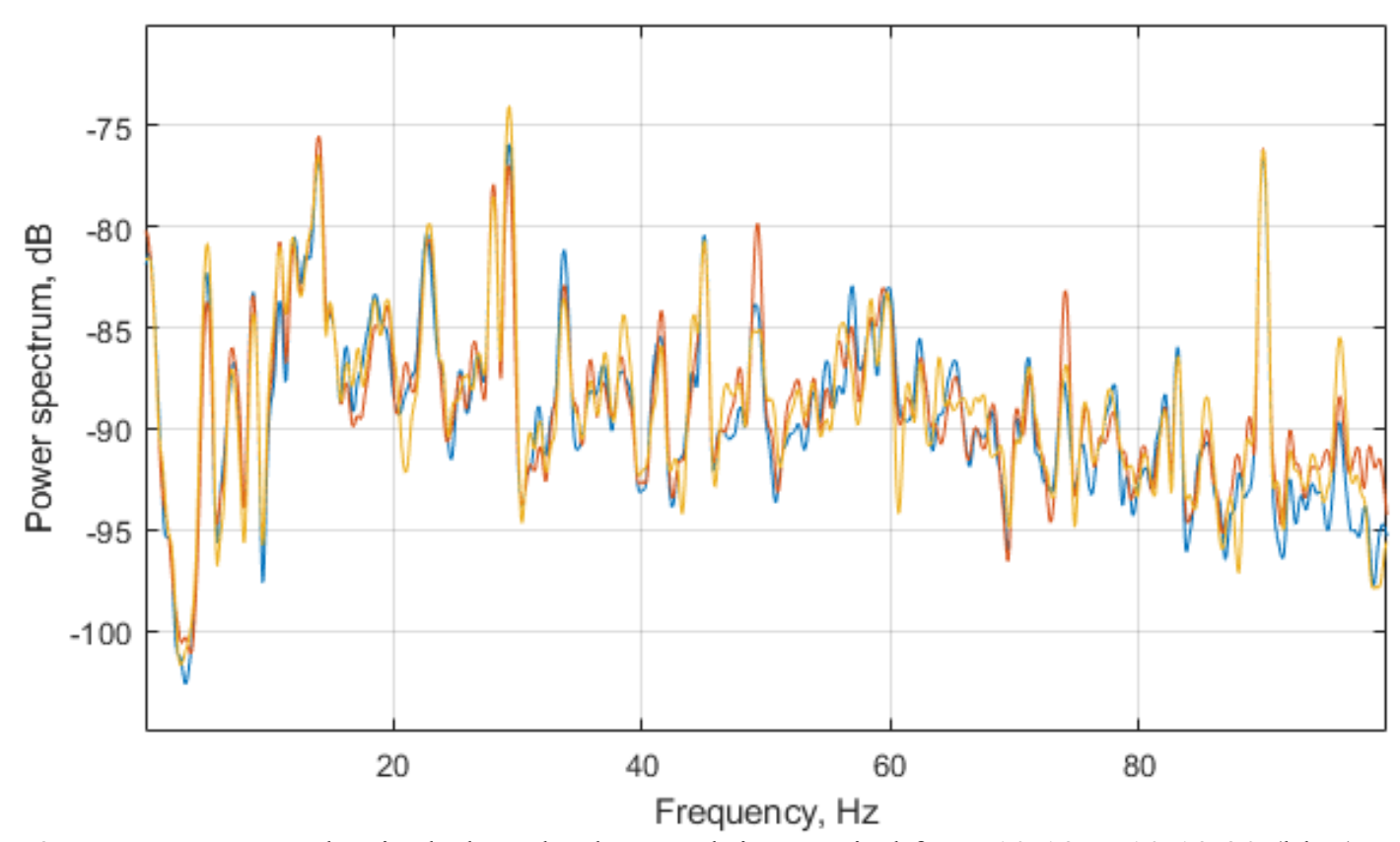

Figure 37. Power spectra that includes a background time period from 10:19 to 10:19:30 (blue), upward 3-ton crane movements (orange), and downward 3-ton crane movements (yellow) for frequencies that range to $100 \mathrm{~Hz}$. 


\section{3-Ton Crane Up/Down}

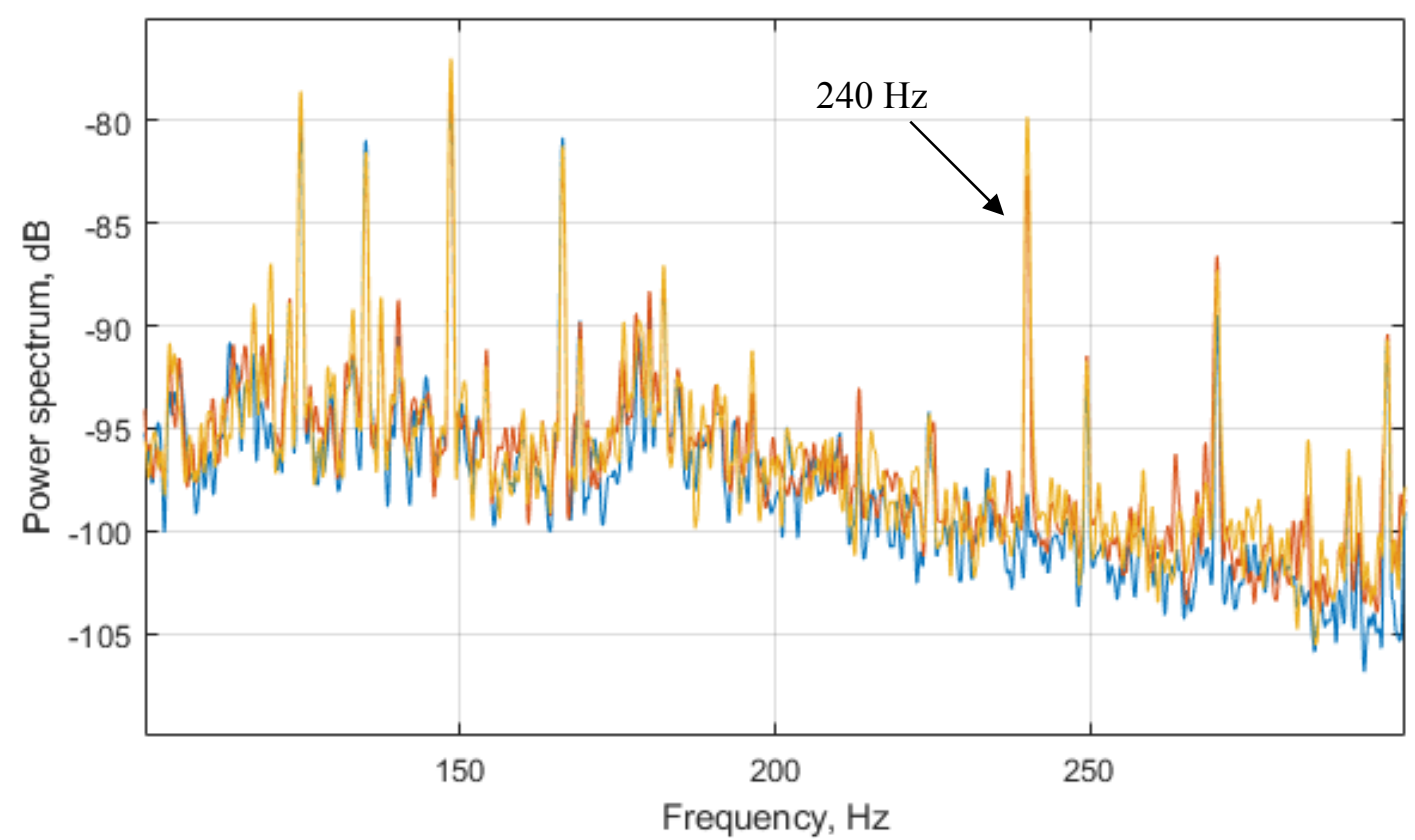

Figure 38. Power spectra that includes a background time period from 10:19 to 10:19:30 (blue), upward 3-ton crane movements (orange), and downward 3-ton crane movements (yellow) for frequencies that range from 100 to $300 \mathrm{~Hz}$. 


\subsubsection{50-Ton Up/Down Movements}

Unloaded 50-ton crane hook up movements occurred at 10:21 and 10:22 am according to events noted by INL team members. Signals within these time frames are indicated on the spectrogram of Figure 36 for the 50-ton upward and downward crane operations. Furthermore, power spectra displayed in Figure 39 and Figure 40 include time periods from 10:19 to 10:19:30 am, 10:21:41 to 10:22:09 am, and 10:22:16 to 10:22:44 am for the background, crane movements down, and crane movements up, respectively. Figure 39 shows frequencies that range to $100 \mathrm{~Hz}$ with no significant differences in power between the three spectra. The frequency range includes 100 to $300 \mathrm{~Hz}$ in the spectra displayed in Figure 40. The most notable difference between 50-ton crane movements and the background is similar to those observed in the 3-ton crane data with a dominant peak occurring at approximately $240 \mathrm{~Hz}$, however, the power measures approximately $-74 \mathrm{~dB}$ for both up and down movements. Upwards movements also have increased power over downward movements at approximately $230 \mathrm{~Hz}$ and $236 \mathrm{~Hz}$. In addition, the power is larger for downward over upwards movements just beyond approximately $240 \mathrm{~Hz}$.

\section{0-Ton Crane Up/Down}

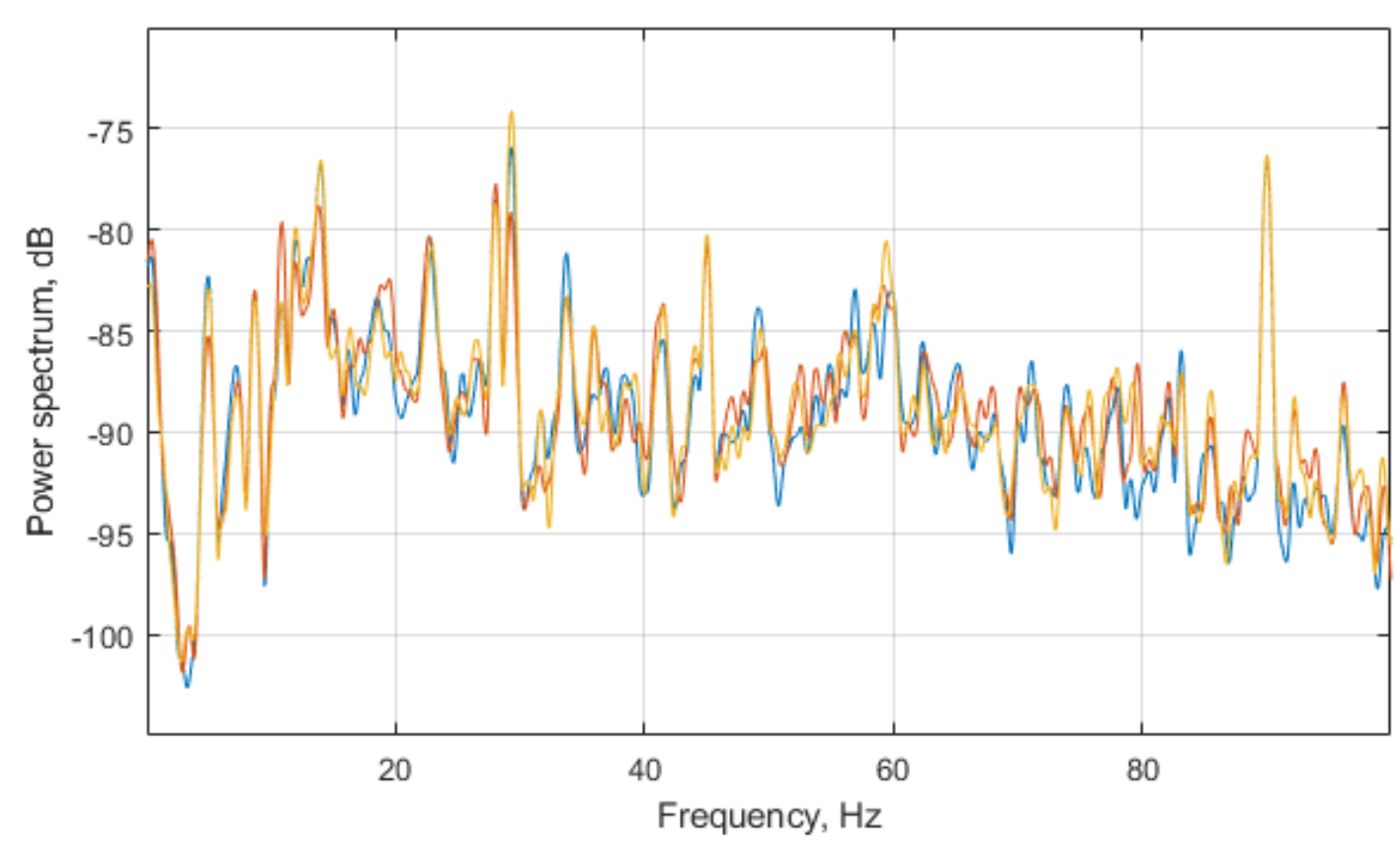

Figure 39. Power spectra that includes a background time period from 10:19 to 10:19:30 am (blue), downward 50-ton crane movements (orange), and upward 50-ton crane movements (yellow) for frequencies that range to $100 \mathrm{~Hz}$. 


\section{0-Ton Crane Up/Down}

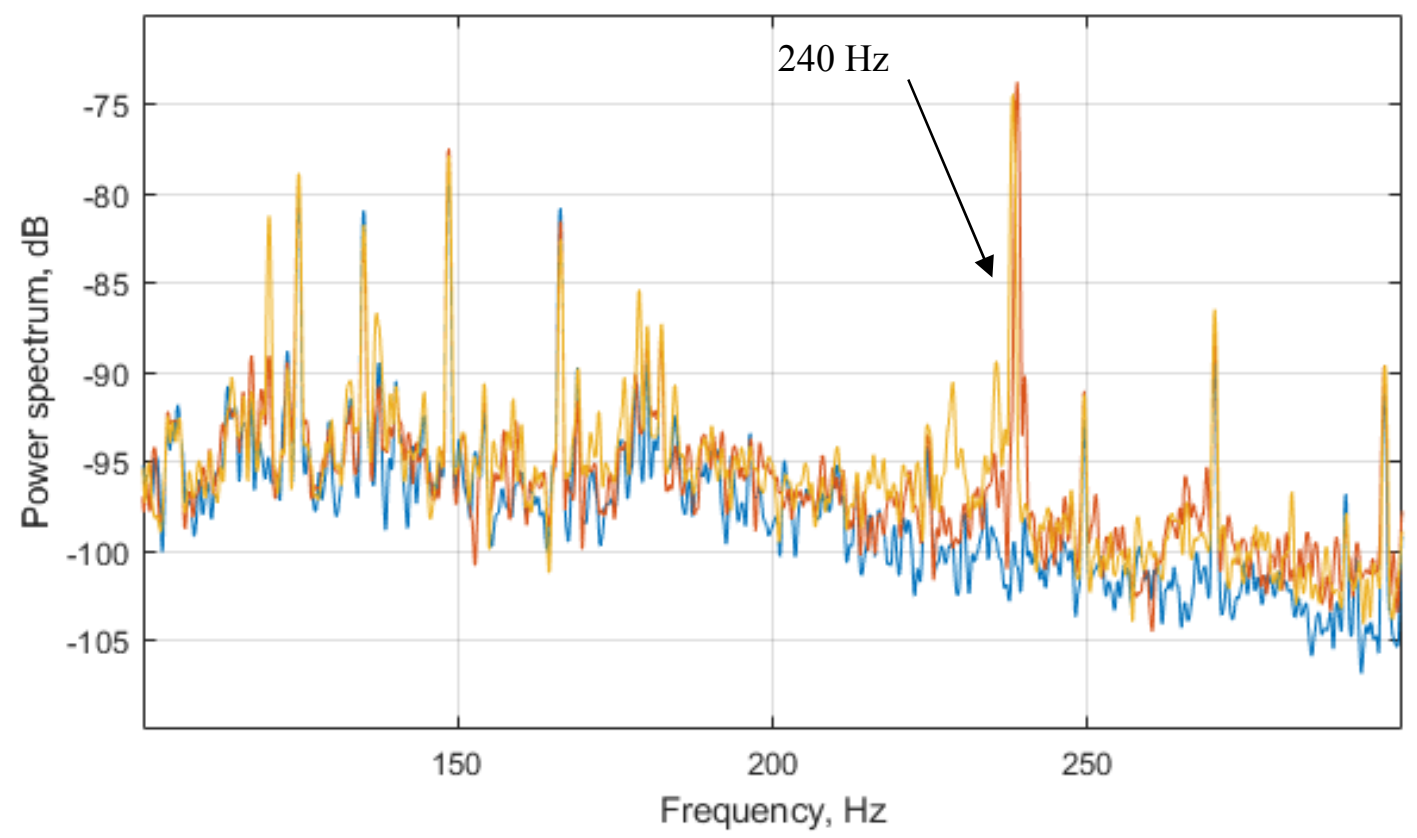

Figure 40. Power spectra that includes a background time period from 10:19 to 10:19:30 am (blue), downward 50-ton crane movements (orange), and upward 50-ton crane movements (yellow) for frequencies that range from 100 to $300 \mathrm{~Hz}$. The red arrow points to peaks at approximately $240 \mathrm{~Hz}$. 


\subsubsection{3 and 50-Ton Crane Hooks in Housing}

Crane housing north and south translations, including simultaneous movements of both 3- and 50-ton crane hooks, were recorded directly following 50-ton crane hook up/down operations as noted in the spectrogram of Figure 36. Translation times were annotated at 10:22 and 10:23 am toward the south and north respectively. The power spectra, displayed in Figure 41, include time ranges from 10:22:16 to 10:22:44 am and 10:22:53 to 10:23:41 am for south and north translations, respectively. The same background time period as described above for 3- and 50-ton crane movements is also shown in Figure 41. The power increases for both the south and north translations over the background in the frequency band ranging from approximately 5 to $7 \mathrm{~Hz}$. Furthermore, the power is greater for north compared against south translations by approximately $7 \mathrm{~dB}$ on average. Between 100 and $300 \mathrm{~Hz}$, displayed in Figure 42, the power differs at approximately $120 \mathrm{~Hz}$ and between approximately 220 and $240 \mathrm{~Hz}$ for translations compared to the background. At $120 \mathrm{~Hz}$, the power measured -81 and $-85 \mathrm{~dB}$ for south and north translations, respectively. Furthermore, at $240 \mathrm{~Hz}$, the power measured -90 and $-81 \mathrm{~dB}$ for the south and north, respectively.

\section{Crane House Move South/North}

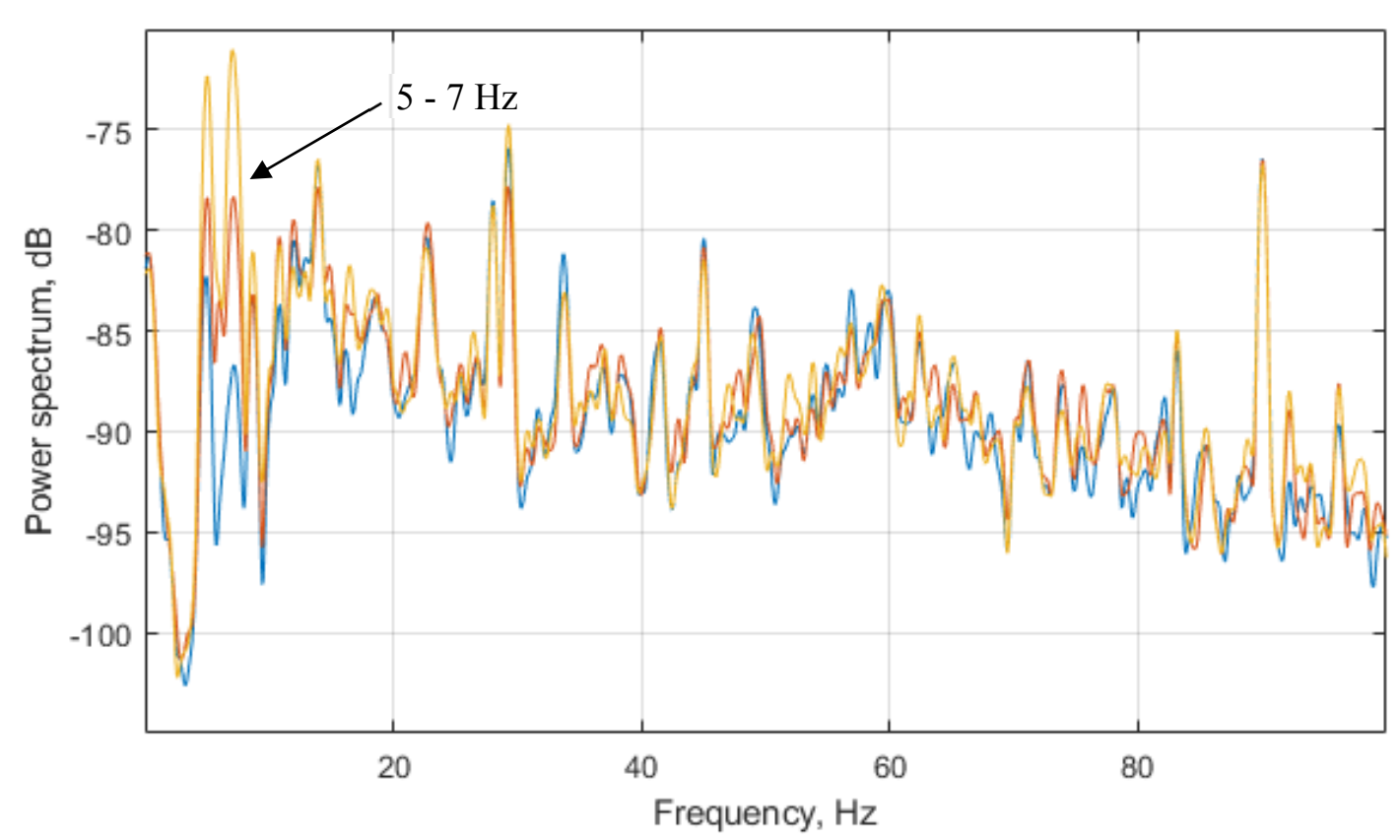

Figure 41. Power spectra that includes a background time period from 10:19 to 10:19:30 am (blue) and translations of the crane housing south (orange) and north (yellow) for frequencies that range to $100 \mathrm{~Hz}$. 


\section{Crane House Move South/North}

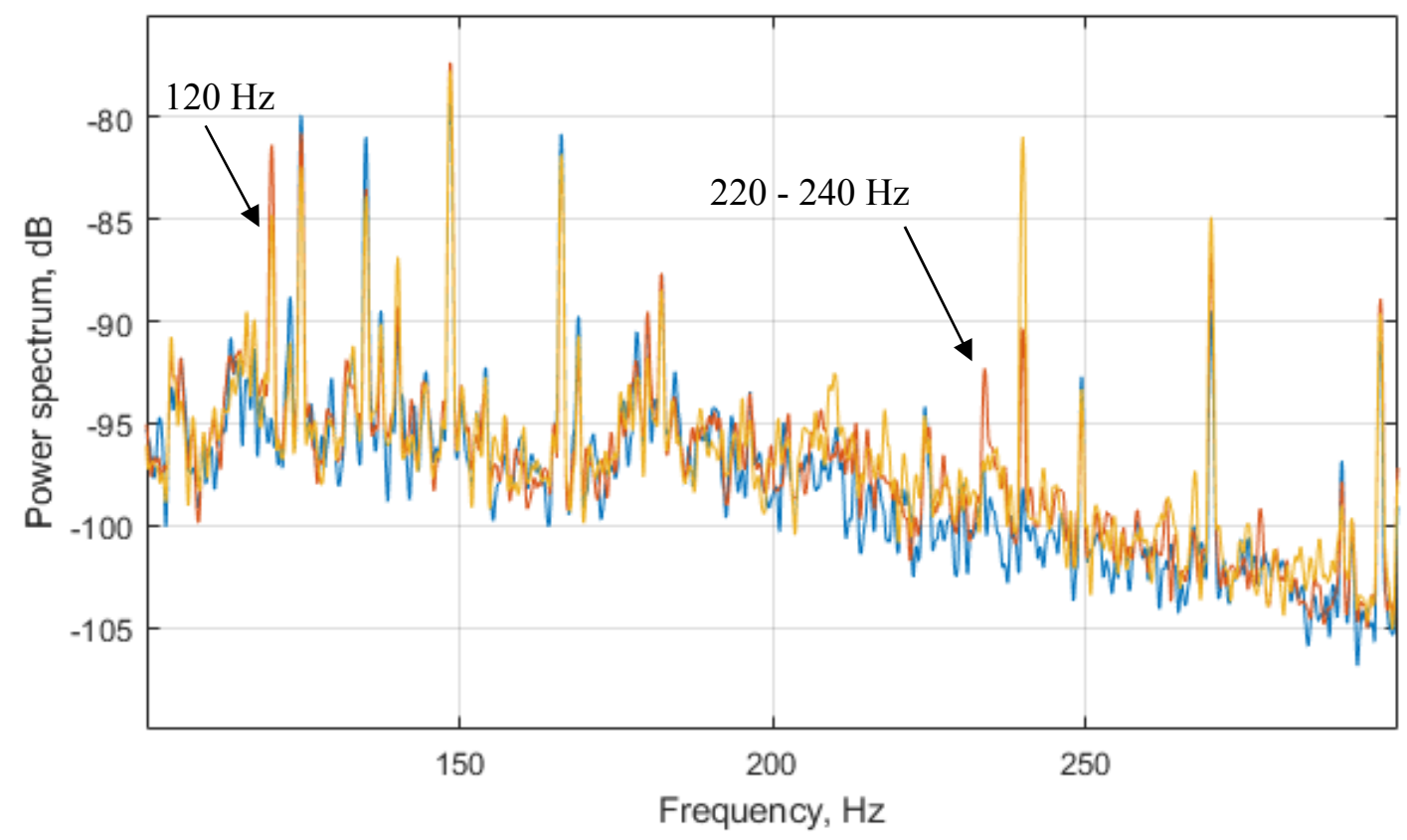

Figure 42. Power spectra that includes a background time period from 10:19 to 10:19:30 am (blue) and translations of the crane housing south (orange) and north (yellow) for frequencies that range from 100 $300 \mathrm{~Hz}$. 


\subsubsection{50- Ton Crane Bridge East/West Operations}

East and west bridge crane movements occured at 10:24 am as noted in the laboratory notebook. The power spectra for times ranging from 10:24:22 to 10:24:52 am and 10:24:53 to 10:25:29 am for east and west operations respectively are displayed against the background in Figure 43 and Figure 44 . The time period for the background spectrum is the same as described above. The most notable difference for bridge movements, in the frequency range up to $100 \mathrm{~Hz}$ displayed in Figure 43, occurs from approximately 5 to $9 \mathrm{~Hz}$ as an overall gain in power over the background. The power is also increased in the bridge movement data from approximately 14 to $19 \mathrm{~Hz}$. Beyond $100 \mathrm{~Hz}$ and to approximately $200 \mathrm{~Hz}$, the base power for bridge events is increased over the background by a few decibels as observed in Figure 44, which shows the power spectra of Figure 43 in the frequency range from 100 to $300 \mathrm{~Hz}$. The base power for the bridge movements for the frequency band ranging from approximately 200 to $300 \mathrm{~Hz}$, displayed in Figure 44, averages around the $-95 \mathrm{~dB}$ level while the base power of the background slowly decreases from approximately $-98 \mathrm{~dB}$ to $-105 \mathrm{~dB}$. This power difference is visible in the spectrogram of Figure 36 . There are slight differences in the power profile between east and west bridge movements. Power peaks appear in the data at approximately 187,262 , and $275 \mathrm{~Hz}$ for bridge movements east, but are not visible in west operations. More experiments would need to be performed to see if these peaks are indeed part of an east, but not a west, movement signature.

\section{Crane Bridge Move East/West}

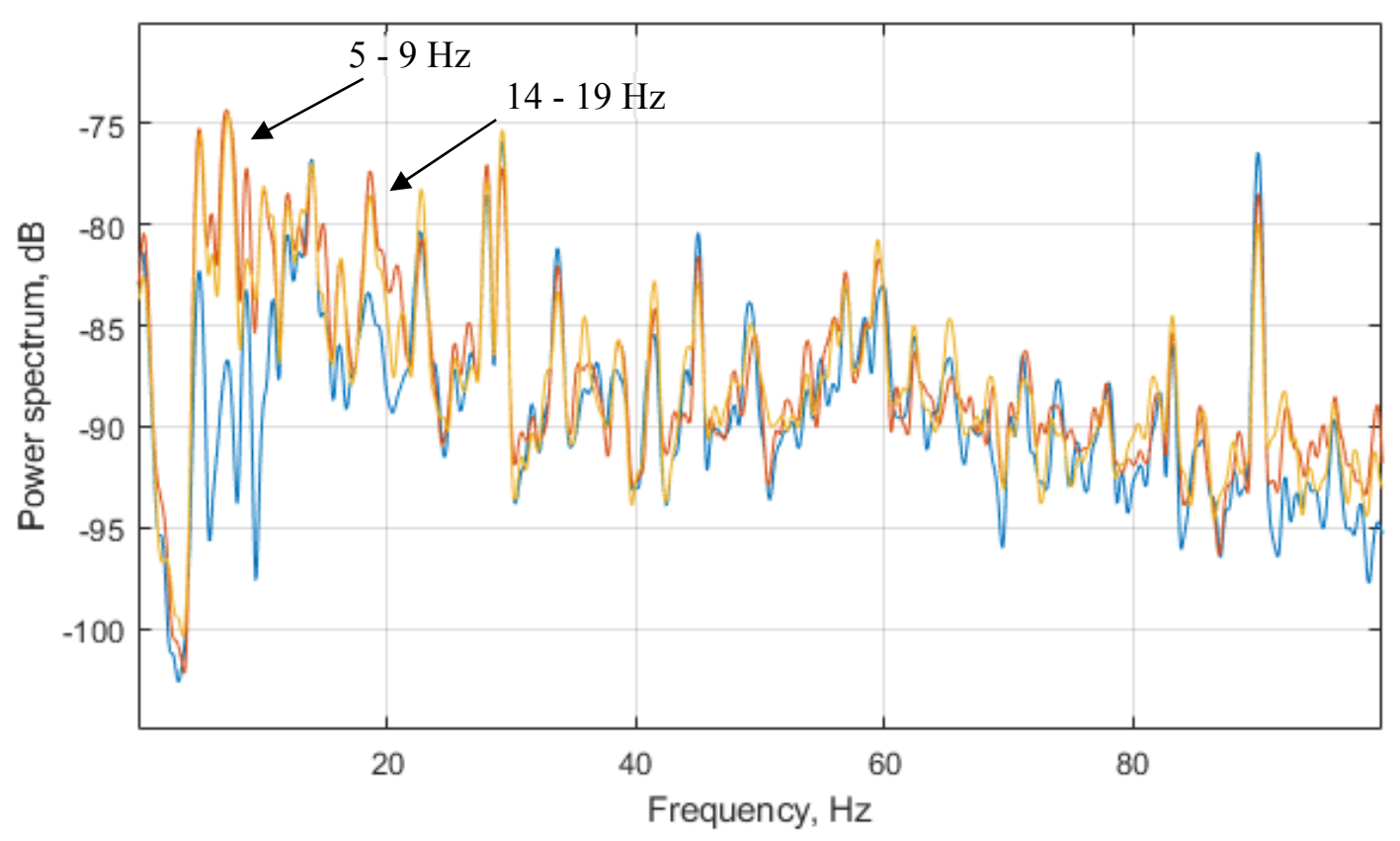

Figure 43. Power spectra showing time periods for the crane bridge east movement (orange) occurring between 10:24:22 and 10:24:52 am, the bridge west movement (yellow) occurring between 10:24:53 and 10:25:29 am; both in comparison to the background (blue) (10:19 to 10:19:30 am). The spectra extend to $100 \mathrm{~Hz}$. 


\section{Crane Bridge Move East/West}

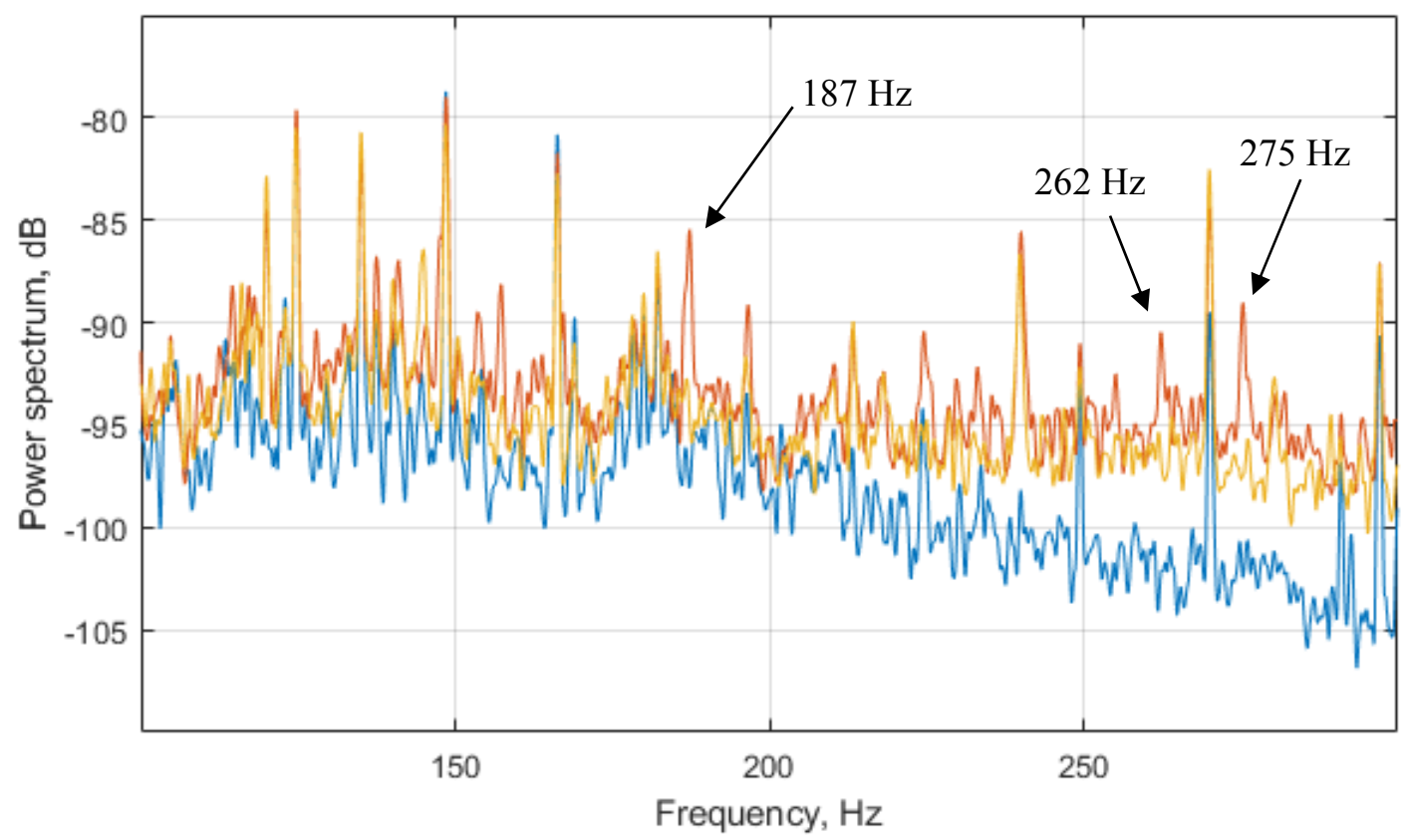

Figure 44. Power spectra showing time periods for the crane bridge east movement (orange) occurring between 10:24:22 and 10:24:52 am, the bridge west movement (yellow) occurring between 10:24:53 and 10:25:29 am; both in comparison to the background (blue) (10:19 to 10:19:30 am). The spectra extend from 100 to $300 \mathrm{~Hz}$. 


\subsubsection{3-Ton Loaded Operations}

Loaded operations were performed with the 3-ton crane that was described in the unloaded operations in section 2.5.2. Sound level meters remained in the same location as described for unloaded operations, at positions 10 and 8 indicated on Map 6 and Map 7 in Appendix 1, respectively. The first operation was not performed specifically for the MINOS project, however, INL team members noted the extension of the 3ton crane hook moving a $\sim 5$-foot diameter flange at 10:40 am.

The raw data signal displayed in Figure 45 was recorded from 10:38 to 10:48 am with the sound level meter positioned at marker 10 indicated on Map 6 appearing in Appendix 1. The signal shows a slight increase in the voltage from 10:40:29 to 10:42:31 am. In addition, visual changes in the pressure occur as displayed in Figure 47 and Figure 48 that include the time period mentioned for crane movements along with a background profile that starts at 10:42:45 and ends at 10:43:19 am. Power differences, shown in Figure 47 for frequencies that range to $100 \mathrm{~Hz}$, are most notable in the infrasound range between approximately 5 and $7 \mathrm{~Hz}$ with an $18 \%$ increase in power from the crane signal at $7 \mathrm{~Hz}$. Furthermore, the base power of the event averages approximately $-93 \mathrm{~dB}$ from approximately 112 to $190 \mathrm{~Hz}$ and reduces to an average of approximately $-90 \mathrm{~dB}$ for the remaining frequencies while the base power of the background slowly decreases from approximately 112 to $300 \mathrm{~Hz}$ starting at approximately $-95 \mathrm{~dB}$ and ending at approximately $-105 \mathrm{~dB}$ as displayed in the spectra of Figure 48 . Power difference of the 3-ton crane loaded with a $\sim 5$ foot diameter flange are considerably different from those described in section 2.5.2 for the crane unloaded. The loaded crane has a signature in the infrasound range that was not observed from the unloaded crane. Furthermore, the loaded crane includes a larger acoustic power profile for the base of the signal starting at approximately $112 \mathrm{~Hz}$ as well as several peaks from approximately 112 to $300 \mathrm{~Hz}$ that were not identified in the signature for the unloaded crane. 


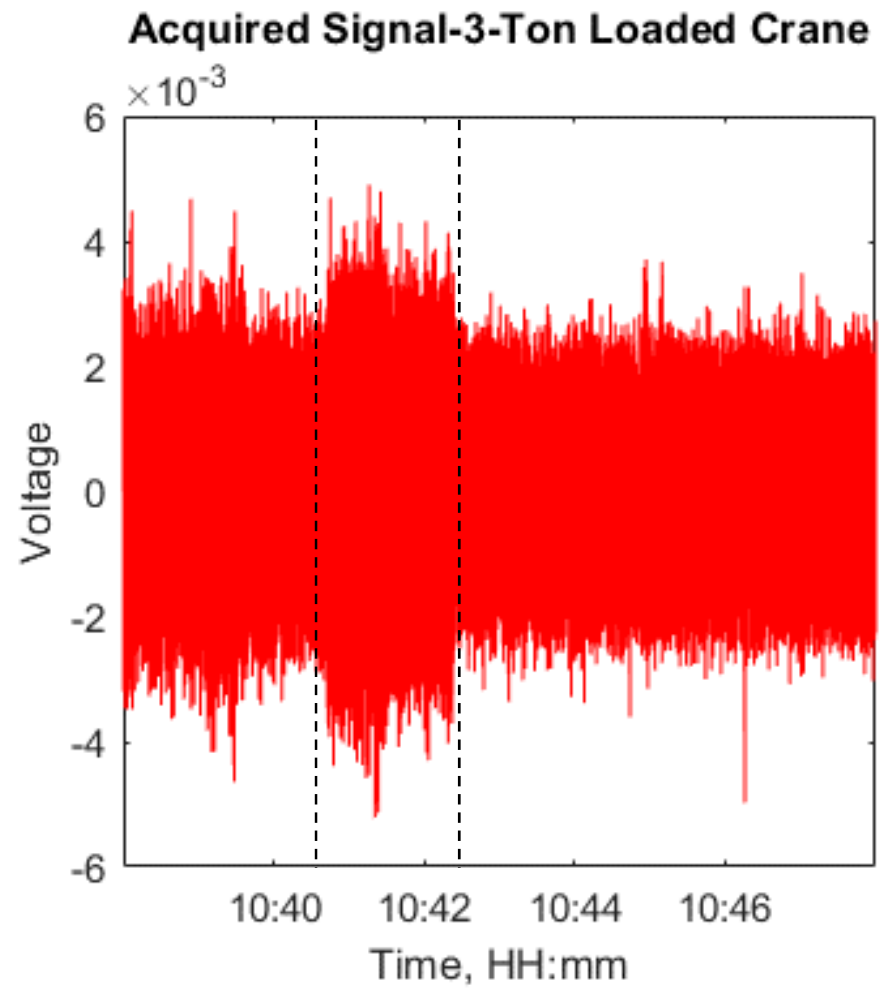

Figure 45. Raw signal recorded from 10:38 to 10:48 that includes signals from the 3-ton crane moving a 5 ' flange. The time period within the black dashed lines indicates the duration of crane movement. 


\section{Spectrogram-3-Ton Loaded Crane}

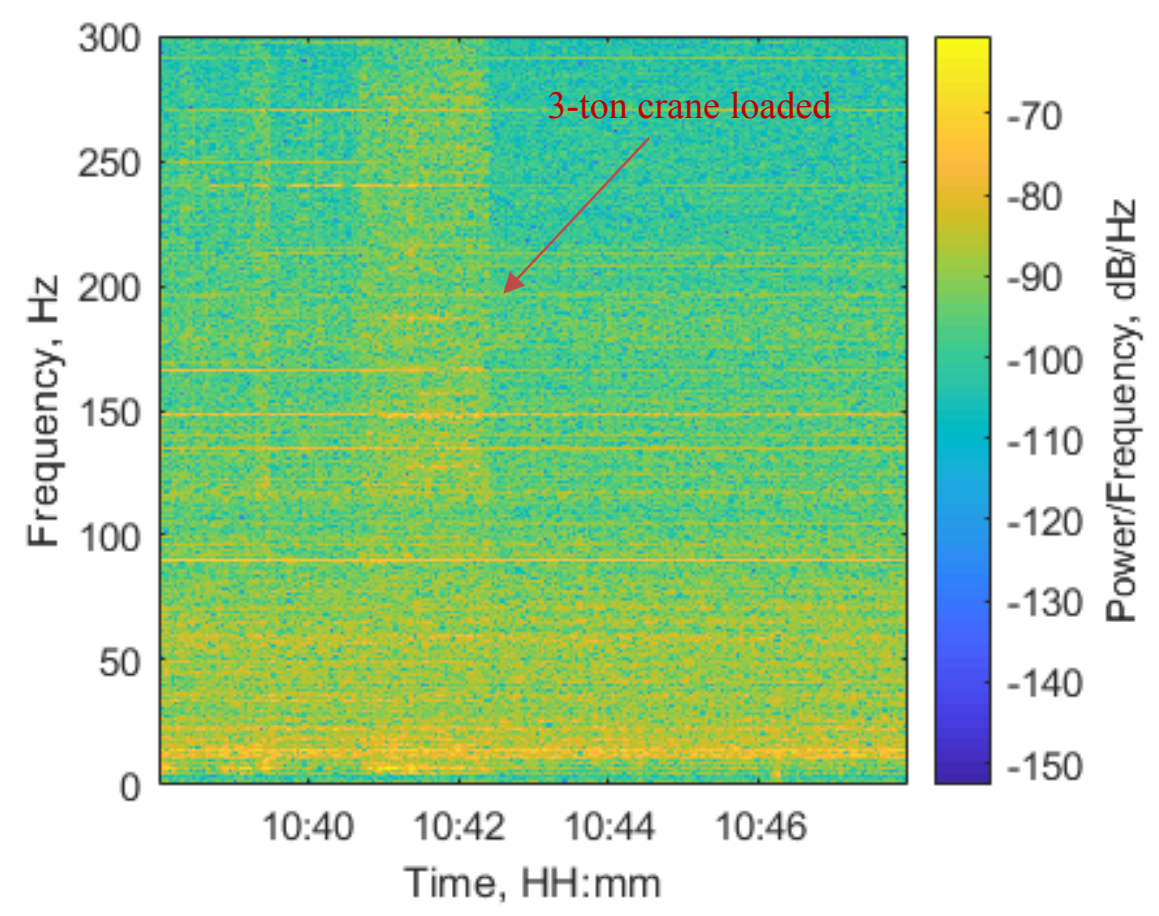

Figure 46. Spectrogram covering duration of 3 -ton crane moving a 5 ' flange.

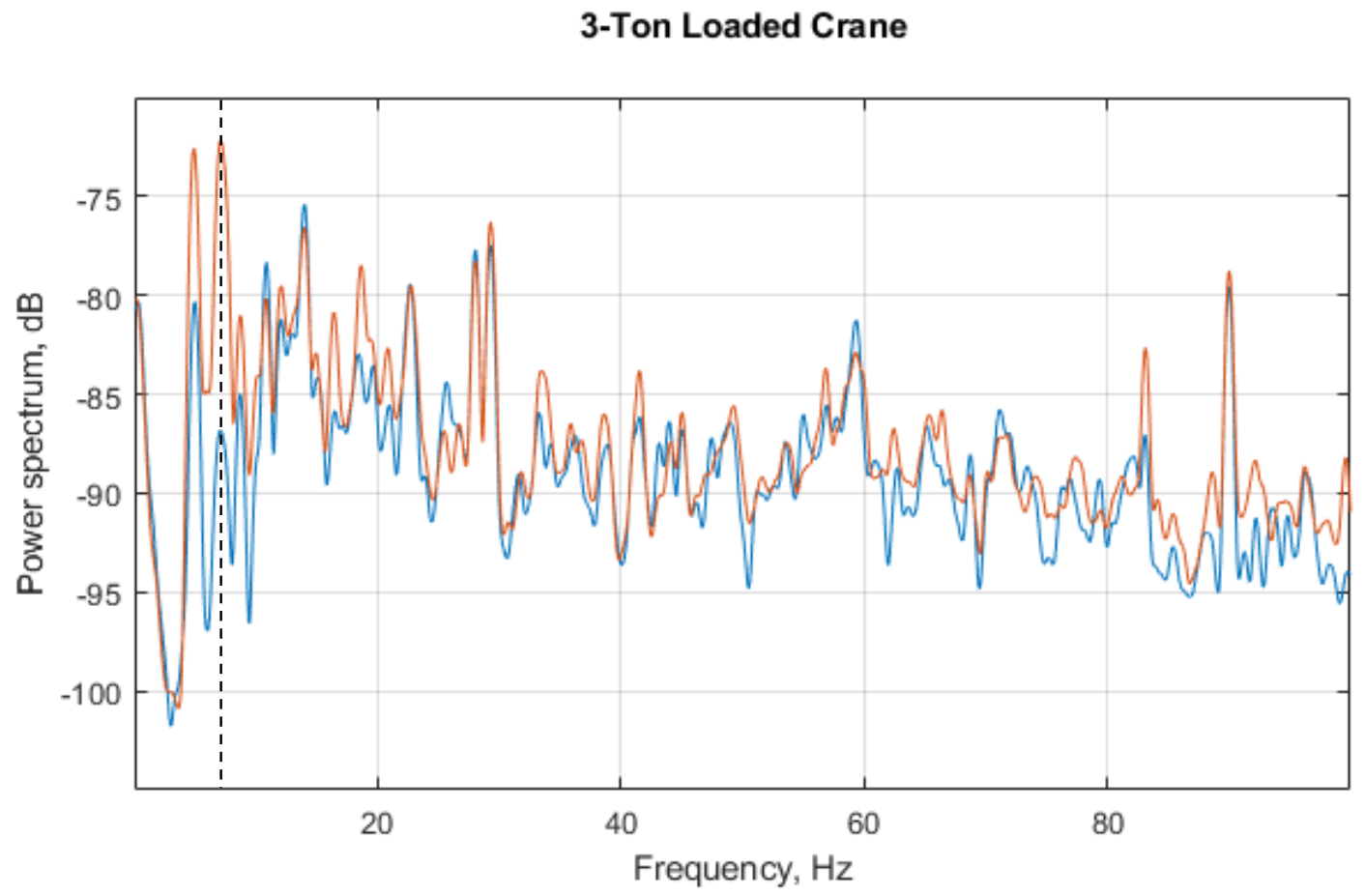

Figure 47. Power spectra comparing time periods for the 3-ton crane moving a $\sim 5$ ' flange (orange) occurring between 10:40:29 and 10:42:31 am against a background (blue) time period (10:42:45 to 10:43:19). The black dashed line is located at approximately $7 \mathrm{~Hz}$. 


\section{3-Ton Loaded Crane}

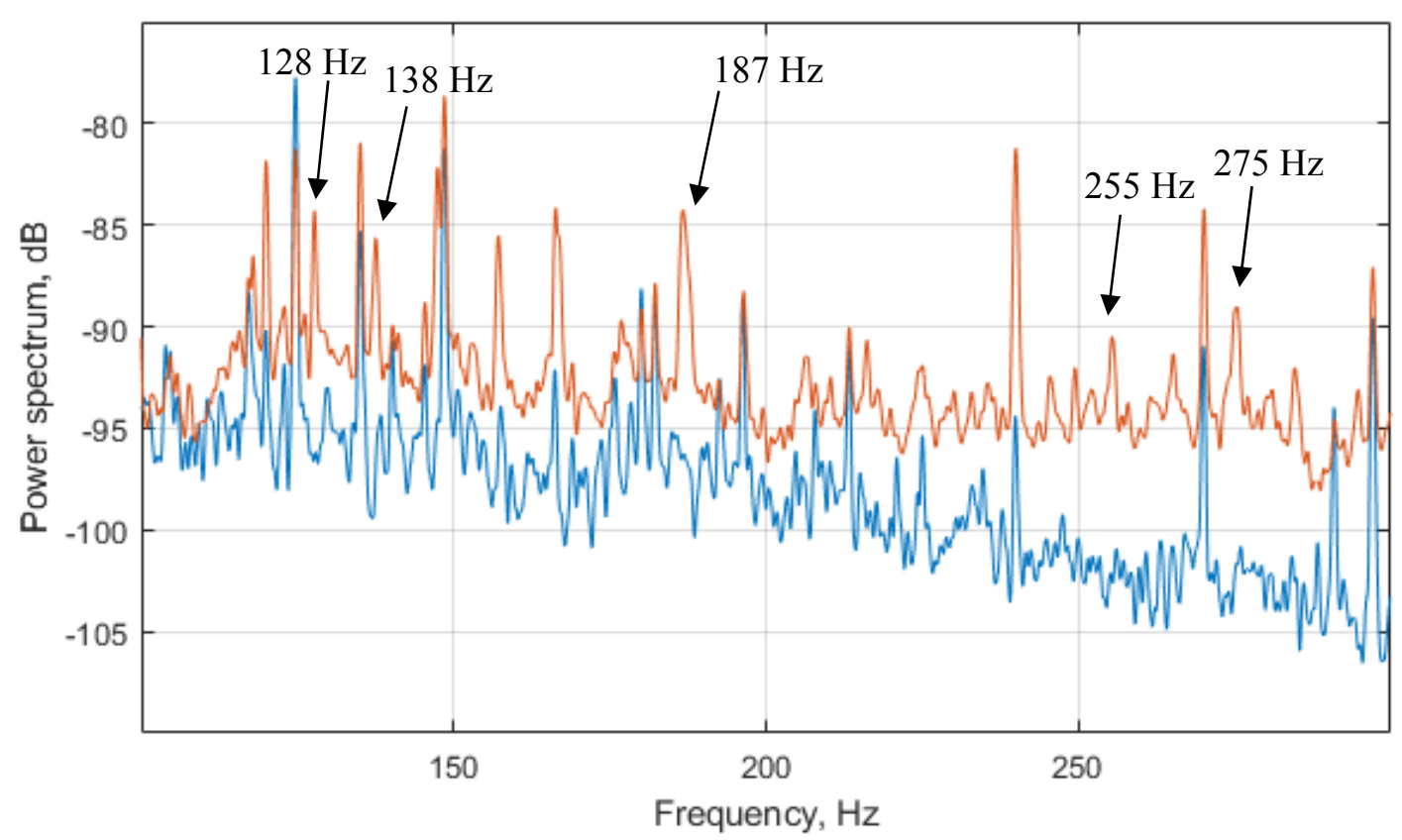

Figure 48. Power spectra comparing time periods for the 3-ton crane moving a 5 ' flange (orange) occurring between 10:40:29 and 10:42:31 am against a background (blue) time period (10:42:45 to 10:43:19). 


\subsection{HFIR Truck Bay}

To the east side of the HFIR reactor bay is a truck bay, room 211 as indicated on Map 6 appearing in Appendix 1, that has two roll-top garage-style doors; one door on each end of the length of the bay. The west door provides access to the reactor bay, room 210, and the east door is used for outdoor access. To maintain negative air pressure in the reactor bay as entry is needed into the truck bay, one door is opened while the other door is completely closed. In the first set of recordings, doors were opened one at a time with nothing entering or exiting the bay. In the second set of recordings, the Sugarman capsule (Sugarman is the name of the designer) would be loaded onto a truck that entered the bay. The opening and closing of truck bay doors is the focus of the recordings. The Sugarman capsule is marked with a large green "X" on Map 6 appearing in Appendix 1. INL personnel logged events as they occurred. The sound level meters were left in the same locations as mentioned for the reactor crane movements, at positions 10 and 8 indicated on Map 6 and Map 7 in Appendix 1, respectively. As indicated on the map, the sound level meter at position 10 was located approximately 20 feet from the capsule.

\subsubsection{West Truck Bay Door No Entry/Exit}

The west door to the truck bay was opened and then closed at 10:25 and 10:26 am, respectively, as noted in the laboratory notebook. The spectrogram for this action is shown in Figure 49, with frequencies ranging to $300 \mathrm{~Hz}$ to more clearly indicate truck bay door events over the 10 minute recorded time period. Time bins in the spectrogram were again set to 5 seconds. West door opening operations could not be distinguished from closing operations. At 10:29 am, the notebook describes an unplanned opening and closing of the west doors, however, the door was not completely opened. This unplanned opening was to allow ORNL personnel into the reactor bay from the truck bay; however, the height that the door was opened was not recorded.

The time periods for west door operations are compared to a background time period (10:19 to 10:19:30 am) and displayed in the power spectra of Figure 50, which extends to $100 \mathrm{~Hz}$. There are no significant power differences between the three power spectra over the frequencies displayed in the figure except for a noticeable difference at $90 \mathrm{~Hz}$ between the west door operations and the background, however, this peak does not reflect a source signature as the peak is present before and after the event. The power spectra for frequencies ranging from 100 to $300 \mathrm{~Hz}$ are shown in Figure 51. These spectra show a larger variance in the power between the west door events and the background for frequencies in the range of approximately $125 \mathrm{~Hz}$ and for frequencies greater than approximately $200 \mathrm{~Hz}$. In addition, there are some differences in power from approximately 240 to $250 \mathrm{~Hz}$ between the door operations. Determining signatures in the audio frequency range is beyond the scope of this compendium; however, for a more complete picture additional recordings and further analysis would be necessary to determine whether these power differences are consistent in complete and partial west door open operations. 


\section{Spectrogram-Air Lock Door to Truck Bay}

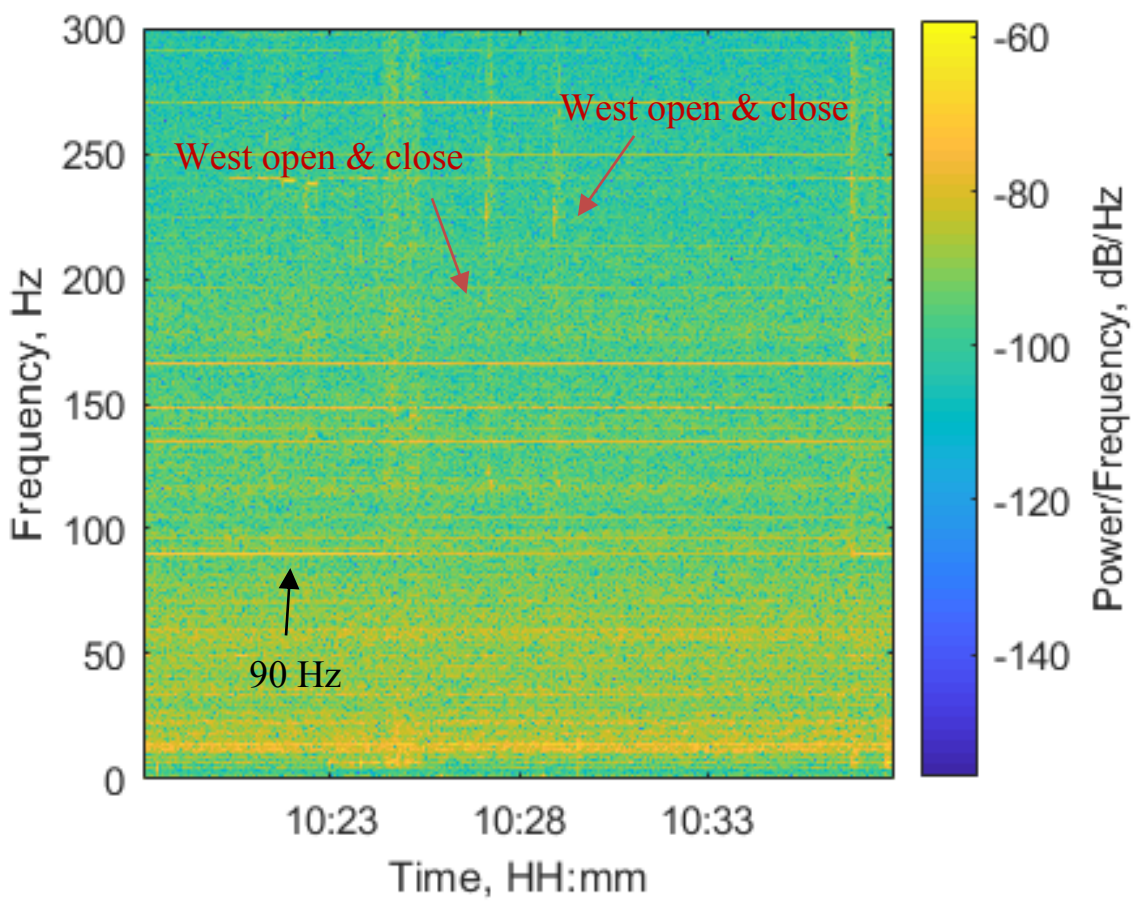

Figure 49. Spectrogram displaying east and west truck bay doors opening and closing as indicated with red arrows.

\section{Air Lock Inner Door to Truck Bay}

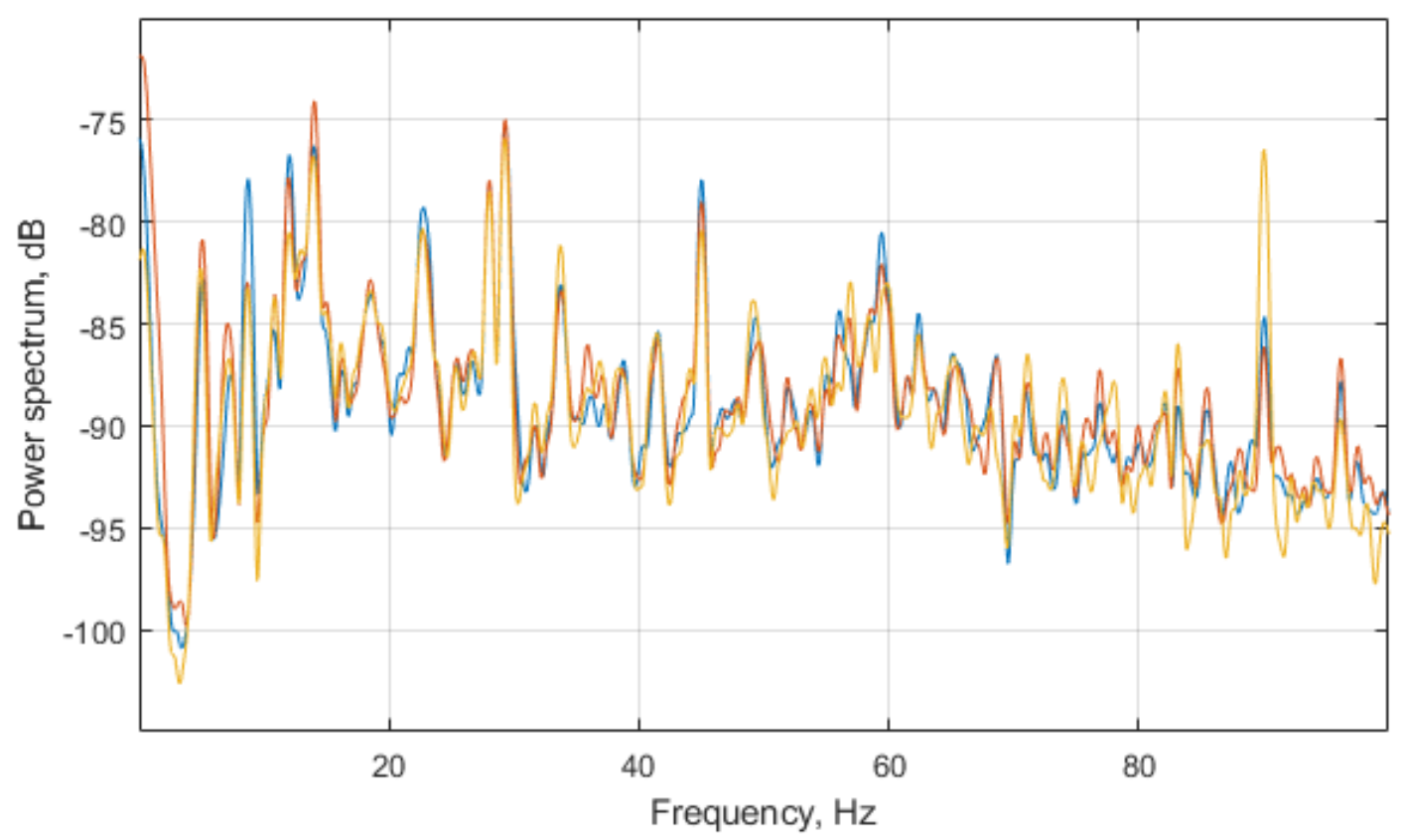

Figure 50. Power spectra for the west truck bay door opening and closing between 10:26:43 and 10:27:29

(blue) and opening and closing between 10:28:23 and 10:29:19 (orange) compared to a background period (yellow) measured between 10:19 and 10:19:30 for frequencies up to $100 \mathrm{~Hz}$. 


\section{Air Lock Inner Door to Truck Bay}

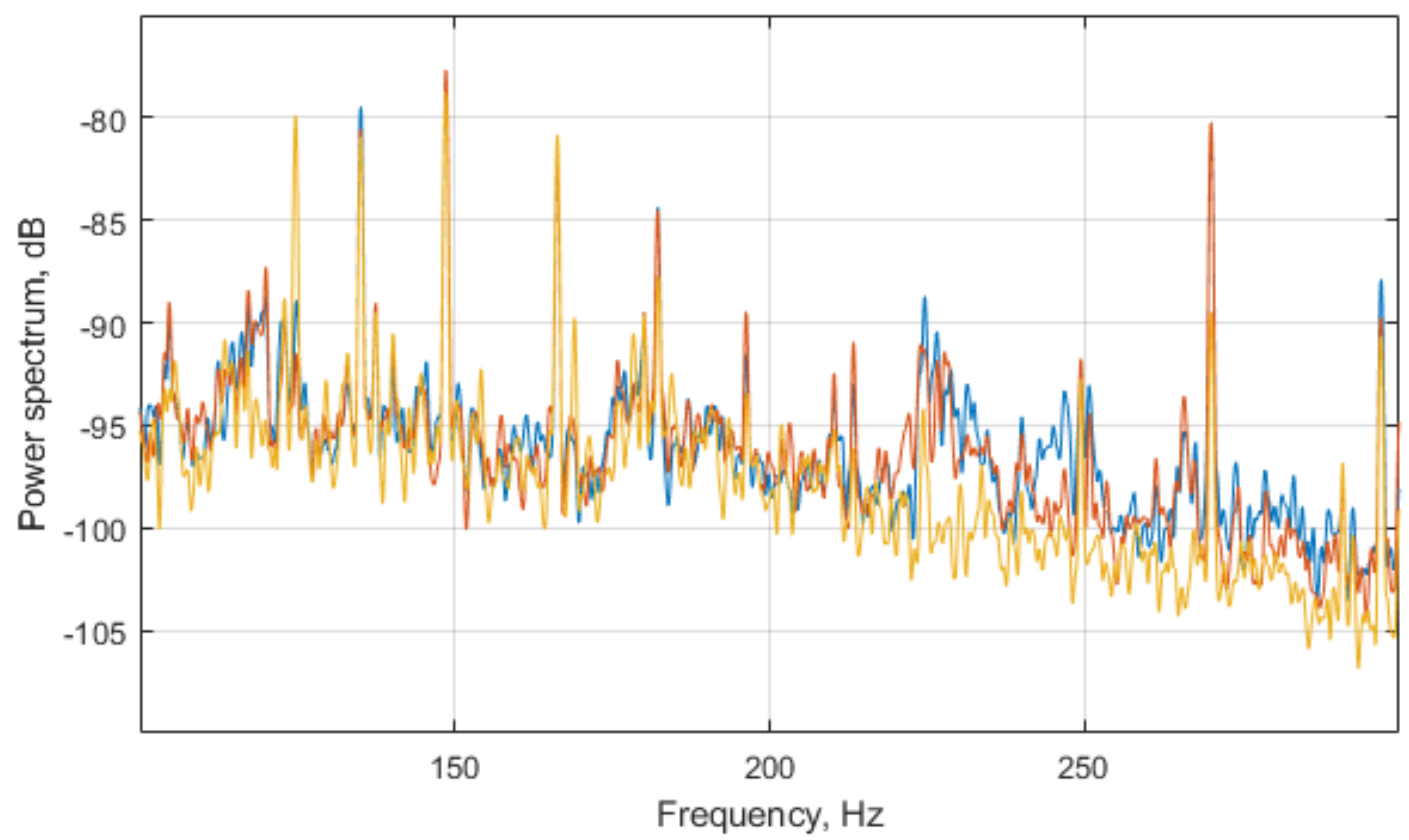

Figure 51. Power spectra for the west truck bay door opening and closing between 10:26:43 and 10:27:29

(blue) and opening and closing between 10:28:23 and 10:29:19 (orange) compared to a background period (yellow) measured between 10:19 and 10:19:30 for frequencies between 100 and $300 \mathrm{~Hz}$.

\subsubsection{East Truck Bay Door No Entry/Exit}

The east door to the truck bay was opened and closed at 10:27 and 10:28 am, respectfully, as noted in the INL notebook. The east event time period is between west door operations as indicated on Figure 51 where no signals are observed in the data.

\subsubsection{Loading the Sugarman Capsule}

The Sugarman capsule was scheduled to be loaded and moved as part of HFIR operations that were unrelated to the MINOS project. As part of the process, the Sugarman capsule would be lifted and translated then loaded onto a truck. This section describes entry and exit through the truck bay doors and operations with the 50-ton bridge and housing including loaded movements with the 3-and 50-ton hooks.

A truck was positioned in the truck bay prior to the logging of the events described in this section. Before the loading process began and with the truck already located in the truck bay, the west truck bay door was opened $\sim 10$ feet and then closed at 1:29 and 1:32 pm, respectively, as noted in the lab notebook. Opening and closing the door 10 feet took approximately 10 seconds for each operation. At 1:35 pm, the west truck bay door was opened completely to allow for truck entry into the reactor bay. The raw signal acquired from 1:28 to 1:38 pm is shown in Figure 52, which includes truck bay operations without and with truck entry. The raw signal does display some interesting voltage changes, however, it is hard to define the source from audio analysis. The spectrogram of Figure 53, covering the same time period described in Figure 52, shows power variations with events indicated. Note that the widths of the time bins in the spectrogram are 5 seconds. The intensity of the signal for the door opening 10 feet, closing, and opening completely show similarities in the frequencies ranging from 200 to $250 \mathrm{~Hz}$.

A more detailed analysis of the power is displayed in the spectra of Figure 54, which includes time periods from 1:28:47 to $1: 29: 07 \mathrm{pm}, 1: 32: 50$ to $1: 33: 08 \mathrm{pm}$, and 1:31:42 to $1: 32: 12 \mathrm{pm}$ for the west truck 
bay door opening 10 feet, closing 10 feet and the background period respectively. The figure shows noticeable differences in the power profiles between the background and door operations. These differences include a larger base power for door operations over the background in the frequency range from approximately 220 to $290 \mathrm{~Hz}$. The largest increase in power for the door operations over the background occurs between approximately 225 and $235 \mathrm{~Hz}$ with an average difference of approximately $8 \mathrm{~dB}$. Although the power for the door opening and closing 10 feet are similar throughout the curves, there are some slight differences. In the frequency range around 230 to $232 \mathrm{~Hz}$, the door closing operation has a higher power profile, while in the range of 261 to $263 \mathrm{~Hz}$ the door opening has higher power. More experiments would need to be performed to verify the consistency of these differences. Note that there are no significant differences in the power profiles for all three spectra from 0 to $100 \mathrm{~Hz}$.

As mentioned, prior to truck movement through the west door, the door was opened and closed 10 feet. This 10 foot opening operation is compared to the complete door opening operation as the truck moves through the door in the power spectra of Figure 55. The time period of the complete door opening occurs between 1:33:34 and 1:34:56 pm. There are some observable differences in the power profiles between the open door operations. The power when the door is partially opened is lower between approximately 12 and $18 \mathrm{~Hz}$; however, it is higher between approximately 213 and $290 \mathrm{~Hz}$. It is possible that more low frequency signals occur when the door completely opens causing a larger power output. These signals could be from the door interacting with mechanisms at the end of the overhead track. It's also possible that the power is attenuated in the higher frequencies when the door is completely opened because the signal is shielded by the building at the top of its track. Of course, these hypotheses would have to be verified with further experiments.

This section compares a partial west door opening with a partial door opening by ORNL staff as described in section 2.6.1. A comparison of the power spectra for these two partial door openings is displayed in Figure 56. The background time periods that were analyzed against each partial door opening are displayed in the power spectra of Figure 57 . At $125 \mathrm{~Hz}$, the power difference in the door operations is approximately $13 \%$ while there are peaks in the background with no difference in their power, therefore the difference in power in the door operations are attributed to differences in the signals. At 135, 166, and $291 \mathrm{~Hz}$ the difference in power in the door opening operations is similar to the differences in power in the background signals, therefore, the power difference observed in Figure 56, can be attributed to background contributions. At $166 \mathrm{~Hz}$, the power difference between the door operations is less than the difference in the background signals; therefore, the power difference displayed in Figure 56 can be partially attributed to door operations and from background signals. In the frequency range that includes $232 \mathrm{~Hz}$, the power is greater for the door opening as part of the Sugarman operations. There are no background peaks in either background spectra in that region; therefore, the power difference corresponds to differences in the door signals. More experiments would need to be conducted to determine whether or not these differences would remain in repeated measurements.

The door was completely opened in preparation for moving the Sugarman capsule. Section 2.6.1 also describes a complete opening of the west truck bay door. There are notable differences that should be considered for these two events. First, during the preparation for movement of the Sugarman capsule, a truck drove through the door following opening operations. Next, after the door was completely opened as described in Section 2.6.1, the door was immediately closed. There were no distinguishing features between opening and closing of the truck bay door. For completeness, Figure 58 displays power spectra for times including when the west door was completely opened in preparation to move the Sugarman capsule and when the door was completely opened and immediately closed, as described in Section 2.6.1. Similar to the partial door opening, at $125 \mathrm{~Hz}$ the power difference in the door operations is approximately $12 \%$, with no power differences in the background; therefore, the difference in power in the door operations are attributed to differences in the signals. Peaks at 135, 166, and $291 \mathrm{~Hz}$ give similar results as they did for partial door operations with the power differences attributed to differences in background power. The areas of higher power for the complete door opening described in Section 2.6.2 in the frequency range between 
approximately 225 and $235 \mathrm{~Hz}$ and approximately 241 and $252 \mathrm{~Hz}$ can be attributed to the door opening signals. It may be that the closing operation leads to the differences observed in these frequency ranges. The background signals do not contribute to the power difference at approximately $270 \mathrm{~Hz}$ between the door operations.

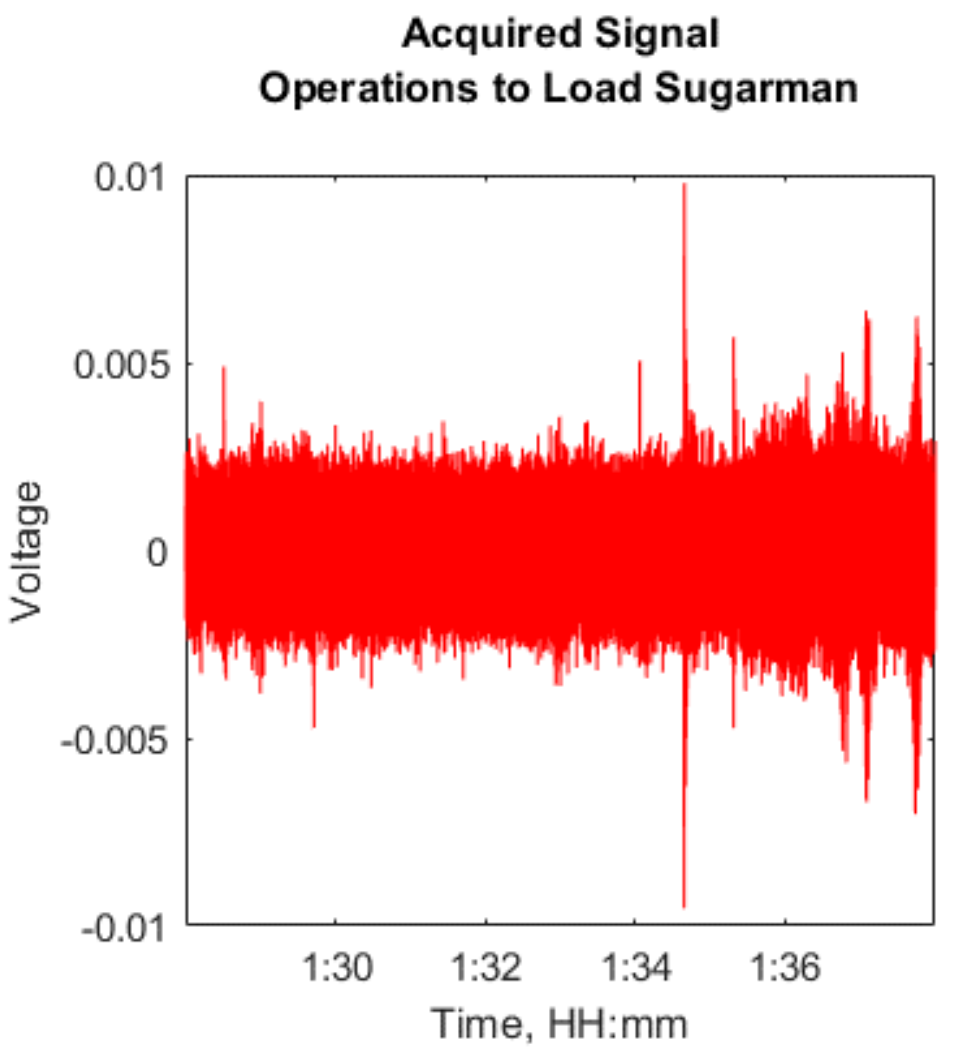

Figure 52. Raw signal that includes Sugarman capsule loading operations from 1:28 to 1:38 pm. 


\section{Spectrogram-Operations to Load Sugarman}

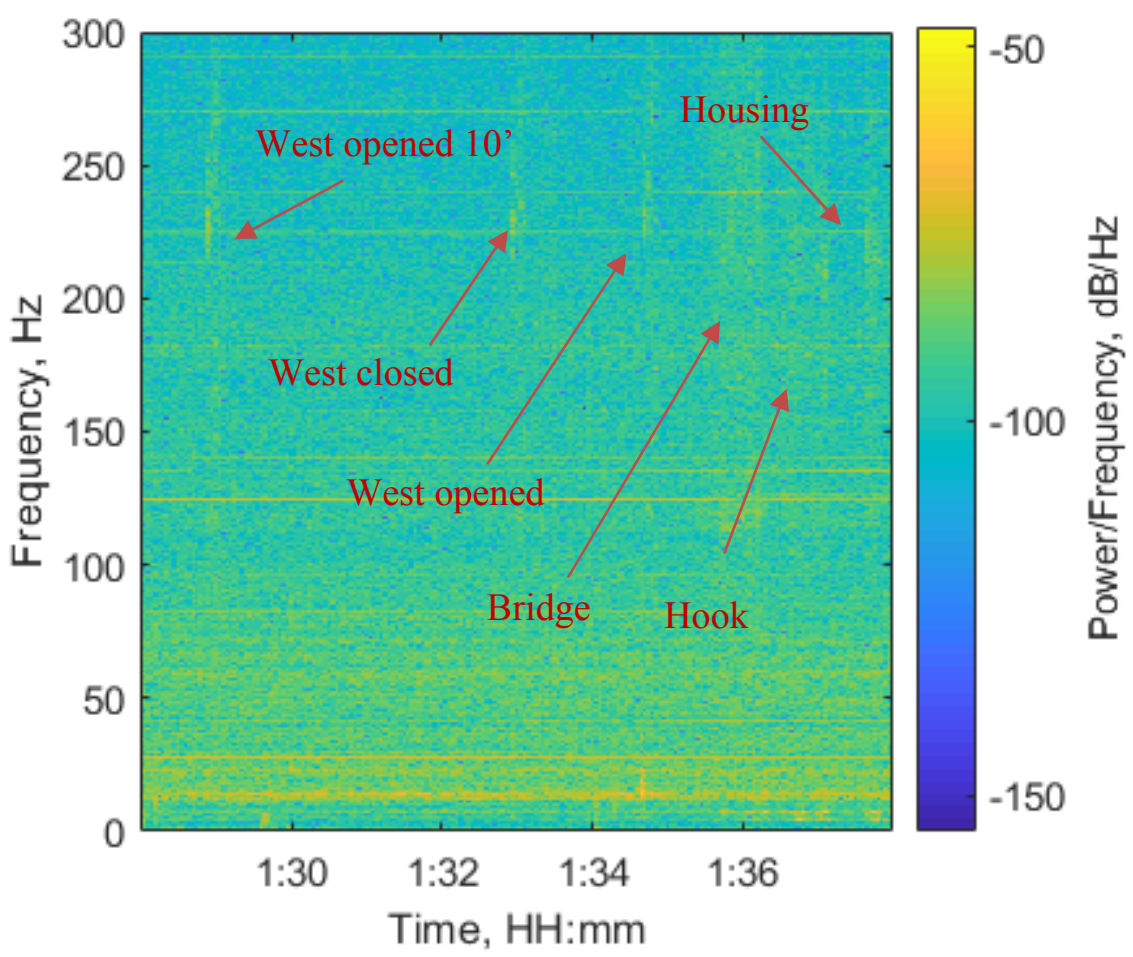

Figure 53. Spectrogram of time period that covers Sugarman capsule loading operations from 1:28 to 1:38 pm. "West opened 10', West closed, and West opened" refers to the west truck bay door operations. "Bridge, Hook, and Housing" refers to the 50-ton bridge and 3-ton crane hook movements. 


\section{Bay Door Operations to Load Sugarman}

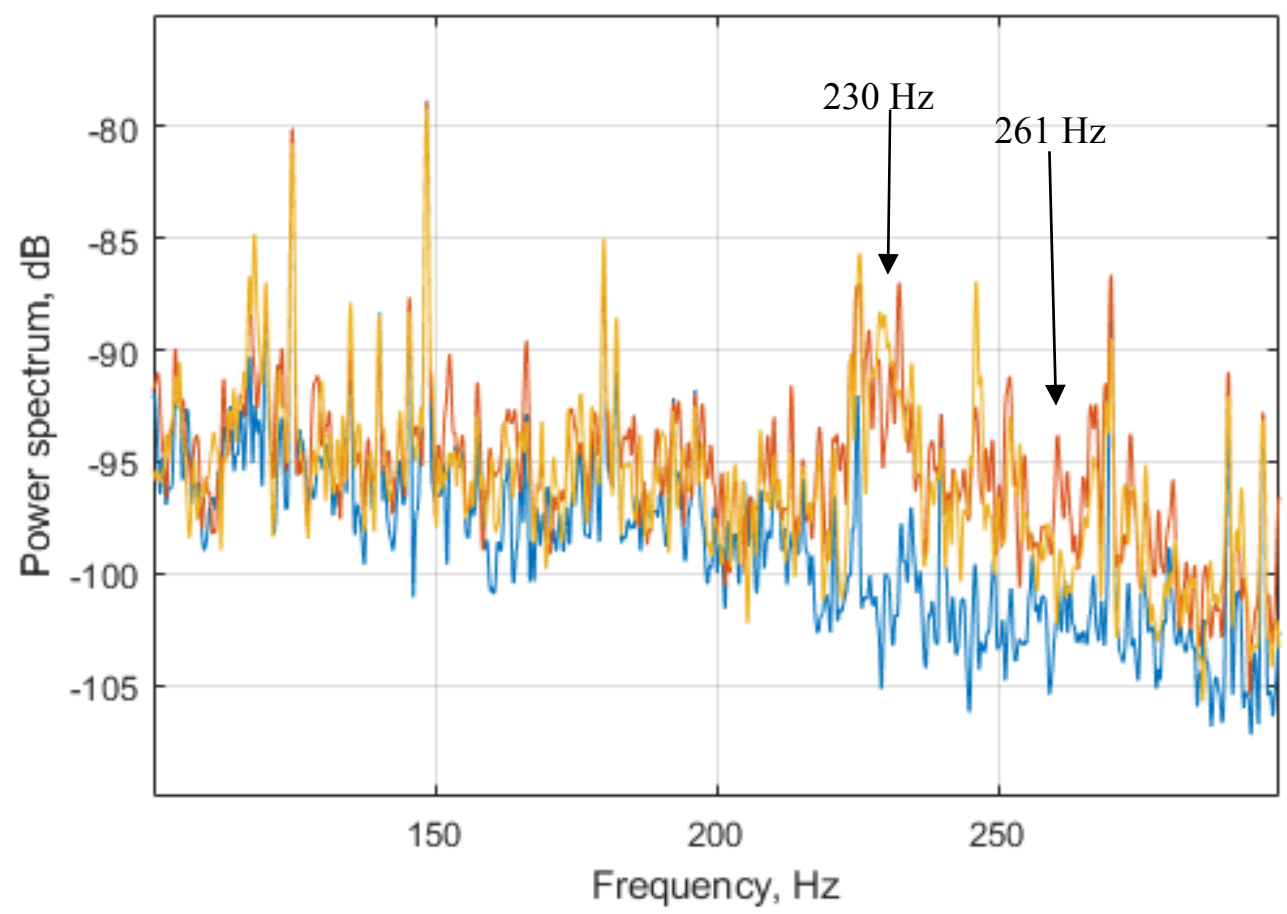

Figure 54. Power spectra showing time periods when the west truck door bay opens 10' (orange), closes 10 ' (yellow), and a background period (blue). 


\section{Bay Door Open Operations to Load Sugarman}

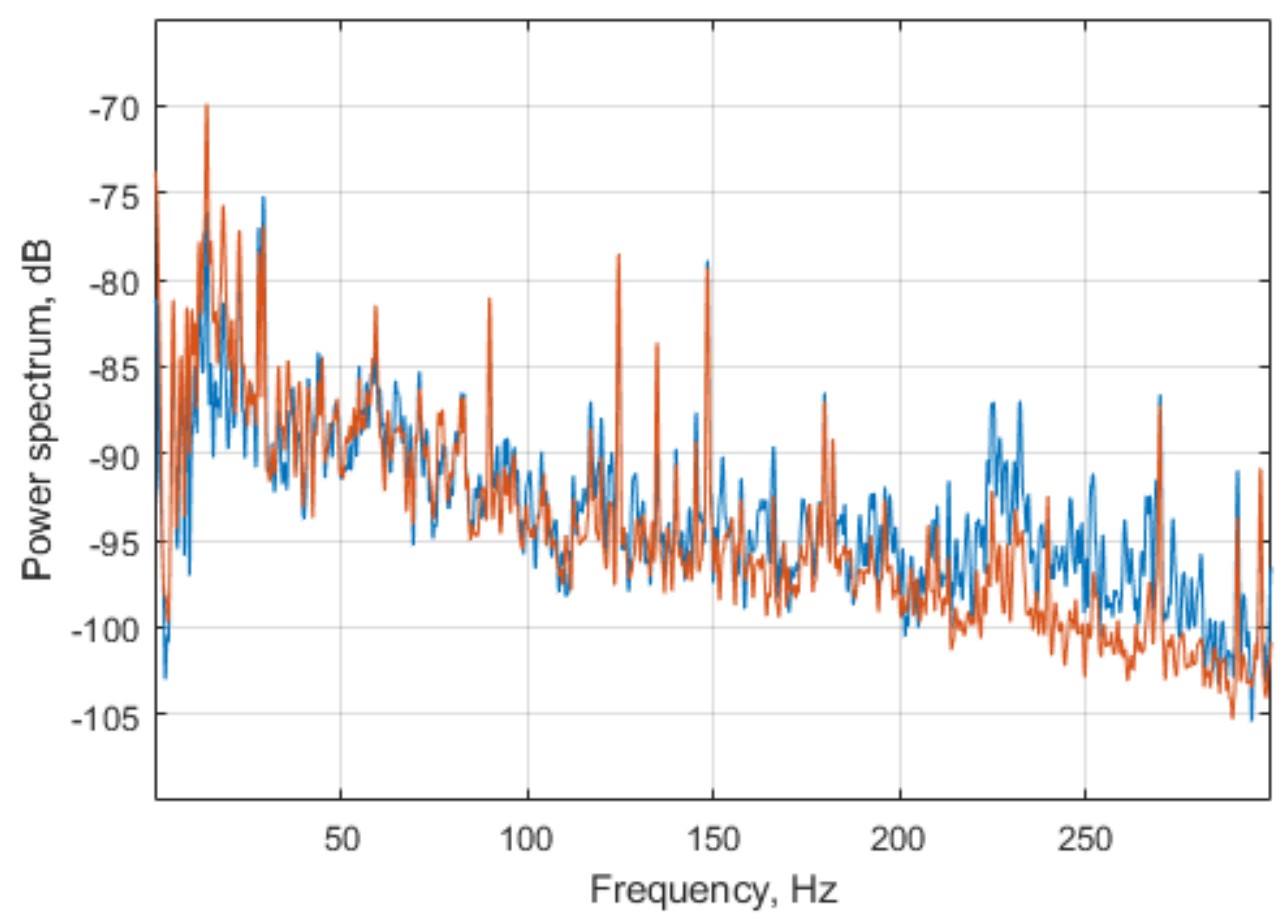

Figure 55. Power spectra with time periods including the west truck bay door opened 10' (blue) and opened completely with the truck passing through (orange) displayed.

\section{Bay Door Open Operations - Partial}

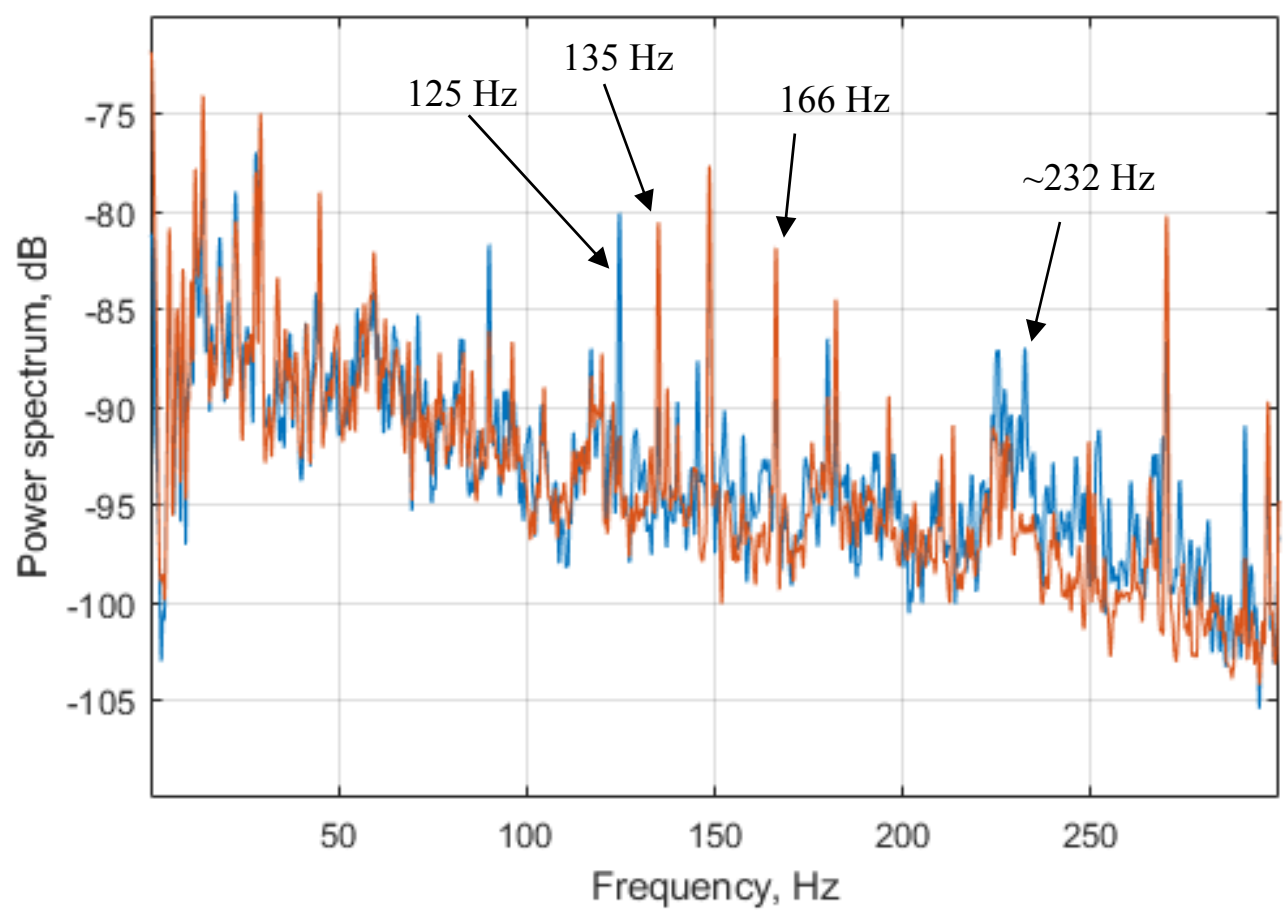

Figure 56. Power spectra comparing the partial openings of the west truck bay door without entry or exit through the door. 


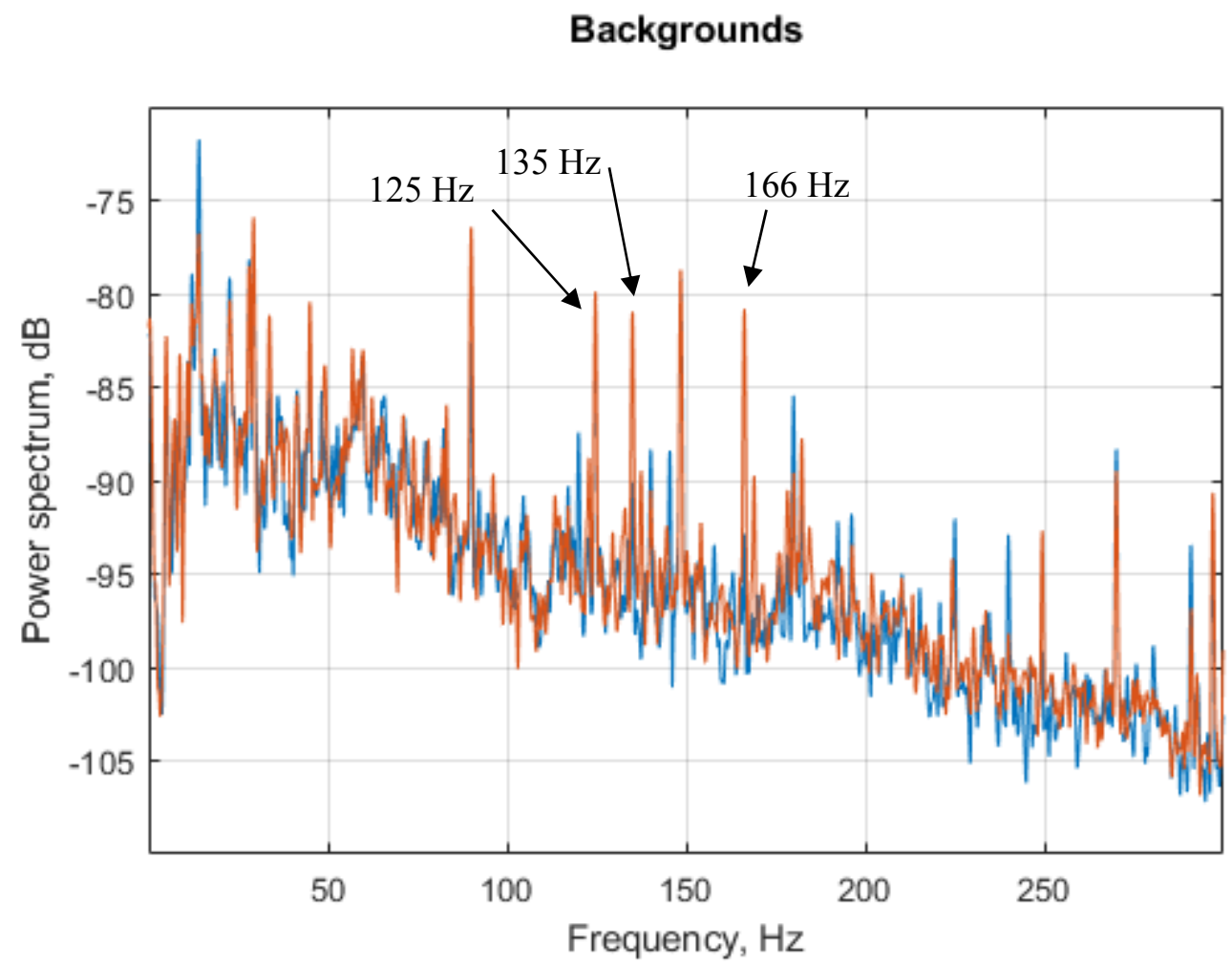

Figure 57. Power spectra comparing the background time periods that were analyzed against each partial west truck bay door opening without entry or exit through the door.

\section{Bay Door Open Operations - Complete}

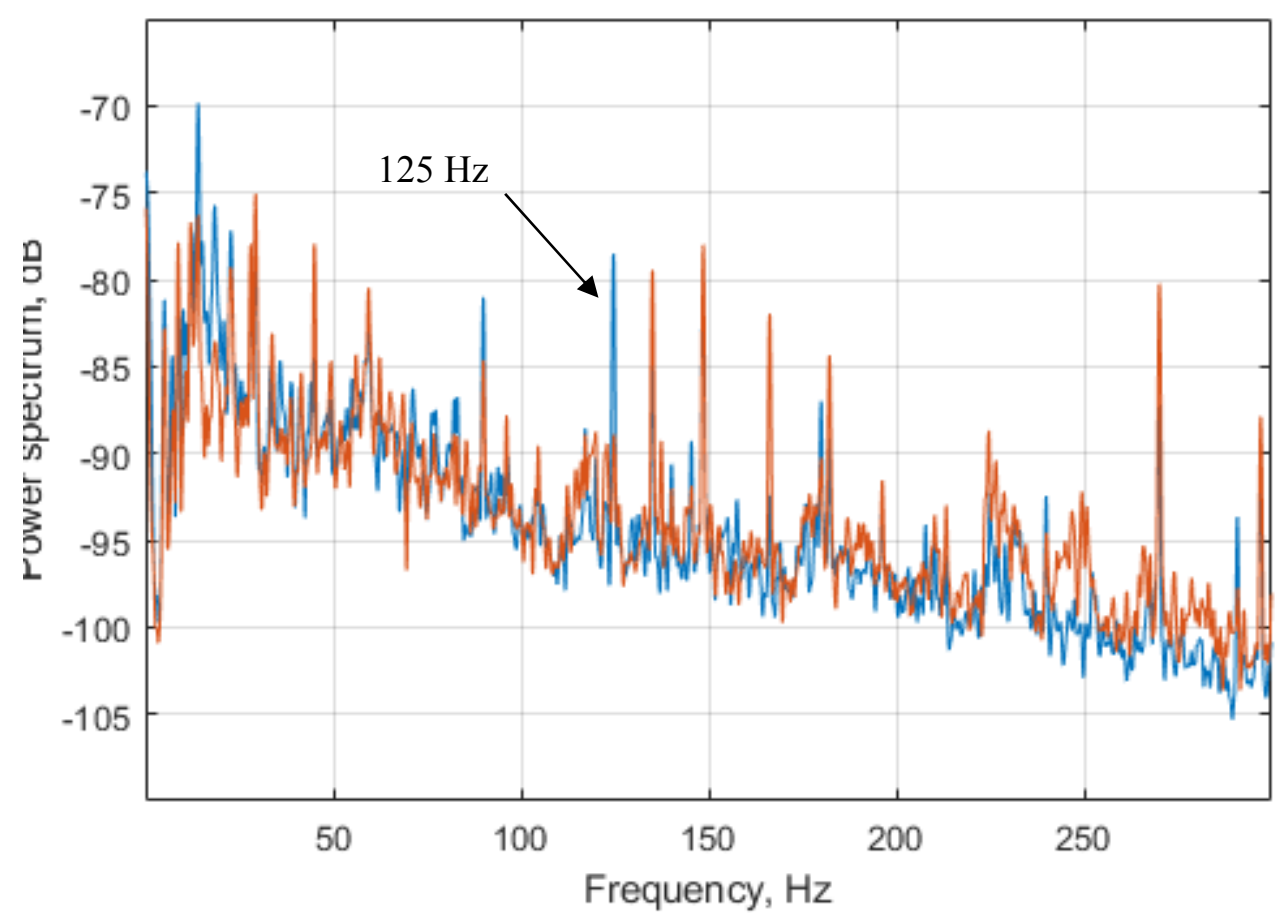

Figure 58. Power spectra comparing the complete openings of the west truck bay door. The opening occurring during preparation for movement of the Sugarman capsule had a truck exit the bay. 


\subsection{HFIR Coolant and Clean-up Pumps}

The HFIR reactor bay primary coolant pumps are located directly below the reactor bay floor in room 210 of building 7900, indicated on Map 6 appearing in Appendix 1. Pumps for the clean-up system are located on the floor below and are offset to the north of the coolant pumps. There are 4 primary coolant pumps with 3 circulating water into the reactor. The primary coolant pumps cycle water through the reactor at a rate of 16,000 gallons/min with 120 gallons/min siphoned off by pumps that direct the water to the clean-up system. There are two clean-up system pumps with only one running at a time. For measurements included here, the running clean-up system pump was turned off with power switched to the alternate cleanup pump and vice versa. Sound recordings were logged at 10:35 am with the duration of the power switch estimated to last approximately 30 seconds. As with the other HFIR reactor bay measurements, sound level meters were located at positions 10 and 8 indicated on Map 6 and Map 7 in Appendix 1. There were no distinguishing features in the data from 0 to $300 \mathrm{~Hz}$ around the time that events were logged. 


\subsection{HFIR Air Conditioning and Cooling Operations}

On the south wall of the reactor bay, room 210 in building 7900, there are 5 air conditioning (AC) units labeled AC-10 through AC-14, indicated in Map 6 appearing in Appendix 1. The air conditioning unit positioned furthest east, AC-14, is typically powered off while the remaining are powered on. ORNL personnel cycled the power in these air conditioning units for the MINOS project on June 19, 2018. Sound level meters remained in the same locations as described for reactor bay crane movements and truck bay door operations described in sections 2.5.2 and 2.6; positions 10 and 8 indicated on Map 6 and Map 7 in Appendix 1, respectively. Sound data for the description in this section was obtained from the meter located at position 10.

Air conditioners 11,12, and 13 were powered off for 20 seconds then powered back on. Air conditioner 10 was powered off while AC-14 was powered on for approximately 1 minute. Power was reversed for AC10 and 14 following the 1 minute cycle. Power for AC-11, 12, 13, and 10/14 were cycled at 1:06, 1:07, 1:08, and 1:10 pm, respectively, as logged by INL team members.

The raw signal, displayed in Figure 59, shows significant acoustic changes starting at 1:08:55 and 1:11:59 pm. These times match changes in the infrasound region indicated on the spectrogram of Figure 53. The first period of voltage change falls near power cycling of AC-13; however, it is unclear whether or not the signal is emitted from that source. The second period of voltage change is well beyond times logged in the notebook for cycle powering any of the AC units. No observed signal in the spectrogram for the early cycled $\mathrm{AC}$ units in combination with the second period of noted change occurring beyond the time logged for any $\mathrm{AC}$ operations infers that the signals were not emitted from the $\mathrm{AC}$ units. More experiments will be necessary to verify the previous statement. Note that higher frequencies were also examined for signature development of the air conditioning units.

\section{Acquired Signal \\ Power Cycled Through AC Units}

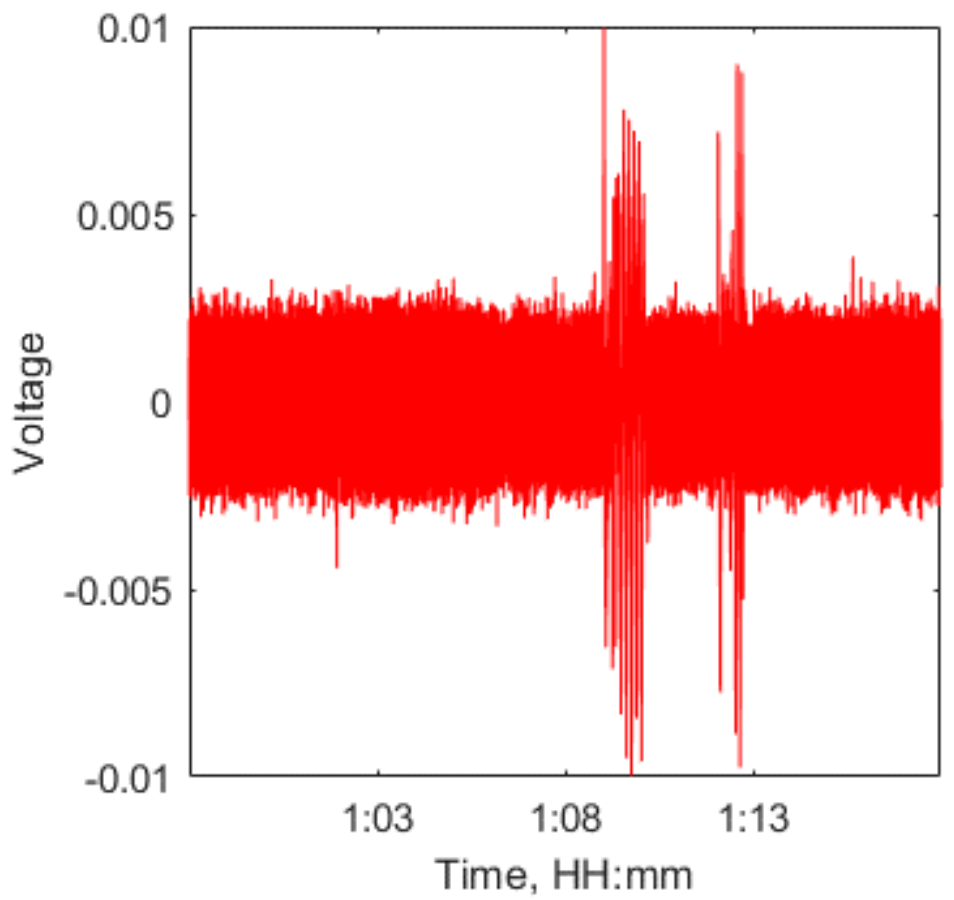

Figure 59. Raw signal acquired covering 10 minute period that includes duration of power cycling for air conditioning units 10-14 located on the south wall of HFIR reactor bay. 


\section{Spectrogram \\ Power Cycled Through AC Units}

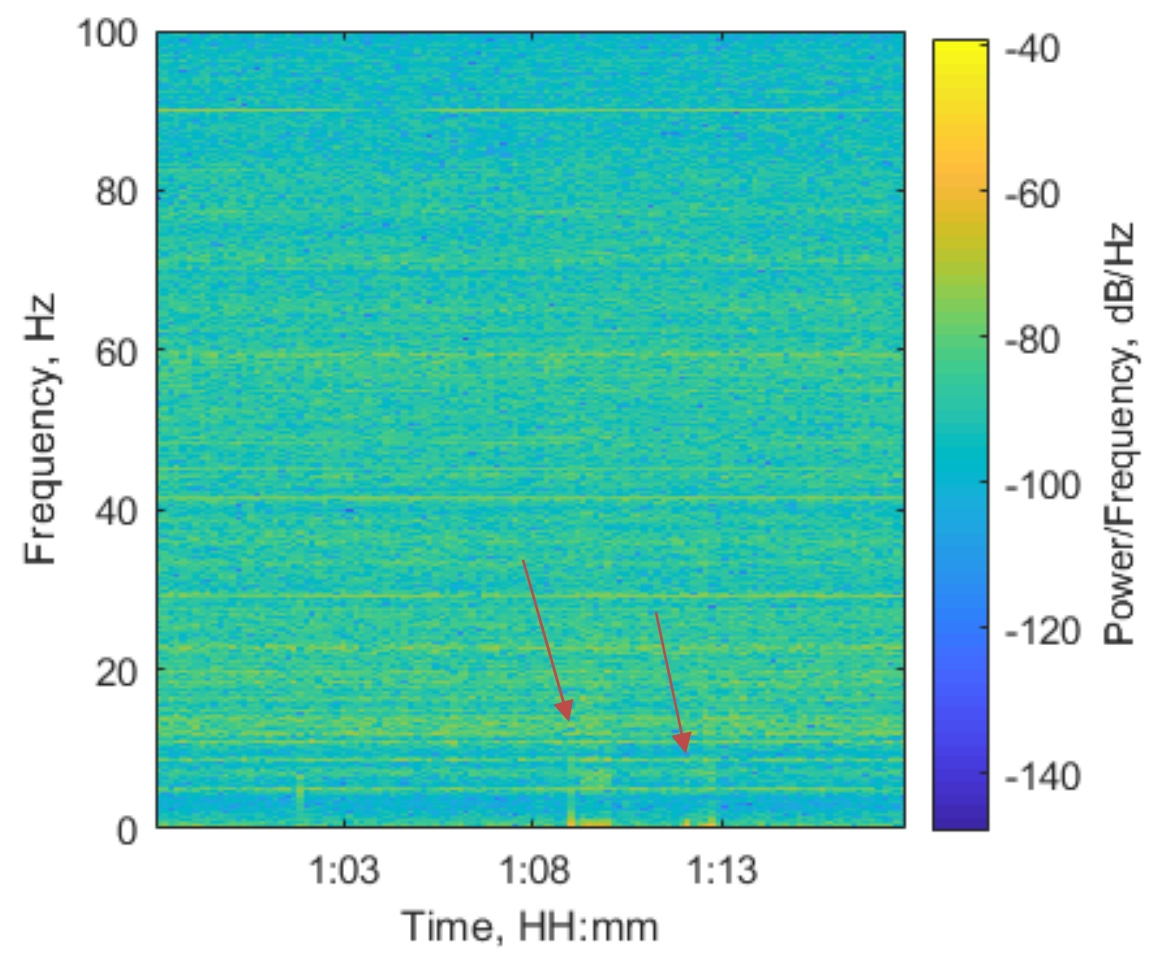

Figure 60. Spectrogram including power cycling of air conditioning units located in HFIR reactor bay. The red arrows point to changes in the power in the infrasound region. 


\section{Appendix 1 - Maps}

Maps were provided by ORNL staff and show detailed aerial views of HFIR and REDC facilities.

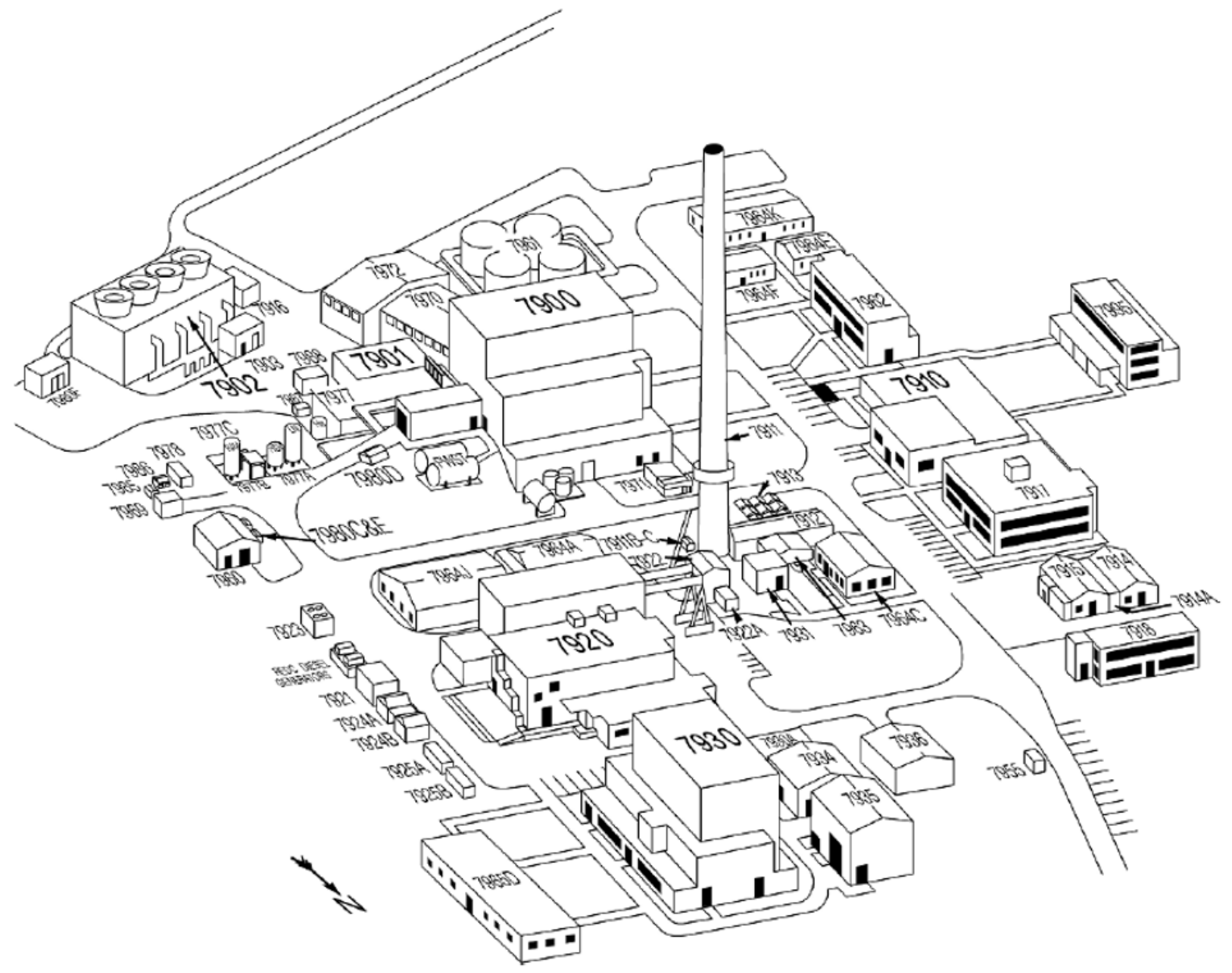

Map 1. Area near 7900 building. 


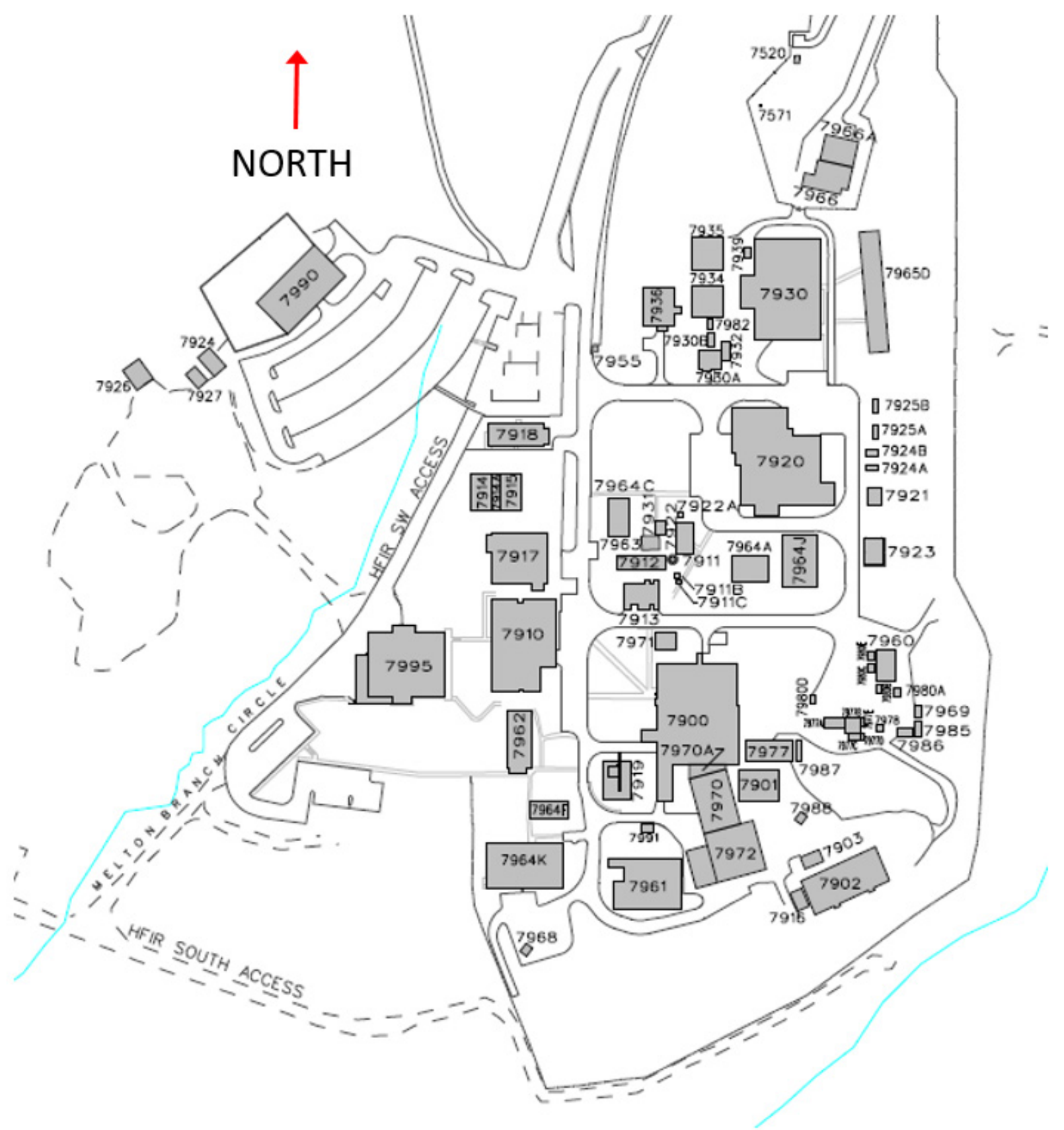

Map 2. Full aerial view with access roads. 


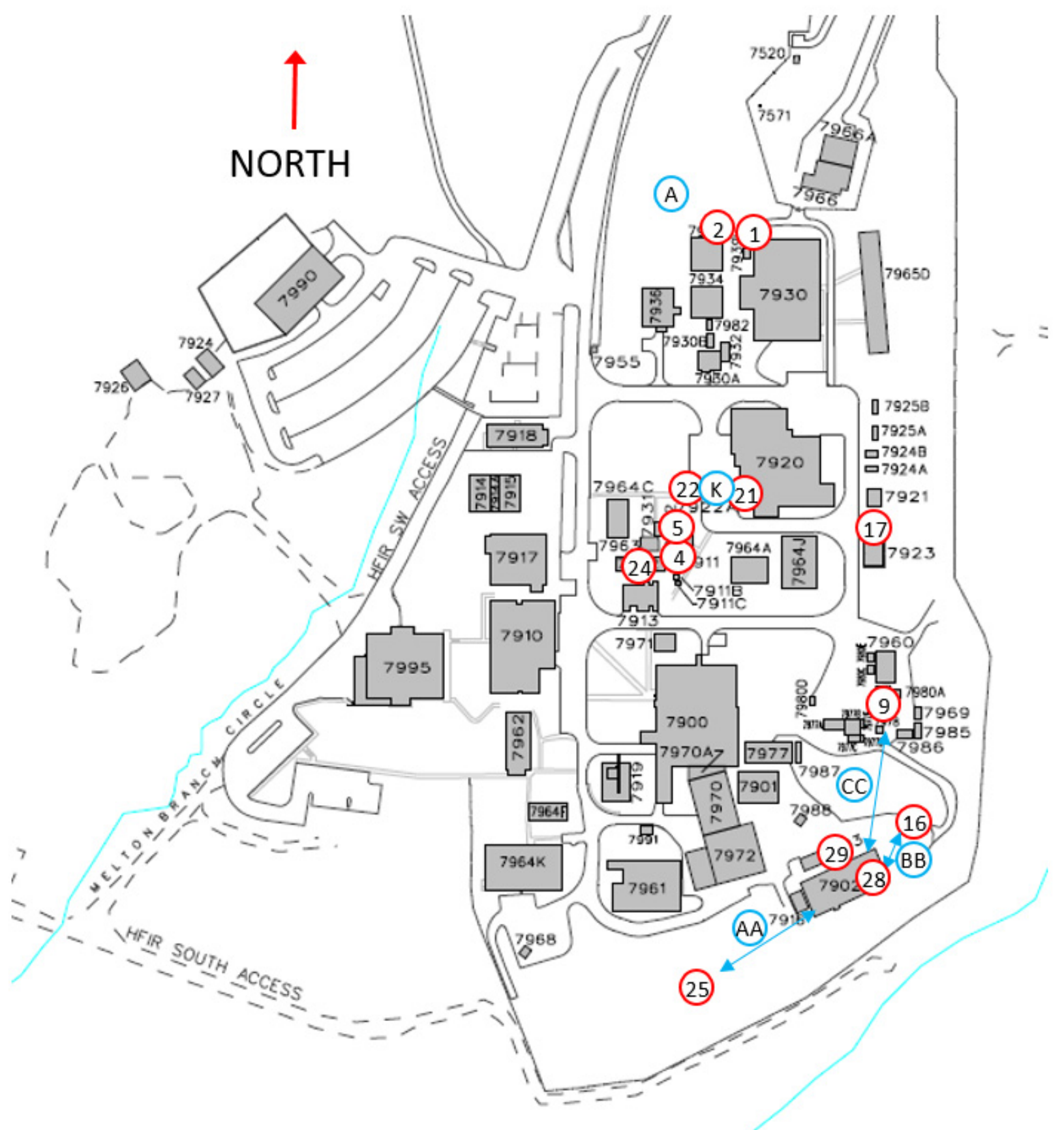

Map 3. Full aerial view with access roads and markings indicating positions of audio recorders. 


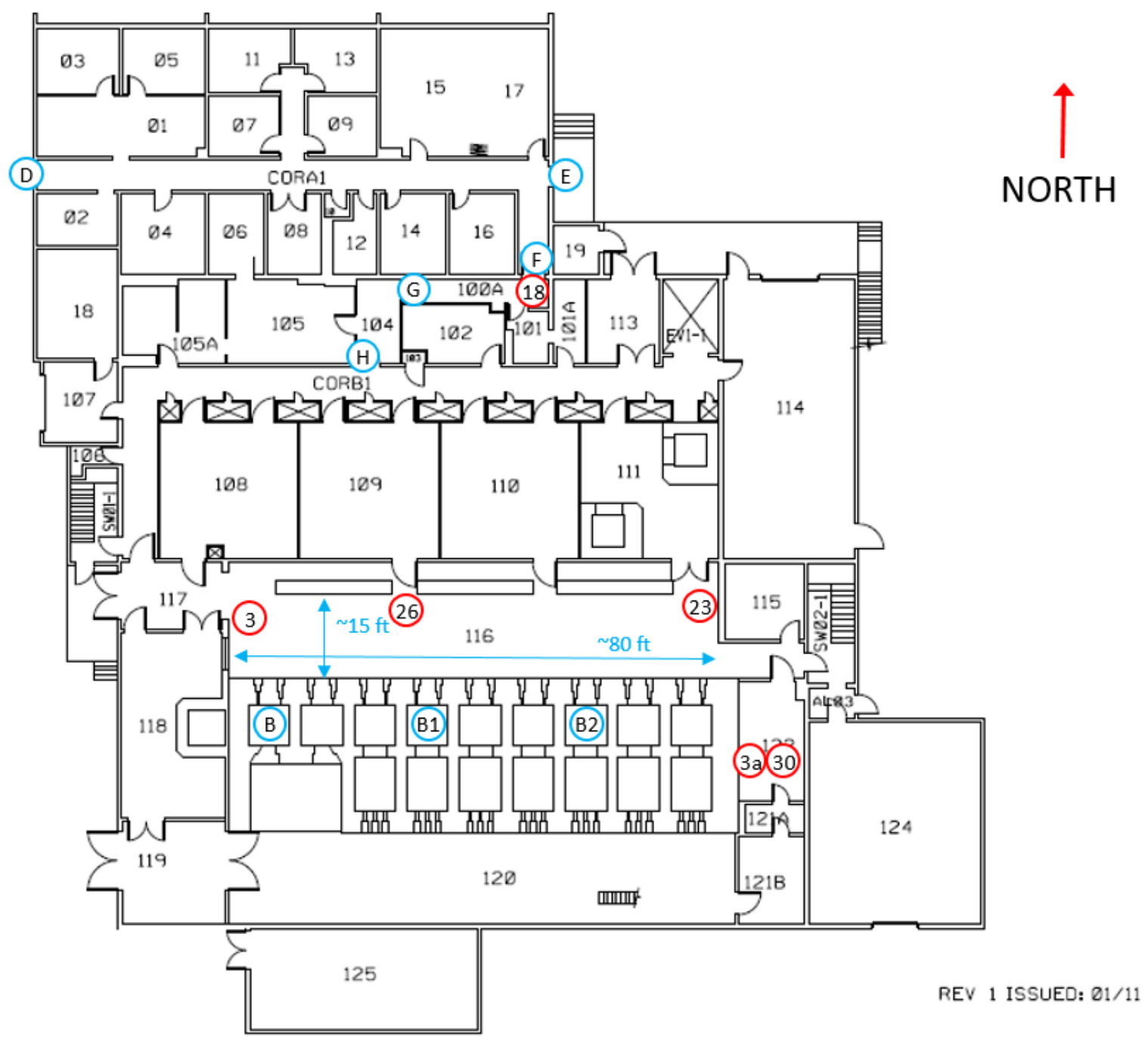

Map 4. Detailed schematic of the first floor in building 7920. 


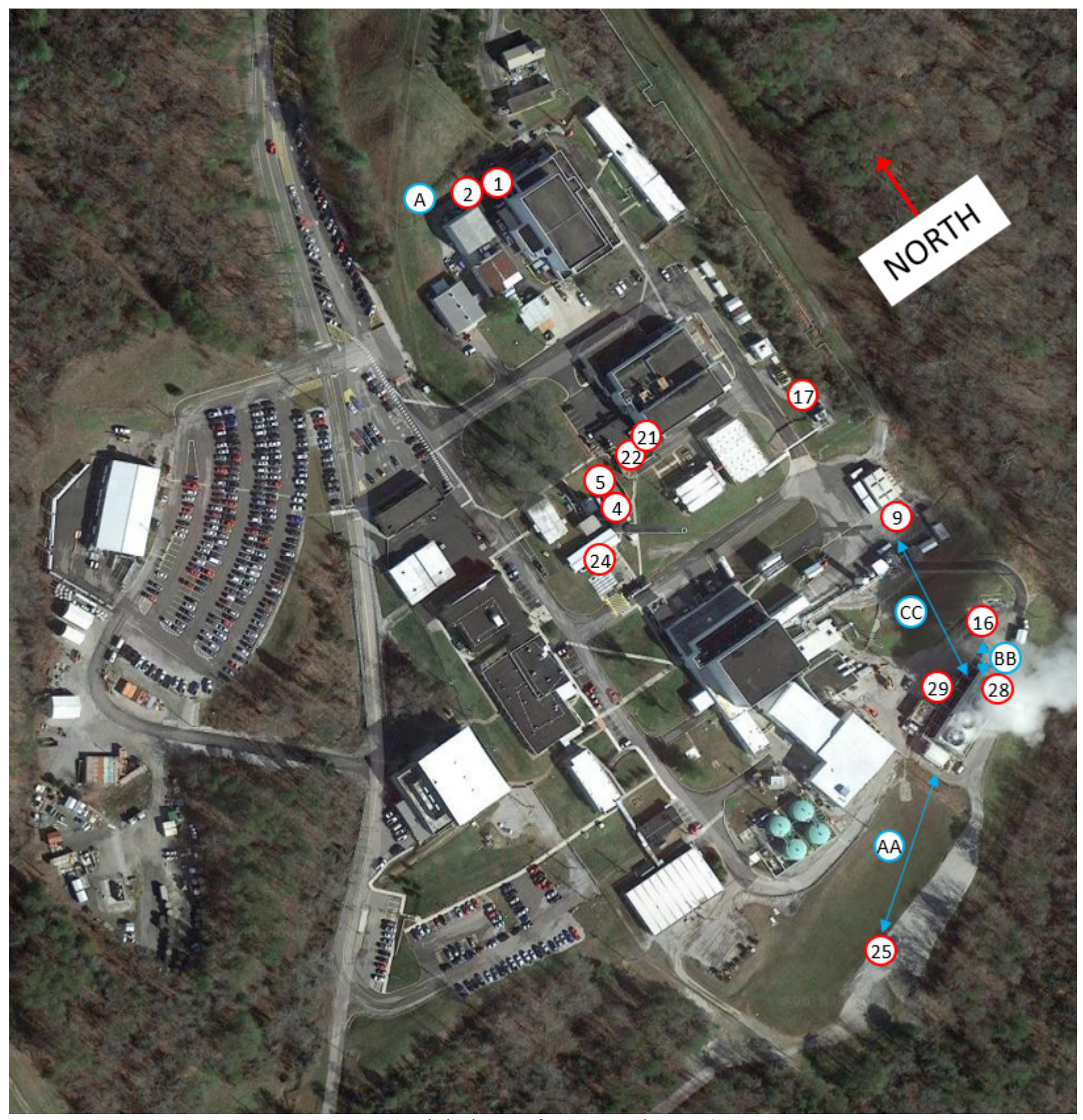

Map 5. Aerial photo of HFIR and REDC area. 


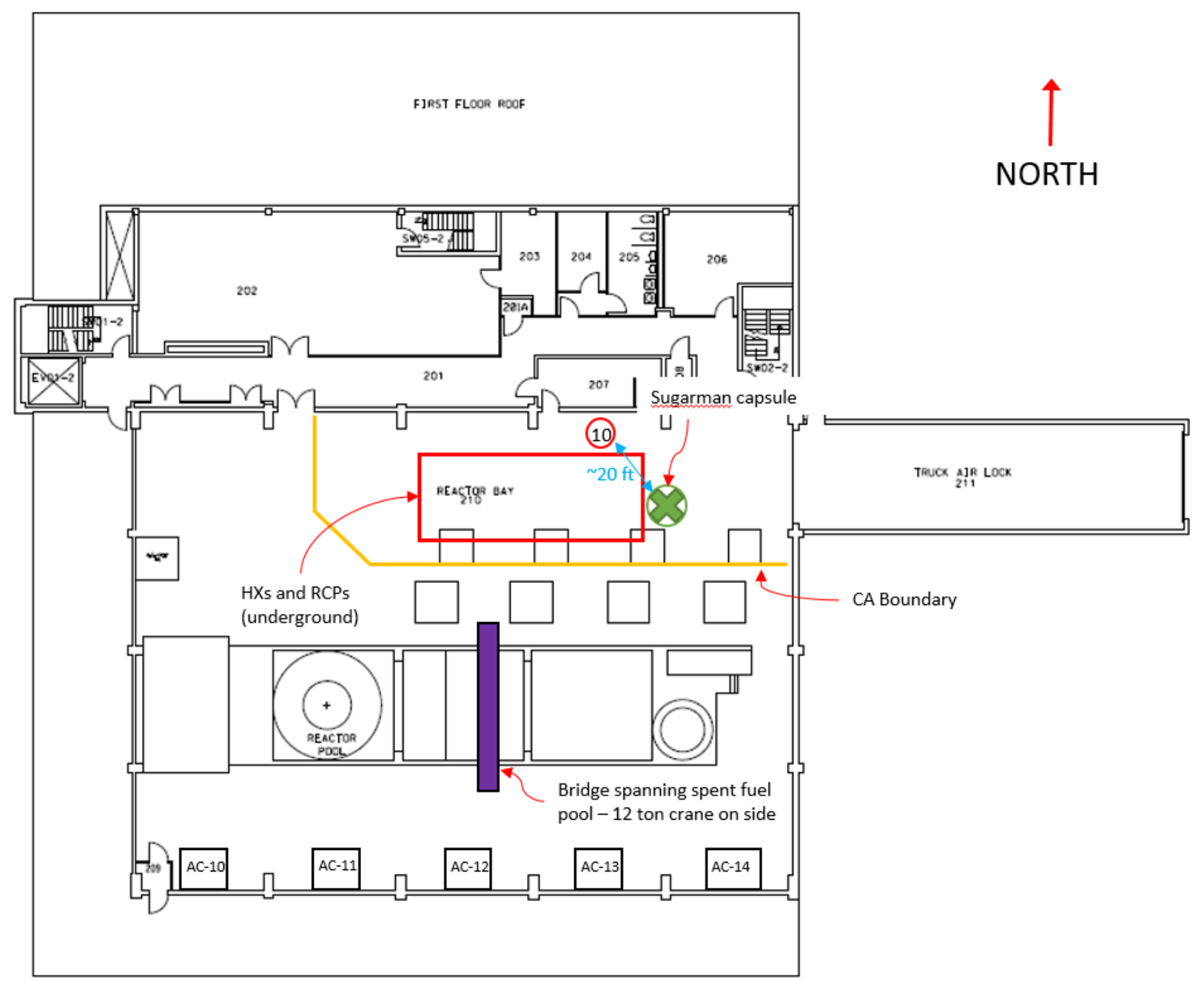

Map 6. Detailed schematic of the second level in building 7900 . 


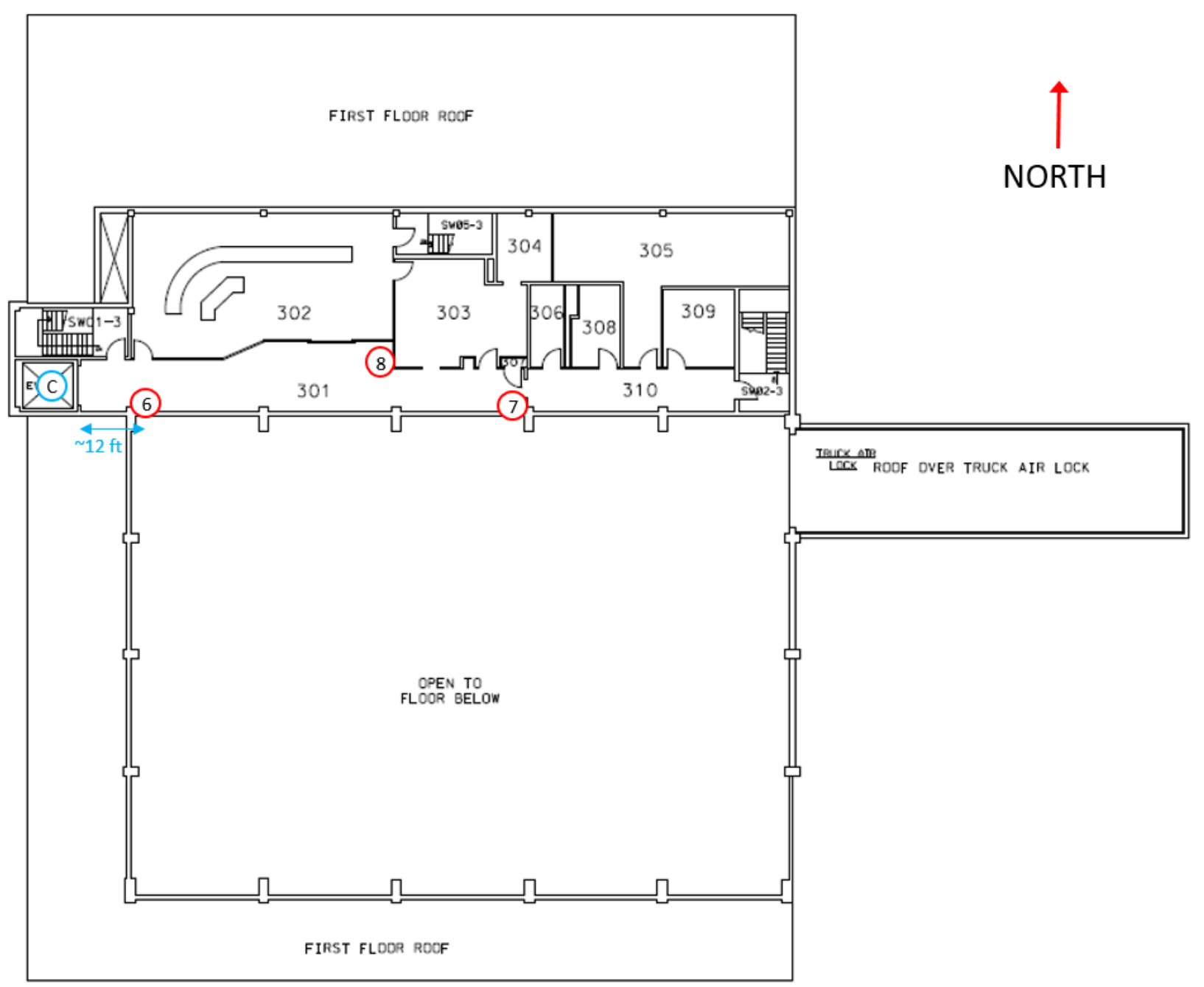

Map 7. Detailed schematic of the third level in building 7900. 


\section{Appendix 2 - Quick Signature Reference}

Table 1. Signature guide

\begin{tabular}{|c|c|c|c|}
\hline Event & $\begin{array}{l}\text { Location } \\
\text { and } \\
\text { Recorder } \\
\text { Positions }\end{array}$ & Description & Signature \\
\hline $\begin{array}{l}\text { Diesel generator } \\
\text { operation }\end{array}$ & $\begin{array}{l}\text { Near building } \\
7939 \\
\text { (1) And (2) }\end{array}$ & $\begin{array}{l}\text { Startup, steady state, and } \\
\text { shutdown of diesel } \\
\text { generator. }\end{array}$ & 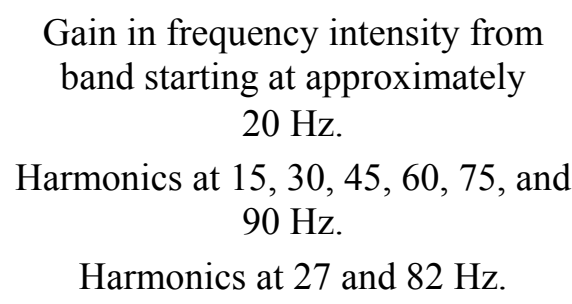 \\
\hline $\begin{array}{l}\text { Hot Cell } \\
\text { Manipulator } \\
\text { Operations }\end{array}$ & $\begin{array}{l}\text { Near hot cells } \\
\text { in building } \\
7920 \\
\text { (3), (23), and } \\
\text { (26) }\end{array}$ & $\begin{array}{l}\text { Various manipulator } \\
\text { operations with time } \\
\text { stamps and movement } \\
\text { descriptions not logged. }\end{array}$ & None identified. \\
\hline $\begin{array}{c}\text { Conveyor System } \\
\text { Operations }\end{array}$ & $\begin{array}{l}\text { Control room } \\
122 \text { in } \\
\text { building } \\
7920 \\
\text { (3a) and (30) }\end{array}$ & $\begin{array}{l}\text { The conveyor belt moved } \\
\text { from hot cell } 4 \text { to } 7 \text { then } \\
\text { from } 7 \text { to } 4 \text {, toward and } \\
\text { away from the sound level } \\
\text { meter respectively. }\end{array}$ & $\begin{array}{l}\text { More testing needed as frequencies } \\
\text { differ for each movement. } \\
\text { Signature visible as a slope gain } \\
\text { over frequency components ending } \\
\text { with a slight drop in slope } \\
\text { sandwiched between bursts in } \\
\text { intensities in frequency band from } \\
\text { approximately } 40 \text { to } 98 \mathrm{~Hz} \text {. }\end{array}$ \\
\hline $\begin{array}{l}\text { Cell and Vessel } \\
\text { Off Gas } \\
\text { Ventilation } \\
\text { Trains }\end{array}$ & $\begin{array}{l}\text { Building } \\
7922 \\
\text { (4) and (5) }\end{array}$ & $\begin{array}{l}\text { Sound level meters were } \\
\text { placed in an open air shed } \\
\text { that houses fans and pumps } \\
\text { pulling a vacuum for } \\
\text { separate ventilation } \\
\text { systems. }\end{array}$ & $\begin{array}{l}\text { Persistent frequency components of } \\
\text { approximately } 28 \text { and } 44 \mathrm{~Hz} .\end{array}$ \\
\hline $\begin{array}{l}\text { HFIR 12-Ton } \\
\text { Crane } \\
\text { Movements }\end{array}$ & $\begin{array}{l}\text { Building } \\
7900 \text { HFIR } \\
\text { reactor bay } \\
(6),(7),(8), \\
\text { and (10) }\end{array}$ & $\begin{array}{l}\text { Movements of the 12-ton } \\
\text { crane bridge were not } \\
\text { logged. }\end{array}$ & $\begin{array}{c}\text { Unclear, however, the intensity } \\
\text { increases for frequencies between } 0 \\
\text { and approximately } 22 \mathrm{~Hz} \text {. }\end{array}$ \\
\hline $\begin{array}{l}\text { HFIR 3-Ton } \\
\text { Crane } \\
\text { Movements - } \\
\text { Unloaded }\end{array}$ & $\begin{array}{l}\text { Building } \\
7900 \text { HFIR } \\
\text { reactor bay } \\
(6),(7),(8), \\
\text { and (10) }\end{array}$ & $\begin{array}{l}\text { Up and down movements } \\
\text { with 3-ton crane hook. }\end{array}$ & $\begin{array}{l}\text { No infrasound signals observed. } \\
\text { A prominent peak at approximately } \\
240 \mathrm{~Hz} \text { was measured at } \\
\text { approximately }-80 \mathrm{~dB} \text {. }\end{array}$ \\
\hline
\end{tabular}




\begin{tabular}{|c|c|c|c|}
\hline Event & $\begin{array}{l}\text { Location } \\
\quad \text { and } \\
\text { Recorder } \\
\text { Positions }\end{array}$ & Description & Signature \\
\hline $\begin{array}{l}\text { HFIR 50-Ton } \\
\text { Crane } \\
\text { Movements - } \\
\text { Unloaded }\end{array}$ & $\begin{array}{l}\text { Building } \\
7900 \text { HFIR } \\
\text { reactor bay } \\
(6),(7),(8), \\
\text { and }(10)\end{array}$ & $\begin{array}{l}\text { Up and down movements } \\
\text { with 50-ton crane hook. }\end{array}$ & $\begin{array}{l}\text { No infrasound signals observed. } \\
\text { A prominent peak at approximately } \\
240 \mathrm{~Hz} \text { was measured at } \\
\text { approximately }-74 \mathrm{~dB} \text {. }\end{array}$ \\
\hline $\begin{array}{l}\text { HFIR } 50 \text { and 3- } \\
\text { Ton Crane } \\
\text { Housing } \\
\text { Movements - } \\
\text { Unloaded }\end{array}$ & $\begin{array}{l}\text { Building } \\
7900 \text { HFIR } \\
\text { reactor bay } \\
(6),(7),(8), \\
\text { and }(10)\end{array}$ & $\begin{array}{l}\text { South translations of the } \\
\text { crane housing with } \\
\text { movements including both } \\
\text { the } 50 \text { and } 3 \text {-ton crane } \\
\text { hooks. }\end{array}$ & $\begin{array}{l}\text { Overall power gain from } \\
\text { approximately } 5 \text { to } 7 \mathrm{~Hz} \text { and from } \\
220 \text { to } 240 \mathrm{~Hz} \text {. At } 120 \mathrm{~Hz} \text { the power } \\
\text { increases to }-81 \mathrm{~dB} \text {. }\end{array}$ \\
\hline $\begin{array}{l}\text { HFIR } 50 \text { and 3- } \\
\text { Ton Crane } \\
\text { Housing } \\
\text { Movements - } \\
\text { Unloaded }\end{array}$ & $\begin{array}{l}\text { Building } \\
7900 \text { HFIR } \\
\text { reactor bay } \\
(6),(7),(8), \\
\text { and }(10)\end{array}$ & $\begin{array}{l}\text { North translations of the } \\
\text { crane housing with } \\
\text { movements including both } \\
\text { the } 50 \text { and } 3 \text {-ton crane } \\
\text { hooks. }\end{array}$ & $\begin{array}{l}\text { Overall power gain from } \\
\text { approximately } 5 \text { to } 7 \mathrm{~Hz} \text { and from } \\
220 \text { to } 240 \mathrm{~Hz} \text {. At } 120 \mathrm{~Hz} \text { the power } \\
\text { increases to }-85 \mathrm{~dB} \text {. }\end{array}$ \\
\hline $\begin{array}{l}\text { HFIR 50-Ton } \\
\text { Crane } \\
\text { Movements - } \\
\text { Unloaded }\end{array}$ & $\begin{array}{l}\text { Building } \\
7900 \text { HFIR } \\
\text { reactor bay } \\
(6),(7),(8), \\
\text { and }(10)\end{array}$ & $\begin{array}{l}\text { East movements with } 50- \\
\text { ton crane bridge. }\end{array}$ & $\begin{array}{l}\text { Overall frequency gain from } \\
\text { approximately } 5 \text { to } 9 \mathrm{~Hz} \text { and } \\
\text { approximately } 14 \text { to } 19 \mathrm{~Hz} \text {. } \\
\text { Higher base power in the band of } \\
\text { frequencies ranging from } 200 \text { to } 300 \\
\text { Hz. } \\
\text { Power peaks at approximately } 187 \text {, } \\
\text { 262, and } 275 \mathrm{~Hz} \text {. }\end{array}$ \\
\hline $\begin{array}{l}\text { HFIR 50-Ton } \\
\text { Crane } \\
\text { Movements - } \\
\text { Unloaded }\end{array}$ & $\begin{array}{l}\text { Building } \\
7900 \text { HFIR } \\
\text { reactor bay } \\
(6),(7),(8) \\
\text { and }(10)\end{array}$ & $\begin{array}{l}\text { West movements with } 50 \text { - } \\
\text { ton crane bridge. }\end{array}$ & $\begin{array}{l}\text { Overall frequency gain from } \\
\text { approximately } 5 \text { to } 9 \mathrm{~Hz} \text { and } \\
\text { approximately } 14 \text { to } 19 \mathrm{~Hz} \text {. } \\
\text { Higher base power in the band of } \\
\text { frequencies ranging from } 200 \text { to } 300 \\
\text { Hz. }\end{array}$ \\
\hline
\end{tabular}




\begin{tabular}{|c|c|c|c|}
\hline Event & $\begin{array}{l}\text { Location } \\
\quad \text { and } \\
\text { Recorder } \\
\text { Positions }\end{array}$ & Description & Signature \\
\hline $\begin{array}{l}\text { HFIR 3-Ton } \\
\text { Crane } \\
\text { Movements - } \\
\text { Loaded }\end{array}$ & $\begin{array}{l}\text { Building } \\
7900 \text { HFIR } \\
\text { reactor bay } \\
(6),(7),(8), \\
\text { and }(10)\end{array}$ & $\begin{array}{l}\text { The crane was loaded with } \\
\text { a 5' diameter flange. }\end{array}$ & $\begin{array}{l}\text { Overall frequency gain from } \\
\text { approximately } 5 \text { to } 7 \mathrm{~Hz} \text { with an } \\
18 \% \text { difference from the } \\
\text { background at } 7 \mathrm{~Hz} \text {. } \\
\text { Power profile for the base of the } \\
\text { signal remains at approximately }-93 \\
\text { dB from approximately } 112 \text { to } \\
190 \mathrm{~Hz} \text { then slowly decreases to } \\
\text { approximately }-90 \mathrm{~dB} \text { from } \\
\text { approximately } 190 \text { to } 300 \mathrm{~Hz} \text {. } \\
\text { Peaks observed at approximately } \\
128,138,187,255 \text {, and } 275 \mathrm{~Hz} \text {. }\end{array}$ \\
\hline $\begin{array}{l}\text { HFIR Truck Bay } \\
\text { Excluding Entry }\end{array}$ & $\begin{array}{l}\text { Building } \\
7900 \text { HFIR } \\
\text { room } 211 \\
(6),(7),(8), \\
\text { and }(10)\end{array}$ & $\begin{array}{l}\text { Opening and closing of } \\
\text { west truck bay roll-top } \\
\text { garage-style doors. Nothing } \\
\text { entered or exited the } \\
\text { reactor bay. }\end{array}$ & $\begin{array}{c}\text { There are no infrasound signatures } \\
\text { observed, however, signatures could } \\
\text { be developed for frequencies above } \\
\text { approximately } 200 \mathrm{~Hz} \text {. }\end{array}$ \\
\hline $\begin{array}{l}\text { HFIR Truck Bay } \\
\text { Excluding Entry }\end{array}$ & $\begin{array}{l}\text { Building } \\
7900 \mathrm{HFIR} \\
\text { room } 211 \\
(6),(7),(8), \\
\text { and }(10)\end{array}$ & $\begin{array}{l}\text { Opening and closing of } \\
\text { east truck bay roll-top } \\
\text { garage-style doors. Nothing } \\
\text { entered or exited the } \\
\text { reactor bay. }\end{array}$ & There are no signals observed. \\
\hline $\begin{array}{l}\text { HFIR Truck Bay } \\
\text { Partial Opening }\end{array}$ & $\begin{array}{l}\text { Building } \\
7900 \text { HFIR } \\
\text { room } 211 \\
(6),(7),(8), \\
\text { and (10) }\end{array}$ & $\begin{array}{l}\text { Partial opening of the west } \\
\text { truck bay door to a height } \\
\text { of } 10 \text {. }\end{array}$ & $\begin{array}{c}\text { There are no infrasound signatures } \\
\text { observed, however, signatures could } \\
\text { be developed for frequencies above } \\
\text { approximately } 200 \mathrm{~Hz} \text {. }\end{array}$ \\
\hline $\begin{array}{l}\text { HFIR Truck Bay } \\
\text { Partial Closing }\end{array}$ & $\begin{array}{l}\text { Building } \\
7900 \text { HFIR } \\
\text { room } 211 \\
(6),(7),(8), \\
\text { and }(10)\end{array}$ & $\begin{array}{l}\text { Partial closing of the west } \\
\text { truck bay door to a height } \\
\text { of } 10^{\prime} .\end{array}$ & $\begin{array}{c}\text { There are no infrasound signatures } \\
\text { observed, however, signatures could } \\
\text { be developed for frequencies above } \\
\text { approximately } 200 \mathrm{~Hz} \text {. }\end{array}$ \\
\hline $\begin{array}{l}\text { HFIR Truck Bay } \\
\text { Complete } \\
\text { Opening }\end{array}$ & $\begin{array}{l}\text { Building } \\
7900 \text { HFIR } \\
\text { room } 211 \\
(6),(7),(8), \\
\text { and }(10)\end{array}$ & $\begin{array}{l}\text { The west truck bay door } \\
\text { was completely opened and } \\
\text { a truck drove through to the } \\
\text { reactor bay. }\end{array}$ & $\begin{array}{c}\text { The power is lower in the frequency } \\
\text { band between approximately } 12 \text { and } \\
18 \mathrm{~Hz} \text { compared with partial } \\
\text { opening. }\end{array}$ \\
\hline
\end{tabular}




\begin{tabular}{|c|c|c|c|}
\hline Event & $\begin{array}{c}\text { Location } \\
\text { and } \\
\text { Recorder } \\
\text { Positions }\end{array}$ & Description & Signature \\
\hline HFIR Reactor \\
$\begin{array}{c}\text { Bay Clean-up } \\
\text { Pump Powered }\end{array}$ & $\begin{array}{c}\text { Building } \\
\text { below reactor } \\
\text { bay } \\
(6),(7),(8), \\
\text { and (10) }\end{array}$ & $\begin{array}{c}\text { Switching the clean-up } \\
\text { pump that is powered on to } \\
\text { the alternate clean-up } \\
\text { pump. }\end{array}$ & $\begin{array}{c}\text { Signatures could not be developed } \\
\text { in the range of frequencies } \\
\text { examined. }\end{array}$ \\
\hline Cycle Power to & $\begin{array}{c}\text { Building } \\
\text { south wall of } \\
\text { AC-10-14. }\end{array}$ & $\begin{array}{c}\text { The power was cycled off } \\
\text { for 20 s to AC-11, 12, and } \\
\text { 13. The power was cycled } \\
\text { off to AC-10 while it was } \\
\text { cycled on the AC-14 for 1 } \\
\text { minute. }\end{array}$ & $\begin{array}{c}\text { Signatures could not be developed } \\
\text { in the range of frequencies } \\
\text { examined. More tests are necessary. }\end{array}$ \\
\hline
\end{tabular}




\section{References}

1. A. D. Pierce, Acoustics An Introduction to Its Physical Principles and Applications, Acoustical Society of America (1989).

2. IEC, 1994. 60050-801:1994 International Electrotechnical Vocabulary (801): Acoustics and Electroacoustics

3. S. W. Smith, The Scientist and Engineer's Guide to Digital Signal Processing, copyright @19971998, www.DSPguide.com.

4. G. Leventhall, "Review What is Infrasound?", Prog. Biophys. Molec. Bio. 93 (2007) 130.

5. H. E. Bass, L. C Sutherland, A. J. Zuckerwar, D. T. Blacstock, and D. M. Hester, "Atmospheric Absorption of Sound: Further Developments," J. Acoustical Soc. America 97 (1995) 680.

6. B. Bilski, "Exposure to Infrasonic Noise in Agriculture", Annals Agr. Envir. Med. 24 (2017) 86.

7. S. T. Parsons, "Infrasound and the Paranormal," J. Soc. Psych. Res. 73 (2012) 908.

8. F. N. Hooge, "1/f Noise," Physica 83B (1973) 14.

9. R. F. Voss and J. Clarke, "1/f Noise in Music: Music from 1/f Noise", J. Acoustical Soc. America 63 (1978) 258. 